\title{
A review on various temperature-indication methods for Li-ion batteries
}

\author{
L.H.J. Raijmakers ${ }^{a, c}$, D.L. Danilov ${ }^{a, b}$, R.-A. Eichel ${ }^{a, d}$, and P.H.L. Notten ${ }^{a, b, e *}$ \\ ${ }^{a}$ Forschungszentrum Jülich (IEK-9), D-52425, Jülich, Germany \\ ${ }^{b}$ Eindhoven University of Technology, $5600 \mathrm{MB}$, Eindhoven, The Netherlands \\ ' Delft University of Technology, 2629 JB, Delft, The Netherlands \\ ${ }^{d}$ RWTH Aachen University, D-52074 Aachen, Germany \\ e University of Technology Sydney, Broadway, Sydney, NSW 2007, Australia \\ * Corresponding author, +31 (0)40 247 3069; p.h.I.notten@tue.nl
}

\begin{abstract}
Temperature measurements of Li-ion batteries are important for assisting Battery Management Systems in controlling highly relevant states, such as State-of-Charge and State-of-Health. In addition, temperature measurements are essential to prevent dangerous situations and to maximize the performance and cycle life of batteries. However, due to thermal gradients, which might quickly develop during operation, fast and accurate temperature measurements can be rather challenging. For a proper selection of the temperature measurement method, aspects such as measurement range, accuracy, resolution, and costs of the method are important. After providing a brief overview of the working principle of Li-ion batteries, including the heat generation principles and possible consequences, this review gives a comprehensive overview of various temperature measurement methods that can be used for temperature indication of Li-ion batteries. At present, traditional temperature measurement methods, such as thermistors and thermocouples, are extensively used. Several recently introduced methods, such as impedance-based temperature indication and fiber Bragg-grating techniques, are under investigation in order to determine if those are suitable for largescale introduction in sophisticated battery-powered applications.
\end{abstract}

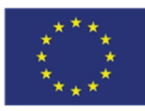

This project has received funding from the European Union's Horizon research and innovation programme under grant greement no. 769900 
Keywords: Thermal battery management; Li-ion batteries; Temperature sensors; Temperature distribution; Temperature measurement methods

\section{Table of contents}

1. Introduction

2. Working principles of Li-ion batteries

2.1. Components and operating principles of Li-ion batteries

2.2. Thermal considerations

2.2.1. Heat generation

2.2.2. Heat conduction

2.2.3. Heat dissipation

2.2.4. Heat balance

2.3. Temperature gradients

2.4. Thermal issues and safety devices

3. Temperature indication methods for Li-ion batteries

3.1. Thermo-resistive devices

3.1.1. Thermistors

3.1.2. Resistance temperature detectors

3.2. Thermo-junctive devices

3.3. Fiber Bragg-grating sensors

3.4. Impedance-based temperature measurements

3.5. Johnson noise thermometry

3.6. Thermal imaging and liquid-crystal thermography

4. Conclusions

5. Outlook

\section{Introduction}

Today's society is extremely dependent on energy. The supply and availability of energy is taken for granted by many people in the developed countries. For instance, in modern society it is easy to power electronic devices, heat up or cool down buildings and drive vehicles. A recent report from the U.S. energy Information Administration [1] predicts that the world's energy consumption will increase in the coming decades. Countries with high rates of economic growth, in particular Asian counties, are mainly responsible for this increase. So far, the fossil fuels, such as coal, oil and natural gas are dominating due to their legacy and associated scientific innovations. Although new fossil fuel fields certainly will be found with advanced techniques it is, however, inevitable that these nonrenewable energy sources deplete in the future $[2,3]$. Moreover, fossil fuels contribute to global 
warming by generating greenhouse gases, which has a major environmental impact in the long term $[2,3]$.

The emission of greenhouse gases from fossil fuels can be strongly reduced by using alternatives, such as nuclear [4,5] and renewable energy sources [6]. However, both sources have their challenges. For instance, the waste of nuclear energy can be radioactive for thousands of years, and improper safety management can lead to disastrous consequences [7]. In that respect, renewable energy sources are safer and cleaner. Examples of renewable energy sources are solar, wind, marine and geothermal [8]. The main challenge of renewable sources is that the energy output is often irregular and, therefore, the energy generation can be absent at moments at which it is desperately needed. The reason is that these sources are highly dependent on time, location and weather. Therefore, such systems would benefit from energy storage devices in order to stabilize the output. Energy can, for example, be stored in a mechanical, electrical, thermal or electrochemical way [9-11]. The electrochemical methods, in particular batteries, have drawn considerable attention in the last decades due to the high round-trip efficiency of these devices [12].

Batteries are currently popular devices to buffer energy that is generated by renewable sources $[13,14]$. These battery systems are better known as stationary energy storage devices. In addition, batteries are also highly suitable for providing mobile devices with energy. Examples of mobile devices are portable phones, laptops, tablets, watches and (hybrid) electric vehicles (H)EV. Especially the $(H) E V$ market may require many batteries since a tremendous increase of $(H) E V$ sales is expected in the near future. However, the increase of $(\mathrm{H}) \mathrm{EV}$ sales is hard to predict due to factors such as cost, technology, infrastructure, consumer acceptance and governmental regulations [15-17]. If (H)EV batteries are charged with electricity generated by renewable energy sources, the environmental impact of a $(\mathrm{H}) \mathrm{EV}$ is far lower than the impact of vehicles using combustion engines running on fossil fuels. In that respect, $(\mathrm{H}) \mathrm{EV}$ are excellent candidates to reduce greenhouse gas 
emissions. Evidently, the battery plays a major role in the success of both stationary and mobile applications.

Due to the high energy density, long cycle-life and low self-discharge, Li-ion batteries are nowadays the technology of choice to power both stationary and mobile applications $[14,18,19]$. However, challenges are met in monitoring and controlling the states of a Li-ion battery, such as Stateof-Charge (SoC), State-of-Health $(\mathrm{SoH})$ and temperature. The consequences of poor monitoring and control can lead to a decreasing battery performance, rapid degradation and, even worse, fire or explosion. This would be detrimental for the success of battery powered devices, especially for $(H) E V$. Therefore, it is of high importance to keep battery states within their safe operating range, which is bounded by voltage, temperature and current windows [20]. A Battery Management System (BMS), including a Thermal Management System (TMS), is an essential component to monitor and control these states in order to guarantee safe and reliable battery operation.

At present, various review papers are written in the field of battery management systems [2029] and thermal management systems [30-39]. These papers mainly describe state estimation techniques and approaches how to design BMS and TMS. In addition, reviews are available dealing with general temperature measurement techniques and methods [40-44]. However, there is no clear overview of the various temperature indication methods, specifically for Li-ion batteries. Such an overview should reflect on the current developments and challenges in battery technologies, in particular Li-ion batteries. The present review is therefore of interest to a broad range of scientists, researchers, and engineers who focus on rechargeable batteries, battery temperature development, battery management, and battery safety. The present contribution summarizes and discusses the available temperature indication methods that can be used to facilitate BMS and TMS in accurately controlling battery states. It starts with a brief overview of the working principle of Li-ion batteries, including the heat generation principles and possible consequences, such as thermal gradients and thermal runaway. This overview gives the reader the required basic battery knowledge and it highlights 
the challenges in measuring battery temperature. After introducing the heat generation principles, different available temperature measurement methods for Li-ion batteries are reviewed and discussed in Section 3. It comprehensively reviews and discusses the working principles, issues, and challenges of all traditional and state-of-the-art temperature measurement methods applied to Li-ion batteries.

Fig. 1 shows a graphical overview of Sections 2 and 3. A comparative analysis of the available methods is made in the last Section (Conclusions).

\section{Section 2: Working principles of Li-ion batteries}

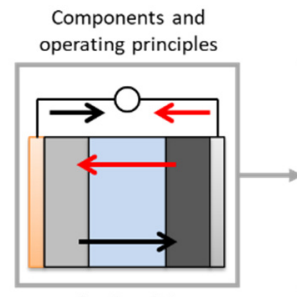

Section 2.1

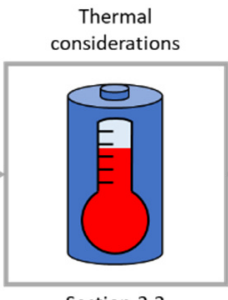

Section 2.2

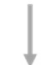

Heat generation

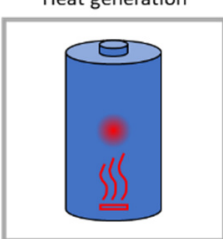

Section 2.2.1

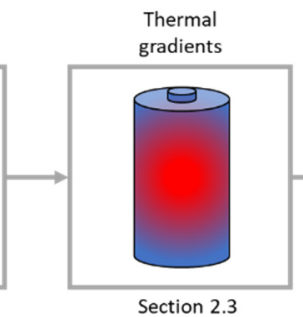

Section 2.3

Heat conduction

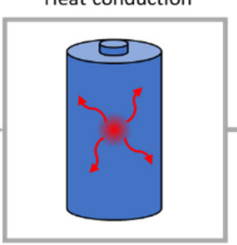

Section 2.2.2

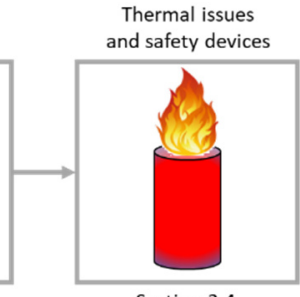

Section 2.4

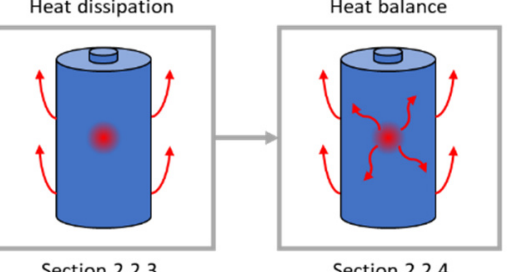

Section 2.2.3

Section 3: Temperature indication methods for $\mathrm{Li}$-ion batteries

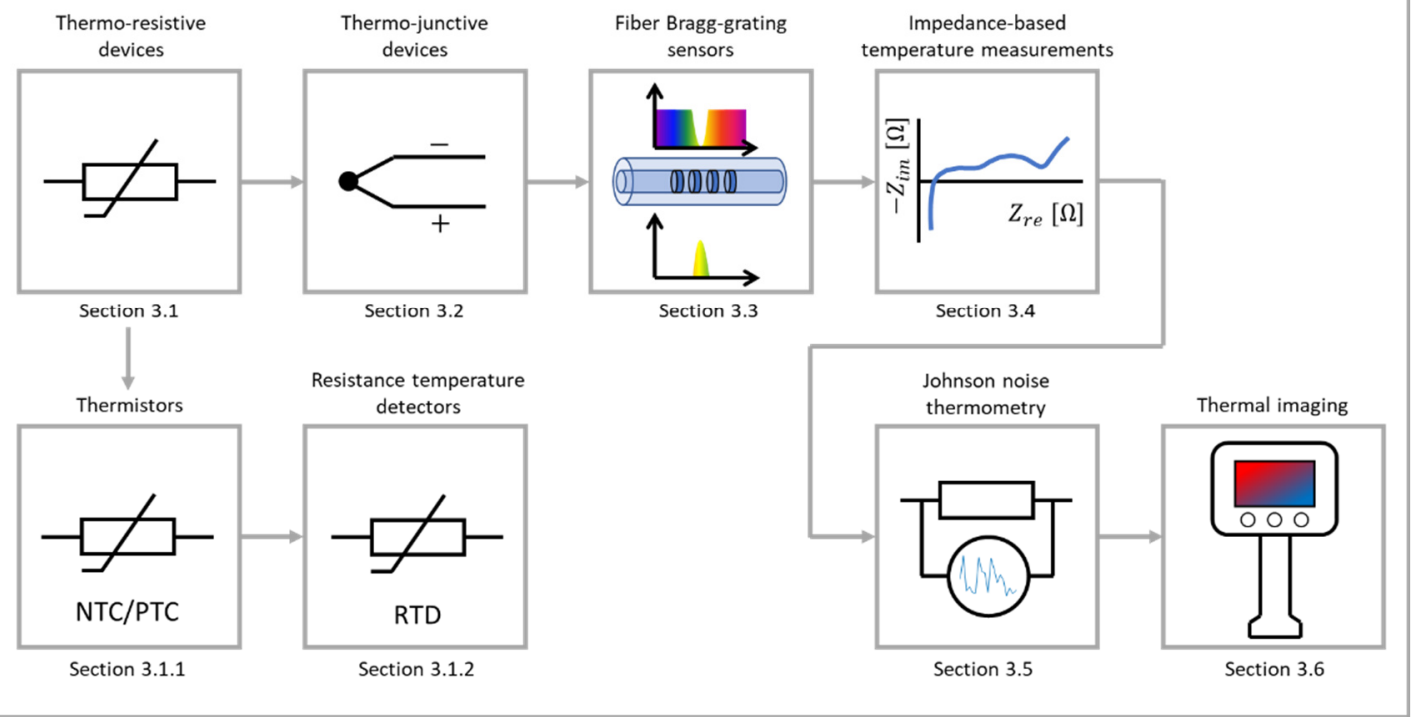

Fig. 1. Graphical representation of Sections 2 and 3. 


\section{Working principles of Li-ion batteries}

Primary Lithium batteries are able to convert chemical energy into electrical energy by means of electrochemical reduction and oxidation (redox) reactions. In Li-ion batteries, these reactions are reversible, which means that the opposite, i.e. conversion of electrical energy into chemical energy, is possible as well, making them so-called secondary batteries. In that respect, secondary batteries are different from primary batteries, in which the stored chemical energy is irreversibly converted to electrical energy. In this overview only Li-ion batteries are considered, whose components and working principles, including thermal considerations, are described in this Section. The used abbreviations and symbols are listed in Table 2 and 3.

\subsection{Components and operating principles of Li-ion batteries}

A schematic overview of a Li-ion battery is shown in Fig. 2 . This figure shows five main components in different colours. At both outer sides, the current collectors are shown on which the active electrode materials are coated. In commercial Li-ion batteries, aluminium and copper are typical materials for the positive and negative current collectors, respectively [45]. The current collectors conduct electrons for charge transfer reactions and serve as a substrate for the electrochemically active electrode materials.

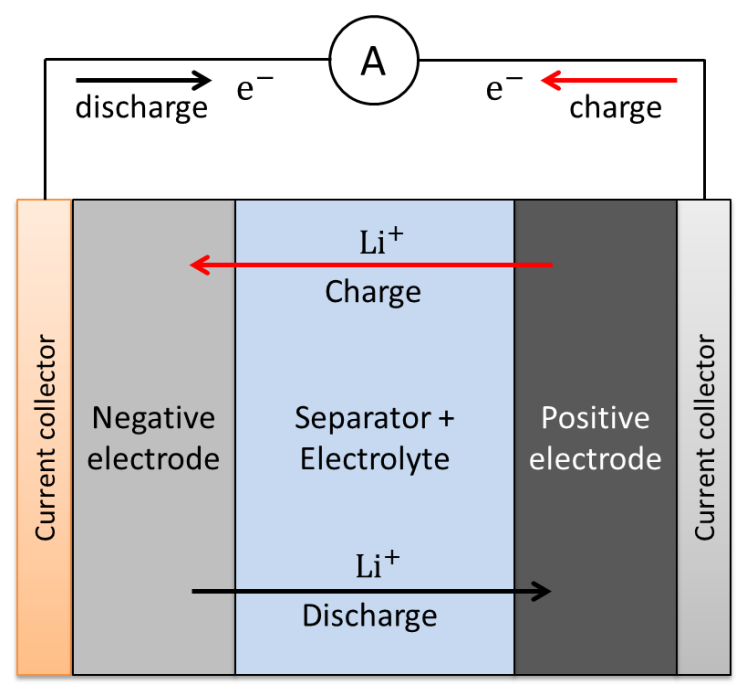

Fig. 2. Schematic representation of a Li-ion battery. 
The negative and positive electrode materials are intercalation materials that function as a host for lithium ions. An overview of common electrode materials used for Li-ion batteries is shown in Table 1. A separator between both electrodes prevents electrical contact but enables ions to pass through. The battery is filled with a non-aqueous electrolyte containing lithium salt, such as $\mathrm{LiPF}_{6}$ and $\mathrm{LiClO}_{4}$, which enables $\mathrm{Li}^{+}$ionic transfer.

As shown by the red arrow in Fig. 2, $\mathrm{Li}^{+}$ions leave the positive electrode, enter the electrolyte, and intercalate into the negative electrode during charging. At the same time electrons leave the positive electrode and flow into the negative electrode through the outer electric circuit. Upon charging, oxidation takes place at the positive electrode and reduction at the negative electrode. In this case energy is required from an external source, and the battery converts electrical energy into chemical energy that is stored inside both electrodes. This process reverses upon discharging, as indicated with the black arrows in Fig. 2. The corresponding partial electrochemical reactions for a $\mathrm{C}_{6} / \mathrm{LiMeO}_{2}$ battery are represented by

$$
\mathrm{LiMeO}_{2} \underset{\text { discharge }}{\stackrel{\text { charge }}{\rightleftarrows}} \mathrm{Li}_{1-x} \mathrm{MeO}_{2}+x \mathrm{Li}^{+}+x \mathrm{e}^{-} \quad(0 \leq x \leq 0.5)
$$

and

$$
\mathrm{C}_{6}+y \mathrm{Li}^{+}+y \mathrm{e}^{-} \underset{\text { discharge }}{\stackrel{\text { charge }}{\rightleftarrows}} \mathrm{Li}_{y} \mathrm{C}_{6} \quad(0 \leq y \leq 1)
$$

for the positive and negative electrode, respectively. The abbreviation Me stands for a transition metal, which in commercial batteries normally is Cobalt (Co) combined with or without Nickel (Ni), Manganese $(\mathrm{Mn})$, or Aluminium (Al) in different ratios [46-48]. Note that for the case $\mathrm{Me}=\mathrm{Co}, x$ is limited to 0.5 to reversibly cycle the positive electrode without causing rapid capacity losses, though $x$ can decrease below 0.5 for modern NMC-type materials. Graphite $\left(C_{6}\right)$ is a typical intercalation material that is generally used for negative electrodes in commercial Li-ion batteries [49-51]. Some examples of Li-ion battery electrode materials with their specific electrochemical characteristics are listed in 
Table 1. Materials with voltages higher than $2 \mathrm{~V}$ are usually used as positive electrode materials, while low voltage materials are normally used for negative electrodes.

A charged battery experiences a chemical driving force due to the difference in chemical potentials between the two electrodes. This can be expressed as the standard Gibbs free energy change $(\Delta G)$. Under equilibrium conditions the chemical driving force is balanced by an electrostatic driving force and equals to $-n F E$. The balance between the chemical and electrical forces can then simply be expressed as

$$
\Delta G=-n F E,
$$

where $n$ is the charge number of the mobile ionic species $\left(+1\right.$ for $\left.\mathrm{Li}^{+}\right), F$ is the Faraday constant and $E$ is the voltage difference between the electrodes [52-55]. Eq. 3 readily makes it possible to calculate the Electromotive Force (EMF) of a Li-ion battery if $\Delta G$ is known. The EMF is defined as the battery voltage under equilibrium conditions. Frequently, this voltage is also referred to as Open-Circuit Voltage (OCV) or Open-Circuit Potential (OCP $)^{1}$.

${ }^{1}$ OCV or OCP are popular terms but can occur under non-equilibrium conditions as well, while the EMF is only defined under equilibrium conditions. 
Table 1. Examples of electrode materials applied in Li-ion batteries. Modified from Refs. [56,57].

\begin{tabular}{|c|c|c|c|c|c|c|}
\hline $\begin{array}{l}\text { Material* } \\
\mathrm{LiMn}_{2} \mathrm{O}_{4}\end{array}$ & $\begin{array}{l}\text { Acronym } \\
\text { LMO }\end{array}$ & $\begin{array}{l}\begin{array}{l}\text { Average } \\
\text { voltage } \\
\text { vs. } \\
\mathrm{Li}^{\prime} \mathrm{Li}^{+}[\mathrm{V}]\end{array} \\
4.1\end{array}$ & \multicolumn{2}{|c|}{$\begin{array}{l}\text { Theoretical } \\
\text { specific } \\
\text { capacity ** } \\
{[\mathrm{mAh} / \mathrm{g}]}\end{array}$} & $\begin{array}{l}\text { Advantages } \\
\text { Low cost and abundance of } \mathrm{Mn} \text {, high } \\
\text { voltage, safety, excellent rate } \\
\text { performance. }\end{array}$ & $\begin{array}{l}\text { Disadvantages } \\
\text { Limited cycle life, low capacity. }\end{array}$ \\
\hline $\mathrm{LiCoO}_{2}$ & LCO & 3.8 & 274 & 295 & Performance, high voltage. & $\begin{array}{l}\text { Cost, resource limitations of Co, which is } \\
\text { also expensive and toxic, low thermal } \\
\text { stability, material instability when } \\
\text { delithiated below reversible limit. }\end{array}$ \\
\hline $\mathrm{LiNiO}_{2}$ & LNO & 3.8 & 275 & 296 & $\begin{array}{l}\text { Co is replaced by } \mathrm{Ni} \text {, which is relatively } \\
\text { inexpensive and environmentally } \\
\text { friendly comparted to Co, high voltage. }\end{array}$ & $\begin{array}{l}\text { Challenging to synthesize } \mathrm{LiNiO}_{2} \text { that may } \\
\text { lead to capacity loss and poor cycling } \\
\text { performance. }\end{array}$ \\
\hline $\mathrm{LiNi}_{0.8} \mathrm{CO}_{0.15} \mathrm{Al}_{0.05} \mathrm{O}_{2}$ & NCA & 3.7 & 279 & 300 & $\begin{array}{l}\text { High capacity, high voltage, excellent } \\
\text { rate performance. }\end{array}$ & $\begin{array}{l}\text { Safety, cost and resource limitations of Co, } \\
\text { material instability when delithiated below } \\
\text { reversible limit. }\end{array}$ \\
\hline $\mathrm{LiFePO}_{4}$ & LFP & 3.4 & 170 & 178 & $\begin{array}{l}\text { Excellent safety, cycling and rate } \\
\text { capability, low cost and abundance of } \\
\text { Iron, low toxicity. }\end{array}$ & Low voltage, capacity and energy density. \\
\hline $\mathrm{Li}_{2} \mathrm{~S}$ & Li-S & 2.2 & 1167 & 1672 & Very high capacity, abundance of sulfur. & Poor cycle life and rate performance. \\
\hline
\end{tabular}




\begin{tabular}{|c|c|c|c|c|c|c|}
\hline $\mathrm{Li}_{7} \mathrm{Ti}_{5} \mathrm{O}_{12}$ & LTO & 1.5 & 168 & 175 & $\begin{array}{l}\text { Good cycling and efficiencies, zero strain } \\
\text { material. }\end{array}$ & High voltage, low capacity/energy density. \\
\hline $\mathrm{Li}_{22} \mathrm{Si}_{5}$ & $\mathrm{Li}-\mathrm{Si}$ & 0.4 & 3120 & 4200 & $\begin{array}{l}\text { Extreme high capacity at relative low } \\
\text { voltage. }\end{array}$ & $\begin{array}{l}\text { Rapid degradation due to large electrode } \\
\text { expansion, solid electrolyte interface (SEI) } \\
\text { layer growth. }\end{array}$ \\
\hline $\mathrm{Li}_{22} \mathrm{Sn}_{5}$ & Li-Sn & 0.4 & 790 & 993 & $\begin{array}{l}\text { High capacity at relative low voltage. } \\
\text { Abundance of } \mathrm{Si} \text {. }\end{array}$ & $\begin{array}{l}\text { Enormous volume changes, large } \\
\text { mechanical strain, high capacity fade upon } \\
\text { cycling. }\end{array}$ \\
\hline $\mathrm{LigAl}_{4}$ & Li-Al & 0.4 & 1416 & 2235 & $\begin{array}{l}\text { High capacity at relative low voltage, } \\
\text { abundant, inexpensive and } \\
\text { environmentally benign element. }\end{array}$ & $\begin{array}{l}\text { Relatively large volume changes, limited } \\
\text { cycle life. }\end{array}$ \\
\hline $\mathrm{LiC}_{6}$ & $\mathrm{Li}-\mathrm{C}$ & 0.1 & 339 & 372 & Long cycle life, abundant, low voltage. & Inefficiencies due to SEI growth. \\
\hline Lithium metal & $\mathrm{Li}$ & 0.0 & 3860 & NA & $\begin{array}{l}\text { High capacity at very low voltage, flat } \\
\text { potential curve. }\end{array}$ & $\begin{array}{l}\text { Dendrite and SEI growth, limited Coulombic } \\
\text { efficiency. }\end{array}$ \\
\hline
\end{tabular}

* All materials are shown in the completely lithiated state.

** The theoretical specific capacity is calculated with respect to the unit weight of completely lithiated host material (left column) and empty (delithiated) host material (right column). Note that some materials cannot be fully delithiated. 


\subsection{Thermal considerations}

Although Li-ion batteries have a very high coulombic efficiency [57,58], lithium (de-) intercalation in both electrodes and all associated processes do not occur with $100 \%$ energy efficiency. This property results in heat generation when the battery is in operation. The generated heat flows through the materials to the battery surface, where it dissipates to the environment. The implications of these processes are described in this Section.

\subsubsection{Heat generation}

Due to various internal impedances the voltage at the battery terminals deviates from the EMF at a given SoC $[59,60]$. This voltage difference is better known as the battery overpotential $\left(\eta_{b a t}\right)$ and can be defined as

$$
\eta_{b a t}=E_{b a t}-E_{b a t}^{e q}
$$

where $E_{b a t}$ is the voltage at the battery terminals and $E_{b a t}^{e q}$ is the EMF. The EMF can be experimentally determined by various methods along the complete SoC range. Methods such as (dis)charging at very low currents, interpolation between the charge and discharge voltage curve, voltage relaxation, and extrapolation to zero current have been used [61-63]. From Eq. 4, it can be seen that $\eta_{b a t}$ is negative during discharging and positive during charging. Similarly, the overpotentials of the individual electrodes $\left(\eta_{\text {pos }}\right.$ and $\left.\eta_{\text {neg }}\right)$ can be defined.

The total overpotential is induced by various processes occurring in a battery, such as the charge-transfer reactions at the electrode/electrolyte interfaces $\left(\eta_{c t}\right)$ [64], the diffusion and migration of Li-ions across the electrolyte $\left(\eta_{e l}\right)$ [65], diffusion and migration of Li-ions in the electrodes $\left(\eta_{d}\right)$ [66] and Ohmic losses $\left(\eta_{\Omega}\right)$ [67]. Therefore, the total battery overpotential can also be expressed as

$$
\eta_{b a t}=\eta_{c t}+\eta_{e l}+\eta_{d}+\eta_{\Omega}
$$


Note that the charge transfer processes, diffusion and migration, and Ohmic losses occur in both the positive and negative electrodes.

The battery overpotential multiplied by the current results in an irreversible heat power, which is given by [68-71]

$$
Q_{\eta}=\eta_{b a t} I(t)
$$

or alternatively

$$
Q_{R}=I(t)^{2} R,
$$

where $I$ represents the battery current and $R$ the total internal battery resistance. From Eq. 7, it can clearly be seen that if the battery current and/or the resistance increases, more irreversible heat is generated. To minimize these thermal losses, it is therefore key to keep the battery resistances as low as possible. Generally, these resistances increase with decreasing SoH during cycling and calendar aging and this consequently leads to more heat generation during the battery life [72-74].

In addition to the irreversible heat generation source resulting from resistances, a reversible heat source is present due to changes of the reaction entropy [75-77]. Entropic heat generation can be either endothermic or exothermic and depends on the direction of the electrode reactions and SoC. The entropy change $(\Delta S)$ can be derived from the enthalpy change $(\Delta H)$ and Gibbs free energy change $[78,79]$. After further derivations, $\Delta S$ can be represented by

$$
\Delta S=n F\left(\frac{\partial E_{b a t}^{e q}}{\partial T}\right)_{\xi, p},
$$

where $T$ is the battery temperature, $\xi$ is the reaction progress, or more specifically the SoC, and $p$ is the pressure. Generally, the entropy change is experimentally obtained by potentiometric or calorimetric measurements [80]. Since these methods usually require long measurement times, alternatives have been developed, such as electrothermal impedance spectroscopy (ETIS) [81] and an 
advanced measurement protocol for potentiometric methods that reduces the measurement time [82]. Once the entropy change is known, the reversible heat power $\left(Q_{S}\right)$ can be calculated, according to

$$
Q_{S}=-I \frac{T \Delta S}{n F} .
$$

Although the entropic heat is sometimes neglected [83-85] or adopted as a constant average value [86-88], its contribution can be significant and, therefore, it is strongly recommended to consider for thermal modelling purposes $[69,79,89]$. Entropic heat generation or absorption can be present at both electrodes, and its magnitude differs for the various electrode materials. Battery electrodes can be selected such that the entropic contributions of both electrodes cancel each other out [90]. In this perfect electrode match, entropic contributions to the total battery cannot be measured.

Two additional heat generation mechanisms are described in the literature: enthalpy-ofmixing and phase-change terms. Enthalpy-of-mixing represents the heat effect that occurs during the generation or relaxation of concentration gradients. The phase-change term stands for the heat effect due to phase transformations $[77,91]$. However, these two terms are often neglected since their contributions are minor in comparison to the two previous mentioned heat generation terms $[89,92]$.

\subsubsection{Heat conduction}

The heat generated by the processes described above flows through the materials of the battery by conduction. This only occurs when temperature differences are present, i.e. thermal gradients have been built up. The corresponding heat flux $\left(\vec{q}_{\text {cond }}\right)$ in isotropic materials that results from thermal conduction can be defined as [93-95]

$$
\vec{q}_{\text {cond }}=-k \nabla T,
$$

where $k=k(x, y, z)$ is the thermal conductivity and $\nabla T$ the temperature gradient. Eq. 10 is also called Fourier's Law for heat conduction. It can be seen that $k$ is a function of location in the battery. Note 
that Eq. 10 reveals a minus-sign and it can therefore be inferred that heat flows from high to low temperatures. Values for $k$ have been investigated for common battery materials and reported in the literature $[88,96]$. These parameter values can be used as input for thermal models.

\subsubsection{Heat dissipation}

When a battery operates in an environment filled with a gas or a liquid, there is a convective heat exchange between the surface and the surroundings. In addition, the battery surface is cooled down by emitting infrared radiation. Convective $\left(Q_{c o n v}\right)$ and radiative heat exchange $\left(Q_{\text {rad }}\right)$ with the environment are represented by [93-95]

$$
Q_{c o n v}=h A\left(T-T_{a}\right)
$$

and

$$
Q_{\text {rad }}=\sigma \varepsilon A\left(T^{4}-T_{a}^{4}\right)
$$

respectively, where $h$ is the heat-transfer coefficient, $A$ the surface area of the battery, $T$ the battery surface temperature, $T_{a}$ the ambient temperature, $\sigma$ the Stefan-Boltzmann constant and $\varepsilon$ is the emissivity $(0<\varepsilon \leq 1)$ of the surface material. $h$ depends on various factors such as natural or forced convection, location, geometry, surface roughness and the medium that surrounds the battery. To increase the heat transfer from the battery surface to the surrounding environment, various external cooling methods can be applied. Examples are air cooling [97-99], liquid cooling [100,101], the use of phase-change materials [102-105], heat pipes [106-108], specially designed heat sinks [109-111], pool-boiling fluids [112], or combinations of these methods.

In addition to external cooling, that only removes heat from the surface of the battery, internal cooling has also been used. For internal cooling either micro-channels or small heat pipes are integrated into the battery [113-116]. Internal cooling can be more effective than traditional cooling since undesirable increase in temperature and thermal gradients are easier to control. In addition, 
internal cooling favourably prolongs battery life and is safer. Despite these advantages, internal cooling is much more difficult to apply since the standard internal battery construction must be changed significantly.

\subsubsection{Heat balance}

Now that heat generation and dissipation principles are known, it is possible to define a simple but convenient heat balance equation in order to calculate the temperature evolution of batteries. Considering a uniform battery temperature, the heat balance equation is defined as

$$
m C_{p} \frac{d T}{d t}=Q_{\text {in }}-Q_{\text {out }},
$$

where $m$ is the mass and $C_{p}$ the specific heat capacity of the battery. $Q_{\text {in }}$ includes all heat-generating processes and can be defined based on the theory described above as

$$
Q_{\text {in }}=Q_{\eta}+Q_{S} .
$$

$Q_{\text {out }}$ represents the heat dissipation from the battery to the environment, which can be defined with the theory above as

$$
Q_{\text {out }}=Q_{\text {conv }}+Q_{\text {rad }} \text {. }
$$

Substantial research on thermal modelling has been conducted using this straightforward general heat equation $[79,117-123]$. The main advantage of this model is the simplicity to predict temperature evolutions and to integrate this into a TMS. An example of simulation results, using this model is shown in Fig. 3. Both experimental (dotted curves) and simulated (dashed and solid curves) temperature evolution are shown for discharging a Li-ion battery at three C-rates. Moreover, the model has been simulated with (solid curves) and without (dashed curves) the entropic term. It can be seen that the model without the entropic term can only predict the global temperature behaviour. Including the entropic term into the model leads to a much better modelling accuracy. 


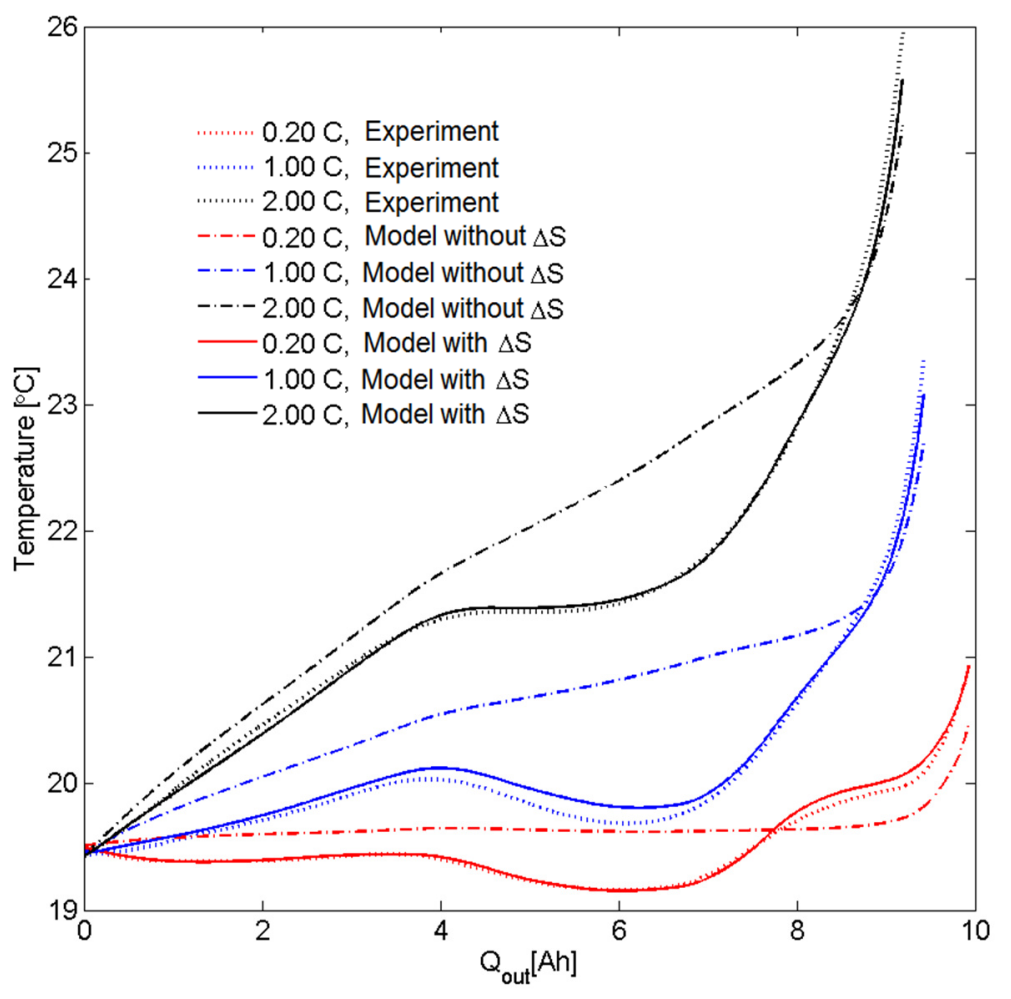

Fig. 3. Example of temperature evolution of a $7.5 \mathrm{Ah}$ cylindrical Li-ion battery during discharge for three C-rates at an ambient temperature of $20^{\circ} \mathrm{C}$. Adopted from Ref. [79].

Due to the simplicity of this general thermal model, there are some shortcomings, such as the assumption that the whole battery has a uniform temperature. In reality, the temperature varies spatially and, therefore, this heat-balance equation must be extended to a two or three-dimensional heat expression. The three-dimensional heat equation is defined as [124]

$$
\rho C_{p} \frac{\partial T}{\partial t}=\nabla \cdot(k \nabla T)+q_{i n}
$$

where $\rho$ is the material density. The density of the heat-generation power $q_{i n}=q_{i n}(t, x, y, z)$ is now a function of location due to the temperature-dependent entropic term (see Eqs. 9 and 14). Note that the total heat-generation power $Q_{i n}$ in the heat-balance equation (Eq. 13) can be obtained by integration of $q_{\text {in }}$ with respect to the volume $V$ of the battery, i.e.

$$
Q_{\text {in }}(t)=\int_{V} q_{\text {in }}(t, x, y, z) d x d y d z
$$


The heat dissipation at each point of the outer surface is written as boundary condition in the following form

$$
-\vec{n} \cdot(k \nabla T)=h\left(T-T_{a}\right)+\sigma \varepsilon\left(T^{4}-T_{a}^{4}\right),
$$

where at the left-hand side $\nabla T$ represents the temperature gradient, $\vec{n}$ the unit (outer) normal vector at the boundary, and the right-hand-side terms describe convection and radiation, accordingly. Using this model, thermal gradients in three dimensions can be simulated and validated with respect to measurements. These models still rely on detailed experiments since the measured overpotentials or resistances are required to calculate the heat generation.

Besides using thermal models for simulation purposes, they may be used to perform temperature predictions of Li-ion batteries in real-life applications, facilitating the BMS and TMS with determining states, such as SoC and SoH. By using models, the number of sensors can be reduced, which saves cost, space and possible malfunctioning of hardware sensors. Essentially, models can be divided into two main groups: (i) electrochemical/first principle/numerical models [125-128], and (ii) equivalent-circuit (EQC) models $[117,119,129-132]$. The numerical models, relying on a set of appropriate equations, have been successfully applied to accurately calculate thermal behaviour of Liion batteries. However, numerical models require strong computation power and are therefore less suitable to be integrated into BMS applications for temperature estimation [133]. For that reason, computationally intensive models can be reduced to simplified numerical models that are less accurate but significantly reduce computations times $[84,134,135]$. Alternatively, EQC models can be used, which have simple constructions and enable fast calculations. Obviously, due to the simple EQC model construction, thermal simulations are less accurate in comparison to numerical models. Moreover, the model accuracy does not only depend on the model complexity but also on the underlying parameter values, some of which are difficult to quantify $[136,137]$.

Thermal models are critically examined in various review articles [31,138-140]. An overview and discussion of these models would be redundant and is, therefore, not given in this work. 


\subsection{Temperature gradients}

Temperature gradients develop as a result of internal heat generation, thermal conduction, and heat dissipation in individual batteries, on a module and pack level. The development of temperature gradients in battery packs is a key issue that cannot be underestimated because gradients can lead to serious complications. One of these complications is temperature monitoring of a battery. Under extreme conditions, such as over(dis)charge, high current loads or short-circuiting, substantial heat is generated internally. Therefore, monitoring the surface temperature underestimates the maximum temperature of batteries. Thermal simulation examples on a cylindrical (high power) 7.5 Ah battery at a 6 C-rate discharge are shown in Fig. 4 . It can be seen that the temperature in the battery core is significantly higher than at the surface. Additional monitoring of the internal temperature therefore provides more accurate information, which will improve the performance, life-time (SoH) and safety of Li-ion batteries.

Other complications, resulting from temperature gradients, are current density distributions and local SoC differences [141]. Temperature gradients cause spatially varying electrochemical impedances and, therefore, current density distributions. SoC inhomogeneities are a result of both non-uniform current density distributions and the temperature dependence of the EMF. These effects lead to local aging differences and hence to global aging of batteries [142]. Moreover, it was found that batteries perform differently in the presence of a temperature gradient in comparison to a uniform battery temperature which has the same average value [143]. 
a)

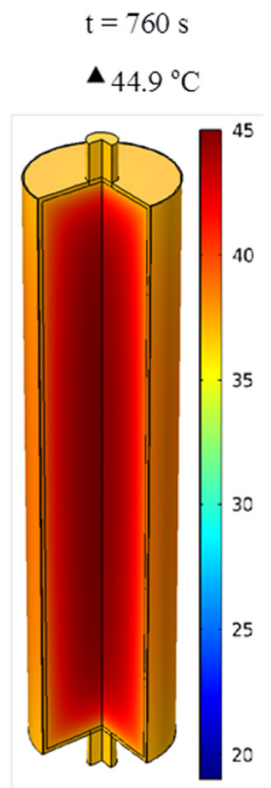

v $36.9^{\circ} \mathrm{C}$

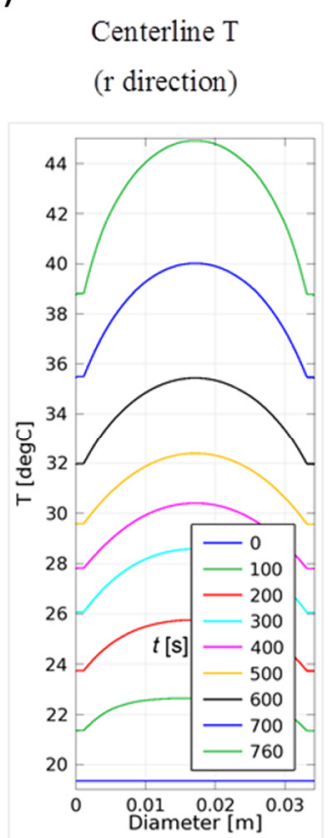

b)

$\mathrm{t}=760 \mathrm{~s}$

$\triangle 41.5^{\circ} \mathrm{C}$

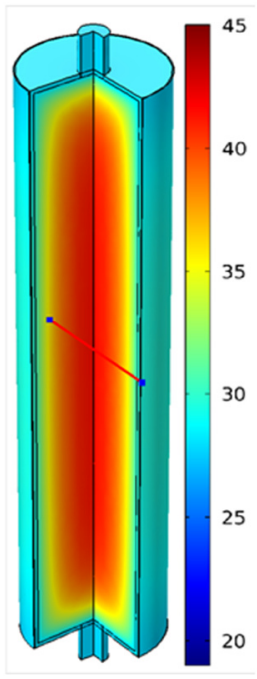

$\nabla 27.4^{\circ} \mathrm{C}$
Centerline T

( $\mathrm{r}$ direction)

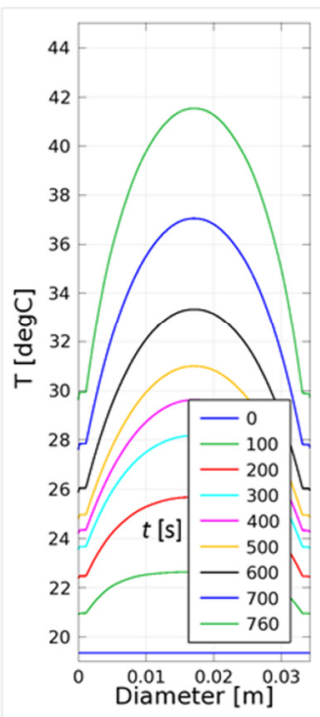

Fig. 4. Examples of thermal simulations of a 7.5 Ah cylindrical battery at $6 \mathrm{C}$ discharge rate, revealing natural convection (a) and forced convection (b). Adopted from Ref. [144].

Apart from temperature gradients inside individual batteries, temperature gradients will also develop in battery packs, in which multiple batteries are connected in series and/or in parallel. Simulation examples of temperature gradients in a battery pack can be seen in Fig. 5 for two different types of air cooling. Temperature gradients in battery packs result in unbalanced (dis)charge currents for parallel-connected batteries $[145,146]$. In addition, batteries far away from the cooling inlets operate at higher temperatures than batteries close to the cooling inlets, which can be seen in Fig. 5a. Using different or modified cooling methods, temperature gradients may be reduced, which is shown in Fig. 5b. Both unbalanced (dis)charge currents and different operating temperatures result in unequal aging phenomena among batteries assembled in packs. 

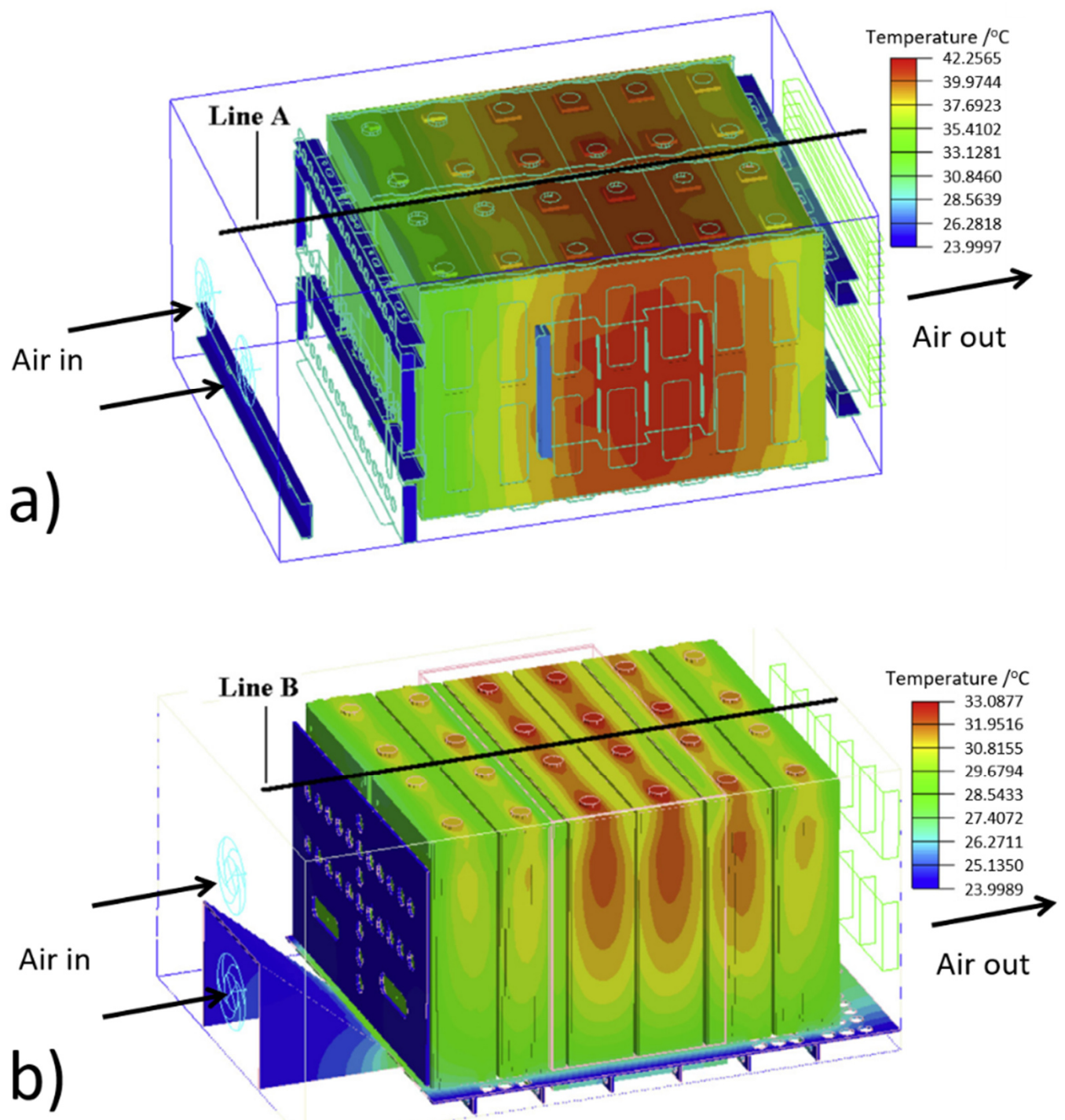

Fig. 5. Examples of thermal simulations of a Li-ion battery pack, containing $12180 \mathrm{Ah}$ batteries, at the end of $1 \mathrm{C}$-rate discharging, using forced convection with one-directional air flow (a) and forced convection with two-directional air flow (b). Modified from Ref. [147].

Generally, high C-rates and low ambient temperatures lead to a high temperature rise and large thermal gradient [148]. At high C-rates, stronger cooling is therefore necessary in order not to exceed the maximum specified temperature. Stronger cooling results in a lower temperature rise; however, larger temperature gradients develop $[144,149,150]$. This effect can clearly be seen in Fig. 4 . Under natural convection (Fig. 4a), the surface temperature is far higher than under forced convection conditions (Fig. 4b). However, the thermal gradient in the case of forced convection is much larger than under natural convection. The cooling method has a large influence on this particular behaviour. 
For example, tab cooling leads to a more homogeneous temperature behaviour than surface cooling [151]. Therefore, surface cooling can lead to higher capacity losses than tab cooling. In terms of temperature control, internal battery cooling is even more superior to tab cooling [152]. However, internal cooling is much more complicated and increases the mass of the battery and, therefore, decreases the specific energy density.

Because of all above-mentioned reasons, it is highly important to give careful consideration to the design of the TMS. On the one hand, it must be designed such that batteries do not exceed the maximum and minimum specified temperatures and, preferably, operate in the optimal working temperature range. On the other hand, it has to keep the temperature difference between individual batteries and modules inside packs as low as possible. Literature suggests that the optimal temperature range, i.e. an appropriate balance between performance, battery life and safety, lies within approximately 20 to $40^{\circ} \mathrm{C}$ with a maximum temperature gradient of less than $5^{\circ} \mathrm{C}$ $[30,31,33,138,153,154]$. Note that, however, the operating temperature can be in a range between 30 and $60^{\circ} \mathrm{C}$. Furthermore, a TMS should be reliable, low-cost, compact, light-weight and easy to maintain [31].

\subsection{Thermal issues and safety devices}

In Section 2.2, it was explained that the battery temperature is determined by the heat balance between the generated and dissipated heat. If the generated heat cannot be sufficiently dissipated, the battery temperature continues to increase, which can lead to failures and dangerous situations. Although the relative number of failures associated with Li-ion batteries is limited, some published incidents related to fires and explosions have raised concerns about the overall safety [155]. Moreover, faults and misuse during manufacturing and operation can cause internal and/or external shortcircuits, over(dis)charge or overheating. This can lead to thermal runaway, venting, fire and/or explosion of batteries under uncontrolled conditions [156]. These events result in hazardous situations and are detrimental for the battery market. 
The worst-case thermal scenario is that of thermal runaway, which can occur under insufficient cooling or abusive conditions and can easily lead to fire or explosions. Although Feng et al. [157] extensively describe thermal runaway to occur in six stages, it is more frequently described by a threestage process $[32,156,158-163]$ that can best be explained by Fig. $6 a[158,161]$. This figure shows experimental results of the self-heating rate of a Li-ion battery, divided into three stages. In this experiment, an external source adds heat to the battery until the moment the indicated onset temperature is reached. At the onset temperature the self-heating rate is equal or larger than a certain threshold value and no external heat from the source is added anymore from that moment on to the battery. From this point onwards, reactions inside the battery are exothermic and self-induce an increase in temperature.

At temperatures around $90^{\circ} \mathrm{C}$ the Solid Electrolyte Interphase (SEI) starts to decompose exothermically. Consequently, this induces electrolyte reduction at the exposed negative electrode surface. This reaction sequence becomes even more significant at $120^{\circ} \mathrm{C}$ (stage 1 in Fig. 6a). At stage 1 the separator can also start to melt, leading to a sudden voltage drop, thereby further increasing the heat generation. In stage 2 heat generation increases more rapidly (acceleration) by both electrolyte reduction and oxidation at the negative and positive electrodes, respectively. At this stage gas venting or even release of smoke may occur. Further internal heating brings the process into stage 3 in which high-rate electrode reactions cause the temperature to increase extremely fast, ultimately leading to the as-denoted thermal runaway. This is mainly caused by positive electrode material decomposition, producing oxygen gas which reacts exothermically with the organic materials in the battery [164]. The results of this process are high-rate venting, possible flames and explosions. Any intervention or strong cooling at this stage most probably does not inhibit thermal runaway anymore. 

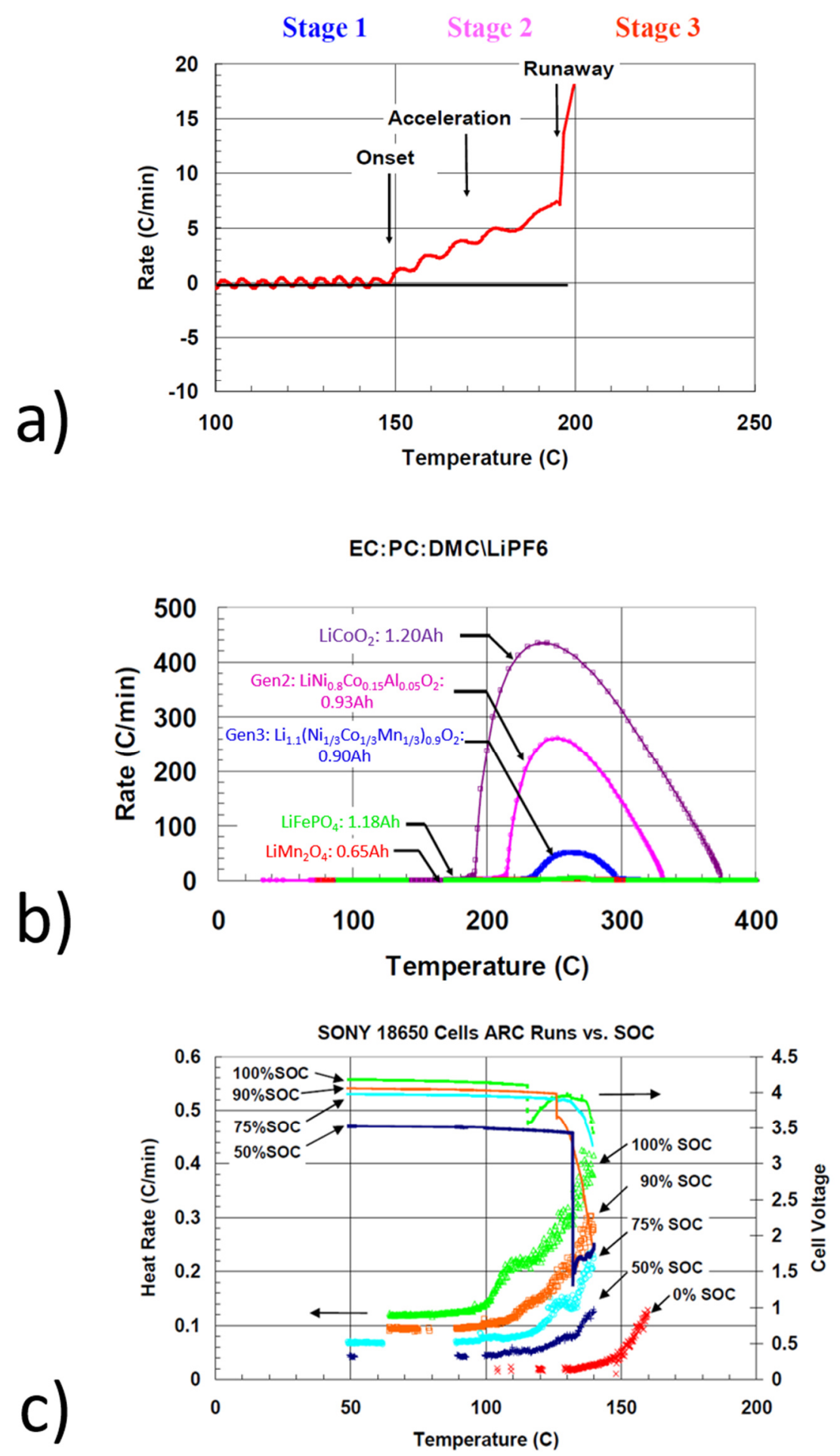

Fig. 6. Self-heating rates of Li-ion batteries. (a) Self-heating rate during a forced thermal ramp test; (b) Self-heating rate of 18650 batteries measured by Accelerating-Rate-Calorimetry (ARC) for different chemistries; (c) Self-heating rate of Sony batteries measured by ARC at different SoC. Note that in (c) an offset is shown for easier comparison. For details of this figure it is referred to Refs. [158,165].

Thermal runaway phenomena are a function of various properties, such as electrode materials, cell design and electrolyte composition [166]. For example, it has been found that the self-heating rate 
of Li-ion batteries is strongly dependent on the chemistry [158,165,167-169]. An example of the selfheating rate for different chemistries can be seen in Fig. 6b [158]. From this figure it is obvious that batteries with $\mathrm{LiCOO}_{2}$ electrodes are thermally less stable than Li-ion batteries with $\mathrm{LiFePO}_{4}$ electrodes. Experiments also revealed that the self-heating rate is dependent on the SoC $[158,165,170,171]$. Generally, the onset temperature decreases with increasing SoC. An example of this behaviour can be seen in Fig. 6c [165], which also shows the battery voltage during the experiment. These measurement results indicate that the electrodes become thermally less stable when the SoC increases. Furthermore, the voltage shows a sharp drop at temperatures around $125^{\circ} \mathrm{C}$. This voltage drop corresponds to the melting of the separator. In addition, it has been found that the thermal stability of the electrodes is dependent on the particle size because the active surface area with smaller particles is larger and, therefore, has more contact area between the electrode and electrolyte $[172,173]$

To prevent dangerous situations such as thermal runaway, the BMS should monitor the voltage, current and temperature. In case of failure the BMS can intervene preventively. However, a BMS cannot always protect batteries against abusive conditions, such as short-circuiting, penetration and external heating. Therefore, safety devices are additionally integrated in or on Li-ion batteries. These devices have to minimize the impact of hazardous situations. Many safety devices have been investigated, ranging from simple safety vents and fuses to shutdown separators, exotic electrolytes and special electrode coatings. A comprehensive review of safety devices is written by Balakrishnan et al. [174].

Hazardous situations arise if the BMS or other safety devices cannot prevent a battery from thermal runaway. This situation becomes even worse if this occurs in a battery pack because a single battery can trigger other batteries inside the pack to a runaway incident [175-177]. A simulation example of thermal runaway propagation through a battery module can be seen in Fig. 7 [177]. In this 
example the first battery is penetrated with a nail in order to initiate thermal runaway. This triggers the neighbouring battery and then continues to propagate up to the last battery.

To prevent thermal runaway propagation through a complete battery pack, various designs have been investigated. Examples are thermal isolations or conductive heat sinks between batteries, stronger cooling, reducing energy in the battery and spacing between adjacent batteries [177-180]. Moreover, it has been found that cylindrical batteries are less prone to thermal runaway propagation than, for example, pouch-type batteries due to the smaller contact areas and large air gaps between the battery covers [176]. It was also found that for cylindrical batteries the electrical connections become pronounced [176]. A parallel connection leads to stronger propagation due to heat transfer through the module and an electrical short at the location where thermal runaway is initiated.

Evidently, careful design considerations have to be taken in order to prevent thermal runaway in a single battery and propagation through a complete battery pack. Once the battery pack is being used in an application, it is important that all batteries inside a module or pack are monitored, not only for performance purposes, but even more importantly also for safety purposes.

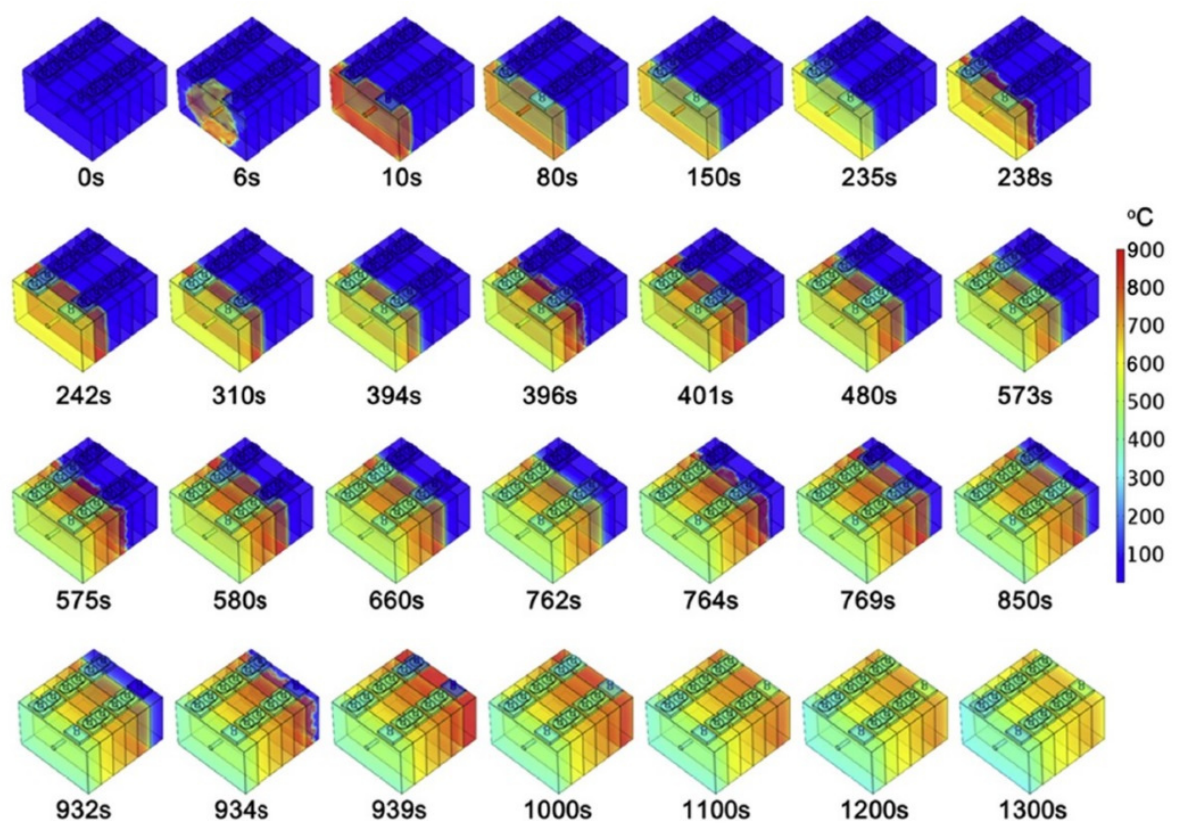

Fig. 7. Simulation example of thermal runaway propagation in a battery module, containing six $25 \mathrm{Ah}$ batteries. Adopted from Ref. [177]. 


\section{Temperature indication methods for Li-ion batteries}

In this Section, various battery temperature indication methods are discussed, ranging from the well-known traditional methods to the novel ones, which are currently being investigated. Key characteristics, such as measurement range, accuracy, resolution (in temperature, space, time) and costs are important for a proper sensor selection. Moreover, in situ temperature measurements are attractive for safety and controlling purposes since temperatures in the battery core are, generally, higher (see Section 2). These unequal temperature distributions increase the challenges in developing and selecting sophisticated temperature sensors for Li-ion batteries, which can assist the BMS in accurate SoC and SoH estimation.

The literature described in this Section is restricted to temperature measurement methods and sensors for Li-ion batteries. The corresponding analogue or digital circuits are not discussed, as well as methods to determine the thermal battery properties, such as thermal conductivity and heat capacity. Thermometers that do not generate electrical signals suitable for BMS, such as glass tube or bimetallic thermometers, are also not reported.

\subsection{Thermo-resistive devices}

Thermo-resistive devices are devices whose resistance changes as a function of temperature. This property makes these devices highly suitable for temperature measurements and are discussed in this Section.

\subsubsection{Thermistors}

Thermistors, or thermally sensitive resistors, are solid semiconductor devices of which the electrical resistance changes rapidly as a function of temperature [181]. Thermistors may have positive or negative temperature coefficients; if the thermistor has a negative temperature coefficient (NTC), the resistance decreases when the material temperature increases. This behaviour is shown in Fig. 8 (curves $a, b$ and c) [182], in which it can be seen that NTC behaviour is nonlinear, making temperature 
indication somewhat challenging. For thermistors that have a positive temperature coefficient (PTC) this behaviour is the other way around, i.e. the resistance increases with increasing temperature. The thermistors with NTC properties are usually used for temperature measurements. Thermistors with PTC properties can also be used for temperature measurements but are also frequently used as protection devices to reduce electric currents when the system reaches too-high temperatures.

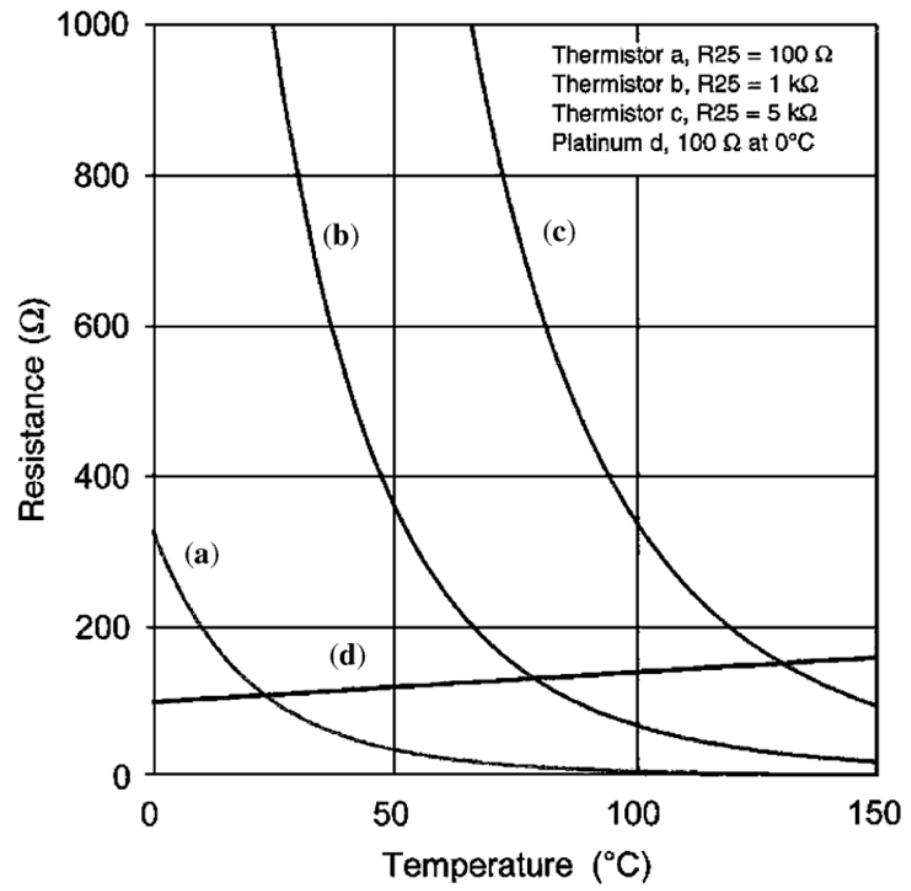

Fig. 8. Resistance as a function of temperature of three thermistors ( $a, b$ and $c)$, and a Platinum (Pt100) resistance temperature detector (d). Adopted from Ref. [182].

Thermistors have the advantages of being inexpensive, highly sensitive to temperature changes (Fig. 8), applicable across a considerable temperature range (-55 to $\left.\sim 300^{\circ} \mathrm{C}\right)$, available in different forms, and can be very small [182]. Due to the small size, it is possible to respond quickly to temperature changes. In addition, a four-terminal contact is not required since thermistors have a high resistivity, which saves cable space and cost. Although thermistors had a reputation of being unstable, the stability improved over the years by adopting new techniques, reaching good long-term stability [183-187]. Using specific provisions with the measurement instrumentation, errors of $<1 \mathrm{mK}$ can be reached [188], although the accuracy in commercial applications often results in the order of $\pm 1^{\circ} \mathrm{C}$ [44]. 
To measure the temperature by using a thermistor, a small well-defined current can be applied at a level at which no or negligible self-heating appears. A voltage measurement across the thermistor can then be used for temperature indication. Conversion to temperature can be performed with the help of lookup tables or by solving equations that approximate the resistance curve. However, other methods, such as those applying linearization techniques, can also be used.

Due to the above-mentioned advantages, thermistors are one of the most widely used temperature sensing devices for many applications [189]. For example, the Toyota Prius and Honda Civic Hybrid are using thermistors to measure battery temperature [190]. Thermistors are also extensively used to monitor the battery temperature in other mobile devices, such as cellular phones, laptops and powerbanks [191]. At present, many Li-ion batteries and battery packs can be purchased, including thermistors or protection circuits. Moreover, component and system suppliers frequently deliver products with thermistors as battery temperature sensors.

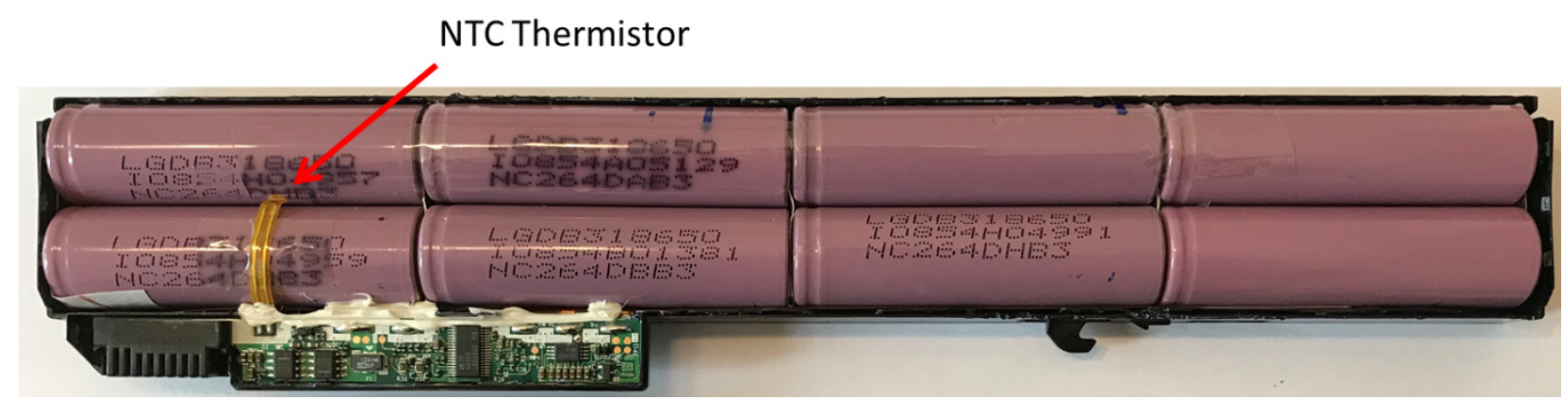

Fig. 9. Example of a $73 \mathrm{Wh}$ laptop battery pack with $10 \mathrm{k} \Omega$ NTC thermistor.

For the present practical applications, thermistors can be placed on the surface, the terminals, or close to a battery. In the example of Fig. 9, a thermistor is placed in the gap between two adjacent cylindrical batteries in such a way that it contacts both batteries. This arrangement only measures the surface temperature of these two batteries, whereas the remaining batteries are not monitored, which can lead to dangerous situations if one of the other batteries becomes overheated. However, for these types of mass-produced applications, cost should be minimized, and thus the number of sensors 
including wiring, connections and installation should be reduced as much as possible. Through extensive experiments and/or modelling, it is possible to reduce the number of sensors, while still accurate temperature indications can be obtained $[192,193]$.

Thermal investigations during the design of the battery pack should also reveal hot spots. At the corresponding 'hot' locations, a thermistor can be placed in order to indicate the maximum surface temperature. However, temperature gradients and possible hot spots at other locations on or inside the battery are unlikely to be detected; therefore, the indicated temperature can strongly deviate from the maximum temperature.

Although thermistors are extensively used in practical applications, the use of thermistors for research purposes is limited. NTC thermistors with an accuracy of $\pm 1^{\circ} \mathrm{C}$ were used to measure the surface temperature of cylindrical 18650 batteries [142] and on three different pouch-type batteries [194]. To validate a thermal model, non-specified thermistors have been used to monitor the temperature inside the mandrel of cylindrical 28650 batteries [195]. This study indicates that thermistors can be used within the chemical environment of a battery for experimental purposes. Moreover, a mass-produced thermistor was used by Debert et al. [85] to measure the temperature of a battery module. The thermistor was placed in an interstice in the module, and the data are compared to model simulation results. Grosch et al. [196] developed a new low-cost PTC thermistor that can be easily produced with printing techniques. The accuracy of this new thermistor is somewhat lower in comparison to commercially available NTC thermistors and thermocouples. However, it was concluded that the present design can be improved by sensor modifications and more accurate calibrations. Using this new thermistor, either the system cost can be reduced or more thermistors can be used at the same cost.

\subsubsection{Resistance Temperature Detectors}

Resistance Temperature Detectors (RTD) are devices containing metallic conductors of which the electrical resistance increases as a function of temperature. In essence, any metal could be used 
for RTD, but the choice is limited due to considerations such as cost, temperature coefficient of the resistance, ability to resist oxidation, manufacturing constraints, and stability [44]. Materials used for the metallic conductors in RTD can be copper, silver, nickel, gold and platinum, of which the last one is the most used, as it offers more advantages than the others. The resistance increase of a platinum RTD is shown in Fig. 8 (curve d) [182]. This figure shows that a platinum RTD is less sensitive to temperature changes than NTC thermistors. However, unlike thermistors, platinum RTD show a linear behaviour, which makes these very convenient for use in an application. Other advantages of platinum RTD are the excellent stability, accuracy (approaching $1 \mathrm{mK}$, but $\pm 0.01^{\circ} \mathrm{C}$ to $\pm 0.2^{\circ} \mathrm{C}$ in industrial applications), and wide operating range $\left(-260\right.$ to $\left.960^{\circ} \mathrm{C}\right)$ [197]. RTD can be offered as inner-coiled, outer-wound, or thin-film device. The thin-film RTD have the advantage to be less expensive, more robust, and smaller with respect to the inner coiled and outer wound RDT. Due to the small size, thinfilm RTD have faster response times.

The type of Platinum RTD is often indicated with the abbreviation 'Pt' followed with a number, e.g. Pt100. The number indicates the resistance at $0^{\circ} \mathrm{C}$. Hence, a Pt100 is a platinum RTD with a resistance of $100 \Omega$ at $0^{\circ} \mathrm{C}$. The most common platinum RTD have a temperature coefficient of resistance (TCR) of $0.00385 \Omega /\left(\Omega \cdot{ }^{\circ} \mathrm{C}\right)$. The TCR indicates the average resistance change per ${ }^{\circ} \mathrm{C}$ across a temperature range from 0 to $100^{\circ} \mathrm{C}$ and can be seen as sensitivity parameter. In other words, the resistance of the most common platinum RTD changes $0.38 \%$ per ${ }^{\circ} \mathrm{C}$. Furthermore, there are two performance classes (Class A and Class B) for Pt100 RTD, which indicate accuracy. The accuracy of Class A is approximately twice as high in comparison to Class B.

Using RTD, temperature measurements can be performed similarly as with thermistors, i.e. a small current $(<1 \mathrm{~mA})$ can be applied at a level at which self-heating can be neglected and a voltage drop can then be measured across the RTD [198]. Subsequently, the voltage can be converted to temperature. However, using an RTD in a branch of a Wheatstone bridge on which a constant voltage is applied is possible as well. Although a four-wire connection is preferred for the most accurate 
measurements, two- and three-wire connections can also be used. However, the two- and three-wire connections are more prone to measurement errors due to cable resistances.

In comparison to thermistors, RTD are more frequently used for Li-ion battery research purposes. Various authors used one or more commercial Pt100 elements to measure battery surface temperatures during (dis)charging [79,83,199-202]. Interestingly, all these measurements were used for thermal model validation purposes. A particular reason why these authors selected Pt100 RTD for their experiments is unknown. Moreover, from these authors only Daud et al. [83] indicate that Class A Pt100 RTD were used for surface temperature measurements. Furthermore, Day et al. [203] used Pt100 RTD to measure battery temperature and to control a cryostat apparatus for differential thermal analysis.

Pt1000 RTD with sizes $2.3 \mathrm{~mm} \cdot 2.0 \mathrm{~mm} \cdot 0.9 \mathrm{~mm}$ were used by Wang et al. [204] for temperature measurements inside and on the surface of a coin-type battery. The internal RTD was positioned between both electrodes, separated by two insulation diaphragms. The RTD sensing the internal temperature was connected to copper foil, utilized as measurement leads. Both the sensor and foil were covered by a $50 \mu \mathrm{m}$ thick polyimide insulation to prevent electrical contact with other parts and to prevent reactions with the electrolyte. It appeared that the charge capacity reduced tremendously by introducing an internal RTD. This has been attributed to the relatively large size of the sensor in comparison to the coin-type battery. It is expected that such a large capacity reduction is absent when the sensor is used in large-capacity batteries. However, the used internal RTD provides a more representative temperature than the RTD at the surface of the coin.

Recently, a self-heating Li-ion battery has been introduced that is able to rapidly self-heat at temperatures below $0^{\circ} \mathrm{C}[71,205-207]$. The principle of self-heating is based on an insulated nickel foil, having an electric resistance, which is integrated between the electrodes of a battery. When a current is applied under freezing circumstances, the battery current flows through the resistive nickel foil, generating internal heat and warming up the battery. The advantage of this construction is that the 
nickel foil can be used both for heating and as an RTD to measure the internal battery temperature $[71,206]$. The authors $[71,206]$ showed that the nickel foil has a linear resistance increase in a temperature range from -40 to $60^{\circ} \mathrm{C}$, making it suitable and convenient for internal battery temperature indication. However, this method requires an extra terminal on the battery and integration of the nickel foil, which increases cost and reduces the specific battery capacity. On the other hand, in comparison to platinum RTD, nickel advantageously has a higher sensitivity and lower material price.

Flexible thin-film micro RTD for internal battery temperature measurements were developed by Lee et al. [208]. The authors claim that these sensors can be easily mass-produced, measure temperature accurately and have very short response times due to their limited size. The working principle of this sensor is based on a $200 \mathrm{~nm}$ thick layer of gold deposited on a substrate of which the resistance changes as a function of temperature. A photograph of this thin-film device is shown in Fig. 10. The sensor resistance shows linear behaviour in a temperature range between -20 to $90^{\circ} \mathrm{C}$ over three consecutive cycles. However, the linearity has not been quantified and the stability for more than three cycles, as well as the calendar stability, have not been shown, which is of considerable importance if these sensors are used inside batteries. The authors integrated two thin-film micro sensors into a pouch-type battery at different positions, including a thermocouple on the surface, and compared the temperature development of the battery. The thin-film micro sensors showed faster response times and higher temperatures than the thermocouple on the surface. The same research group [209-211] continued this work with adding a voltage and current probe to the same sensor, making it a three-in-one sensor. The authors reported that temperature measurements with this sensor can be performed with an accuracy of better than $0.5^{\circ} \mathrm{C}$ and a response time less than $1 \mathrm{~ms}$ [211].

Using Electrical Resistance Tomography (ERT), the temperature of a battery can be obtained by relating the measured ERT resistivity to temperature. ERT is a technique to measure and visualize 
cross-sectional conductivity distributions within its sensing region [212,213]. Hong et al. [214,215] used ERT on the metal surfaces of Li-ion batteries and were able to map surface- and internal temperature profiles. The temperatures obtained with ERT were, however, not verified against a sufficient number of calibrated surface and internal temperature sensors. Moreover, a metal surface and a large array of properly-attached sense electrodes with corresponding cabling is required in order to measure temperature with this method, as is shown in Fig. 11. Furthermore, the SoC of the battery influences the ERT measurement data. This implies that the ERT temperature must be corrected for the SoC. Although this method is practically somewhat complicated, a three-dimensional temperature map of the battery can favourably be obtained.

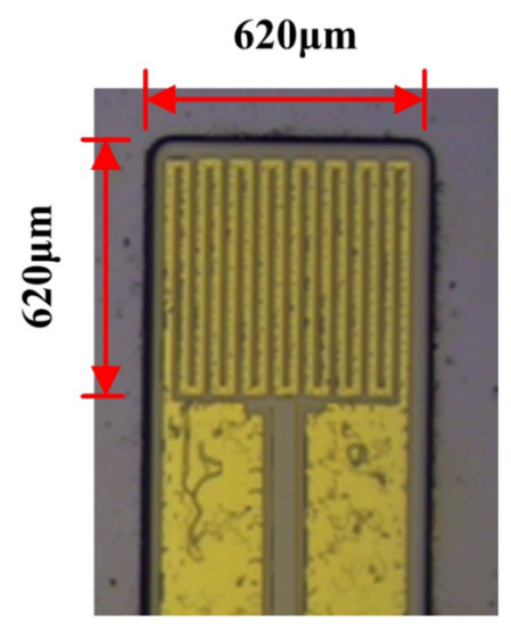

Fig. 10. Flexible micro-temperature sensor developed by Lee et al. [208].

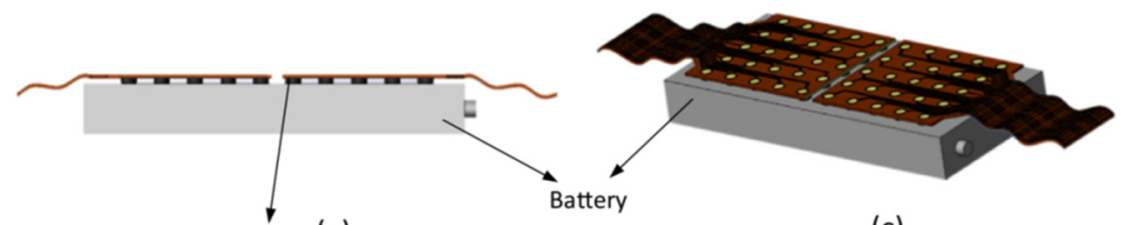

(a)

(c)

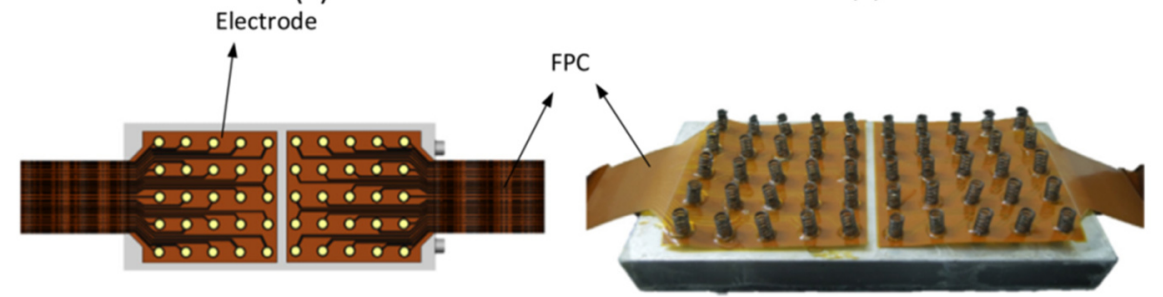

(b)

(d) 
Fig. 11. Schematic (a-c) and real (d) representation of a Li-ion battery with ERT sensors shown at various viewing angles. The sense electrodes can clearly be distinguished in (b-d), which are attached to a so-called flexible printed circuit (FPC), serving as measurement cable. Adopted from Ref. [215].

\subsection{Thermo-junctive devices}

Thermocouples are devices working on the basis of the Seebeck effect, which is called after the inventor Thomas Johann Seebeck [216]. The Seebeck effect is the generation of an electromotive force (EMF) by subjecting two different (semi)conductors to a temperature gradient. In Fig. 12, an illustration of the thermocouple measurement principle is shown. It can be seen that two dissimilar metals (Metal A and B) are connected at one end. This is the so-called measurement junction, which is located at the temperature measurement position. At the other end, an EMF can be measured due to a temperature difference across the dissimilar metals. As shown in Fig. 12, a measurement device cannot simply be connected to a thermocouple since this introduces another dissimilar metal junction with the measurement cables. To compensate for this effect, a so-called reference junction must be introduced that has a known temperature.

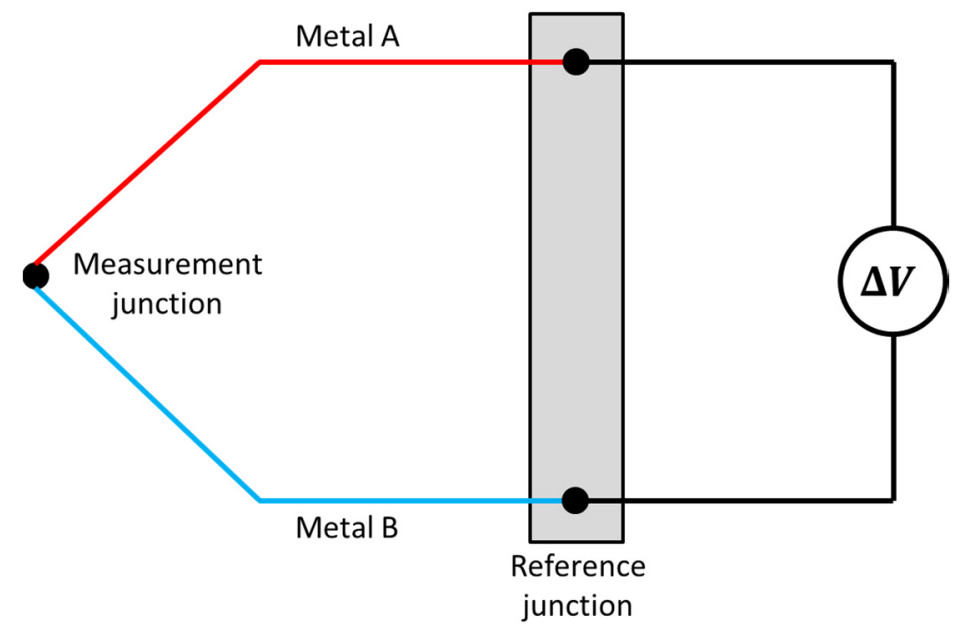

Fig. 12. Illustration of the working principle of a thermocouple.

Thermocouples have become the industrial standard because of the low cost, robustness, size and temperature range $[44,198,217]$. The sensitivity and response time are adequate for the most 
applications as the dimensions can be made very small. Although better accuracy can be reached, it is typically within 1 or $2^{\circ} \mathrm{C}$ and is therefore moderate. Small additional drawbacks of thermocouples are the requirement of reference-junction compensation, the sensitivity to corrosion, and that the cables cannot simply be extended. Furthermore, the EMF is a nonlinear function of temperature, making it complicated to obtain accurate temperature readings [217]. The sensitivity to corrosion is caused by the dissimilar metal junction. For this reason, thermocouples may need protection and maintenance. These properties make them somewhat unsuitable for long-term battery temperature measurements.

The number of material combinations used for thermocouples is numerous. Each combination has its own temperature and voltage characteristics. However, only eight types are standardized and regularly used, which are listed by for example Childs et al. [44] and Tong [198]. The EMF versus temperature characteristics of these types are shown in Fig. 13. The most common types of this selection are the so-called J-, T- and K-types, of which the last one is the most popular due to the relative wide temperature range and low cost. Although these three are commonly used, the E-type would be very suitable for accurate battery temperature measurements due to the high EMF output, which can also be clearly seen in Fig. 13b. The EMF measured at the cables can be directly converted to temperature with help of a lookup table or by using a mathematical function. No power source is required and, therefore, self-heating is not an issue, such as with thermistors or RTD.

(a)

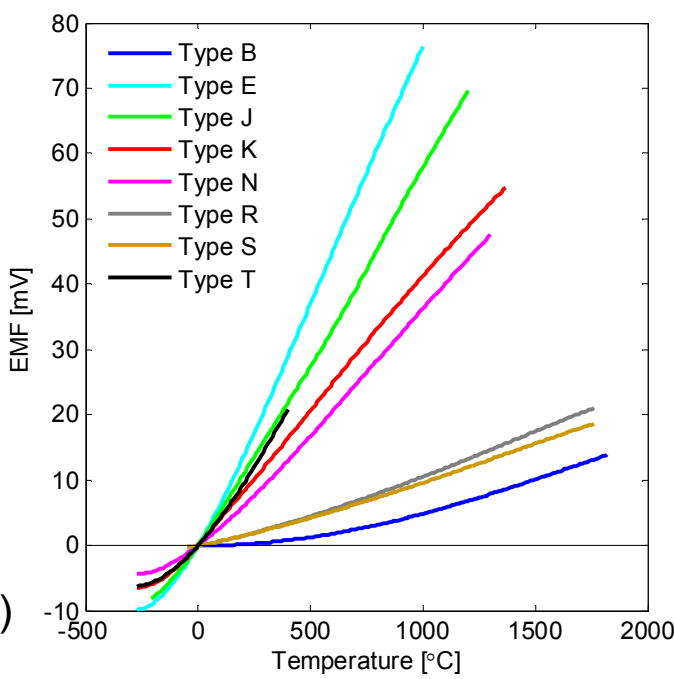

(b)

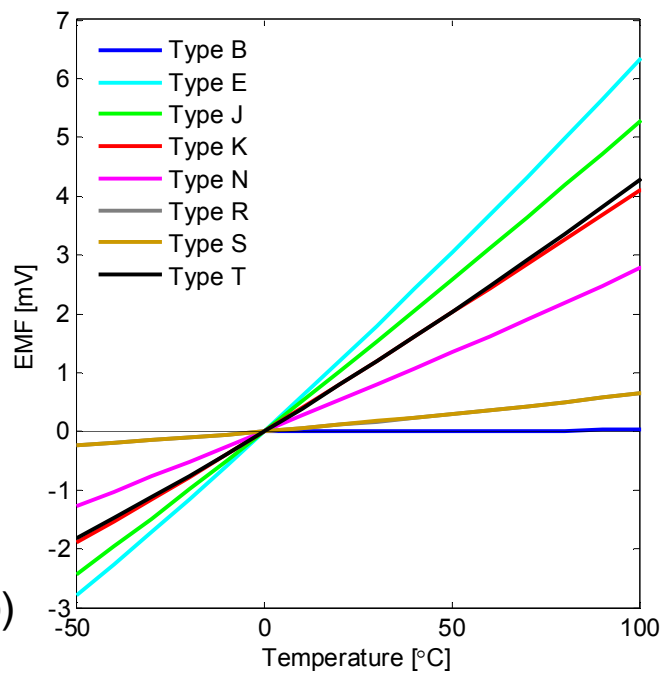


Fig. 13. (a) EMF versus temperature characteristics for the eight standardized thermocouples; (b) a zoom on the temperature range useful for Li-ion battery temperature measurements. This figure is generated with the data provided by the NIST ITS-90 thermocouple database [218]. Note that the reference junction is at $0^{\circ} \mathrm{C}$.

It can be concluded that, among the available scientific literature on battery temperature measurements, commercial thermocouples are numerously used. The reason is, most likely, that scientific measurement devices are often equipped with thermocouple input channels. As expected, the vast majority of authors is using the common K-type or T-type thermocouples in order to measure battery temperature. $\mathrm{N}$-types $[68,219,220]$, J-types $[127,221]$ or E-types $[170]$ are used less frequently. About $27 \%$ of the scientific contributions, using thermocouples for temperature measurements, did not precisely indicate what types were used. Therefore, measurement details partly remain unknown, making it impossible to accurately reproduce the measurement results reported in the literature.

As with thermistors and RTD, commercial (micro) thermocouples are also used to measure the internal battery temperature $[149,222-231]$. Although these measurements are useful for quantifying the internal temperature, either specially designed batteries with integrated sensors must be made, or a hole must be drilled into an existing (commercial) battery to insert a sensor. This leads to complicated battery designs and this is therefore less suitable for practical battery-powered applications. In addition, the integrated sensors should be chemically inert and may not react with or dissolve into the electrolyte. For that reason, sensors can be coated with parylene $[149,232]$ or polyimide [204]. Remarkably, most of the thermocouples used for internal measurements are not coated with a protective layer, or at least the authors did not report that. Therefore, it is expected that these sensors show instabilities or malfunctioning on the long term. 


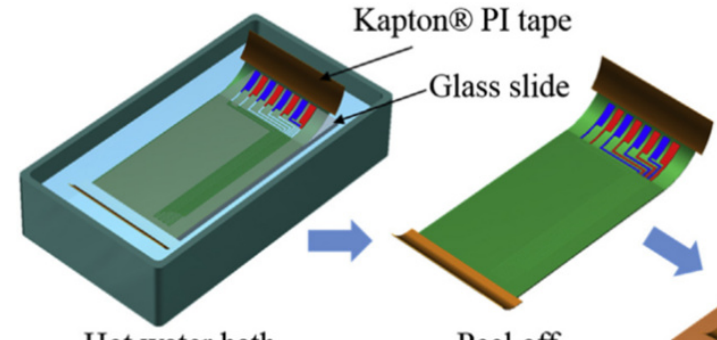

Hot water bath

(a)

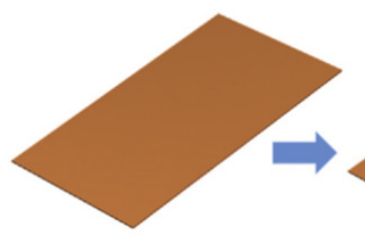

Copper foil

(c) (b)

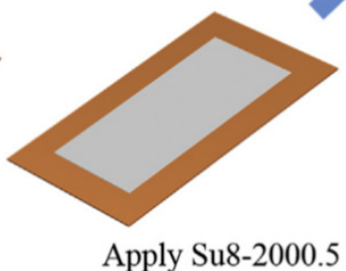

(d)

Fig. 14. Process used by Mutyala et al. [233] to make sputtered K-type thermocouples on a copper strip.

Some specially designed thermocouples for in situ temperature measurements are worthwhile to shed some light on. For example, Mutyala et al. [233] used flexible thin-film thermocouples integrated into a battery to measure the internal temperature. A K-type thermocouple was sputtered on a glass substrate and later transferred onto a thin copper foil. The transferring process and end result are shown in Fig. 14. After insulation with polyimide, the thermocouple was integrated into a pouch battery. The measurement results performed with the integrated flexible thin-film thermocouples are promising, but duration experiments are yet to be proven. 


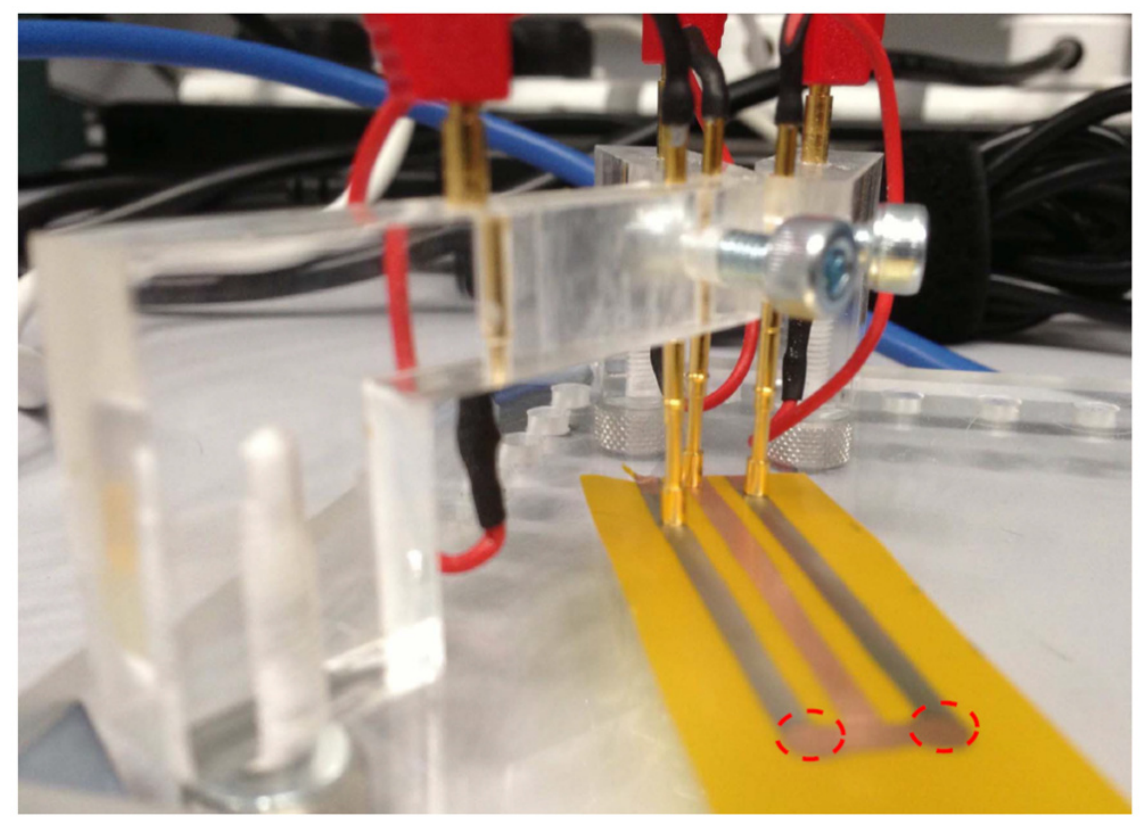

Fig. 15. Photograph of a prototype thermocouple matrix on a $2 \mathrm{~cm} \times 6 \mathrm{~cm}$ substrate, attached to a measurement setup. The two measurement points for internal battery temperature measurements are circled in red. Adapted from Ref. [234].

For spatial internal battery temperature measurements, a thin-film thermocouple matrix was developed by Martiny et al. [235]. Nickel and Copper were used as dissimilar materials for the thermocouple matrix and sputtered onto a Kapton foil. A final coating of parylene $\mathrm{C}$ was applied for protection. In Fig. 15, a photograph of a prototype sensor is shown. The resulting sensor had a thickness of less than $27 \mu \mathrm{m}$ and has been integrated into a laboratory-scale pouch battery. The sensor had no large influence on the battery performance at a $\mathrm{C} / 9$ cycling rate, but the protective coating damaged during battery assembly and, subsequently, caused instability due to corrosion. Zhang et al. $[149,232]$ and Lee et al. $[208,209]$ also used parylene for their internal sensors. Although Lee et al. $[210,211]$ switched to polyimide in their last reports for an unmentioned reason, they did not report any damage or instability of parylene. Nevertheless, the first thermocouple matrix design was improved by using Kapton foil as cover instead of parylene C [234]. Although Kapton increased the sensor thickness to $54 \mu \mathrm{m}$, it both improved the thermal stability and created a more homogeneous sensor as the substrate was Kapton as well. However, the improved version also encountered stability issues and, hence, is not suitable for internal battery temperature measurements. The next step is to 
make stability improvements by using polyimide. In addition to stability issues, this sensor has a relatively large footprint area and, consequently, may reduce the capacity of the battery. However, the sensor has the advantage of measuring internal and spatial-varying temperatures.

\subsection{Fiber Bragg-grating sensors}

Fiber Bragg Gratings (FBG) are deployed along the length of an optical fiber (see Fig. 16) and are used to manipulate the behaviour of light. The so-called Bragg gratings are inscribed into the core of an optical fiber by applying UV-light, creating a permanent change in refractive index [236]. These Bragg gratings act as a wavelength-selective mirror. When a spectrum of light propagates through the fiber core, a specific wavelength is reflected back, while the remaining part of the spectrum is transmitted nearly unaffected. This effect is schematically shown in Fig. 16a. The wavelength of the reflected signal, which is called the Bragg wavelength $\left(\lambda_{B}\right)$, has been defined as

$$
\lambda_{B}=2 n_{e f f} \Lambda,
$$

where $n_{e f f}$ is the effective core index of refraction and $\Lambda$ is the period of index modulation or grating spacing [237]. A change in $n_{\text {eff }}$ and/or $\Lambda$ results in a shift in the reflected Bragg wavelength. The measurement of this wavelength shift, as a result of external influences, is the basis for FBG sensors [238]. Illustrations of two types of external influences on the Bragg wavelength are shown in Fig. 16b and c. When a fiber is compressed or stretched (Fig. 16b), the grating spacing changes, which leads to a shift in the Bragg wavelength. A shift in Bragg wavelength can also be observed for temperature changes (Fig. 16c). This can be mainly attributed to a temperature-dependent refraction index. The influence of thermal expansion is very small and, thus, grating spacing may be neglected; the index changes are by far the most dominant effect [239]. 

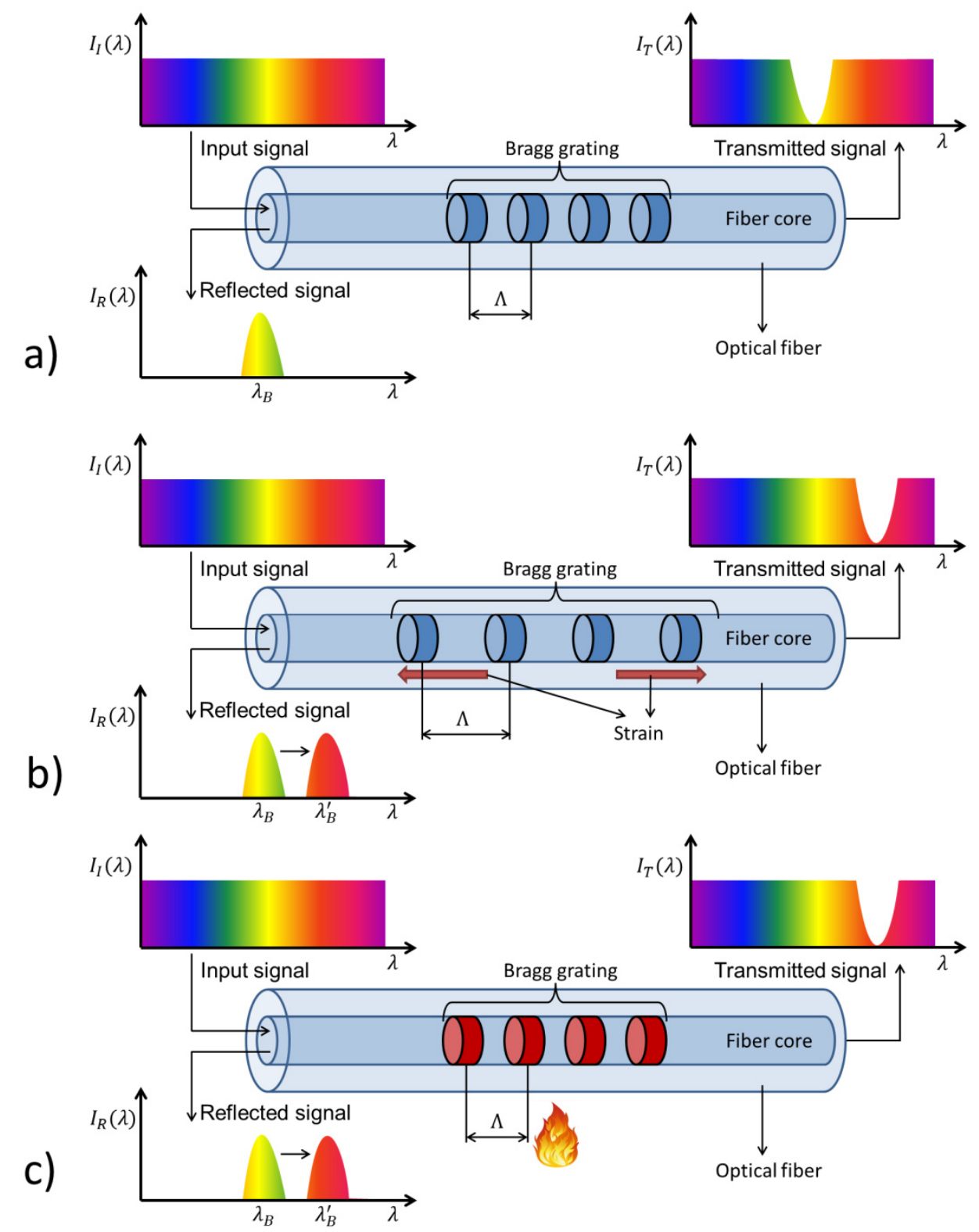

Fig. 16. Working principle of a fiber Bragg-grating sensor (a), FBG sensor under influence of strain (b), and FBG sensor under the influence of heat (c).

FBG sensors are becoming increasingly popular due to advantages such as small size, light weight, passive nature, immunity to electromagnetic and radio-frequency interference, high sensitivity and long-term reliability [240]. Another advantage is that FBG sensors can be multiplexed, which implies that multiple FBG can be inscribed into a single optical fiber. This makes it possible to perform measurements at different locations along the fiber length. In addition, the Bragg wavelength 
favourably shifts linearly with temperature [241]. A typical example of this linear wavelength shift is shown in Fig. 17.

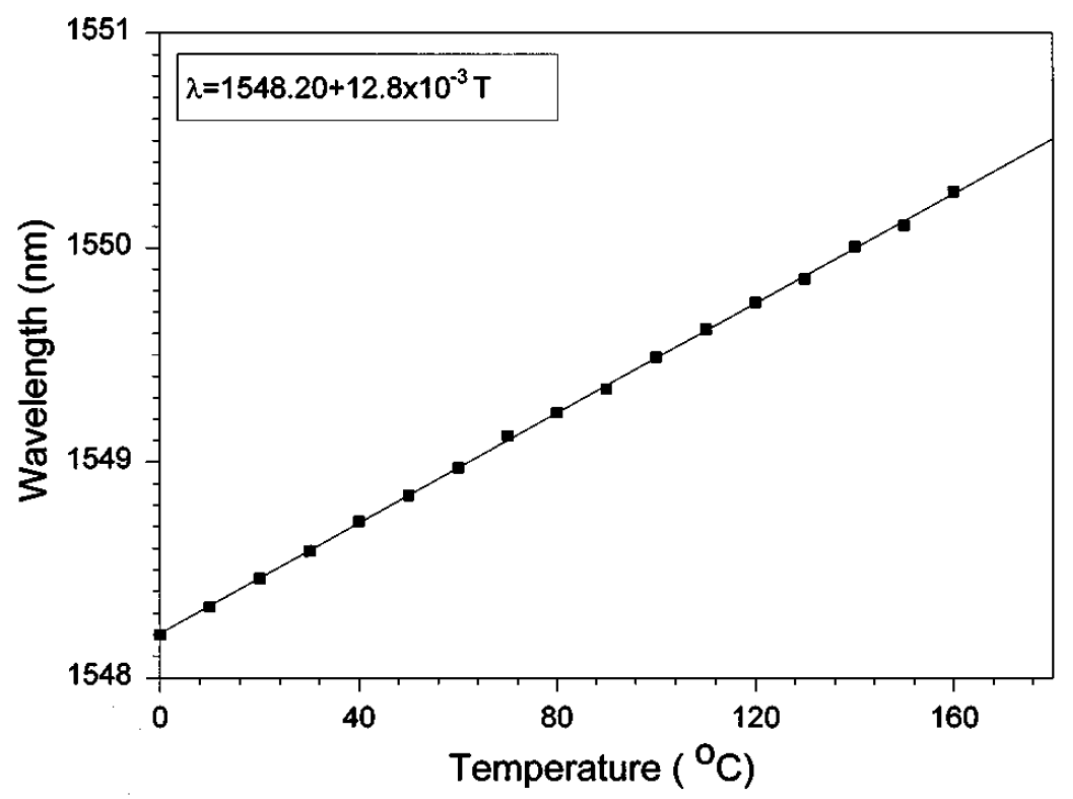

Fig. 17. Bragg wavelength as a function of temperature. Adopted from Ref. [239].

The temperature range of an optical fiber strongly depends on what materials are used. Black et al. [242] listed various optical fiber and coating materials including the corresponding temperature ranges. Silica, the most standard material, can withstand temperatures close to -273 up to $1190^{\circ} \mathrm{C}$ before softening occurs. However, the protective coatings have limitations. For example, acrylate, the standard optical fiber coating has a temperature range of -40 to $85^{\circ} \mathrm{C}$. Polyimide can be used as an alternative, making the temperature range larger $\left(-190\right.$ to $\left.385^{\circ} \mathrm{C}\right)$. Furthermore, the strong chemical resistivity makes it ideal for internal battery temperature measurements. In a temperature range of approximately 20 to $60^{\circ} \mathrm{C}$, measurement accuracies of \pm 0.4 to $\pm 0.2^{\circ} \mathrm{C}$ have been obtained with FBG sensors [241,243]. A typical value for temperature sensitivity is a wavelength shift of $10 \mathrm{pm} /{ }^{\circ} \mathrm{C}$ $[237,239]$.

Although optical FBG sensors were already investigated in electrochemical systems such as PEM fuel cells [244,245], Yang et al. [246] were the first who investigated this type of sensors on Li-ion battery technology. Three coin-type batteries were used at which the temperature was measured with 
FBG at both flat surfaces. In addition, the temperature was measured on the flat and lateral face of an as-denoted columnar (cylindrical) battery. The calibration of the FBG sensors showed a linear response in the temperature range from 0 to $60^{\circ} \mathrm{C}$. Through these calibration measurements, a typical sensitivity of $10 \mathrm{pm} /{ }^{\circ} \mathrm{C}$ was found. It was concluded that FBG temperature sensors show an adequate thermal response in comparison to thermocouples. However, this was not quantified, although the operation of FBG sensors on Li-ion batteries was demonstrated successfully for the first time. After this contribution, research activities with optical FBG sensors in the field of Li-ion batteries increased.

Others followed quickly with temperature and strain measurements on Li-ion batteries using FBG sensors [247-249]. For example, Nascimento and co-workers [249] applied FBG sensors on a cylindrical 18650 Li-ion battery. A single fiber, with two inscribed Bragg gratings ( $2 \mathrm{~cm}$ apart) was used for temperature measurements at two locations on the battery. An additional fiber was attached along the longitudinal axis to monitor variations in strain. The measurement results indicated that temperature and strain evolutions are larger at a high $\mathrm{C}$-rate $(1.33 \mathrm{C})$ in comparison to a low $\mathrm{C}$-rate of 0.25. In addition, it was found that at the highest C-rate, temperature differences between the two inscribed FBG are marginal $\left(0.5^{\circ} \mathrm{C}\right)$.

The same research group [250] continued their work by investigating FBG temperature measurements at Li-ion pouch-type batteries. Two optical fibers, inscribed with two Bragg gratings, were used for internal and external temperature measurements. The silica optical fiber was tested for its chemical resistivity in a $\mathrm{LiPF}_{6}$ salt-containing electrolyte. After two weeks of storage in the electrolyte, it was found that only a very small amount of Si was dissolved, indicating that this fiber type is not sensitive to the electrolyte. In a temperature range of 10 and $35^{\circ} \mathrm{C}$, an average sensitivity of 8.40 and $10.255 \mathrm{pm} /{ }^{\circ} \mathrm{C}$ for the external and internal FBG sensor were obtained, respectively. It was concluded that optical FBG temperature sensors are able to detect temperature changes at multiple locations, both internally and externally, with a superior response rate. However, these FBG sensor measurements were not verified against temperature measurements with other (commercial) sensors. 
Therefore, the same group [251] compared FBG temperature measurements with that of commercial K-type thermocouples. The corresponding schematic experimental setup is shown in Fig. 18 [251]. Fig. 18a shows the thermocouple and FBG connections to the battery. It can be seen that only one optical fiber is required for temperature measurements at three different locations (red dashes on blue line) on the surface of the battery. Fig. 18b shows the used equipment and how it is connected. In this particular study, it was found that the response rate of FBG sensors is approximately 1.2 times faster than that of the used thermocouples. Moreover, in the middle measurement position, the difference between the peak temperatures of FBG and thermocouples reaches up to $5.7^{\circ} \mathrm{C}$ at a $\mathrm{C}$-rate of 8.25 . The difference is attributed to the slower response of thermocouples in comparison to FBG sensors. At high C-rates fast thermal evolutions occur which cannot be fully followed by thermocouples. For these reasons, the authors concluded that FBG sensors are a better choice in comparison to thermocouples for real-time monitoring of the battery surface temperature.
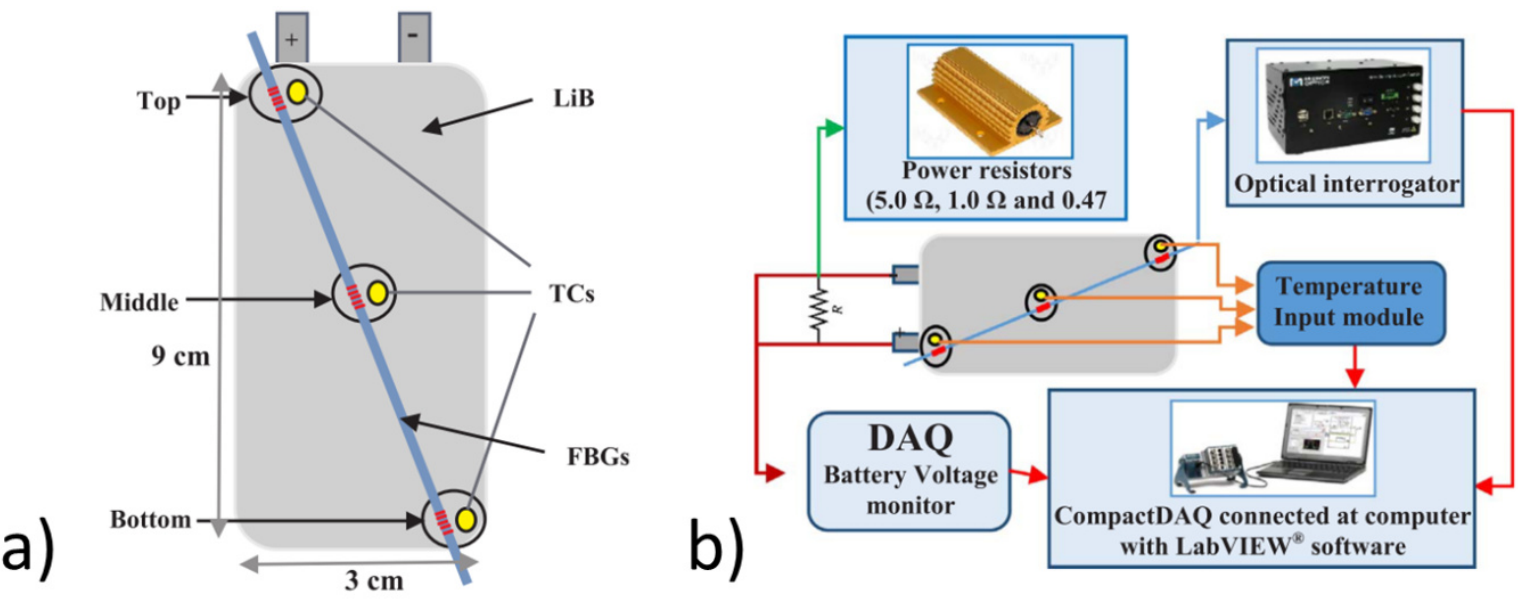

Fig. 18. Locations of thermocouples and FBG on surface of battery (a) and schematic overview of experimental setup (b). Adapted from Ref. [251].

FBG sensors were also used to monitor temperature and strain in battery packs for enhanced safety in a study by Meyer et al. [248]. Every single battery in the pack, containing 96 batteries, was monitored with an FBG temperature sensor on a predetermined hot spot. Thermistors were used as the default temperature sensors and fixed to the terminal of every fourth battery. Clear differences 
were found between the thermistors and FBG sensors. During fast charging, a maximum temperature difference of $15^{\circ} \mathrm{C}$ was reported between the warmest and coldest battery. The relative accuracy of the FBG sensors was determined to be $\pm 0.05^{\circ} \mathrm{C}$, whereas that of the thermistor was only $\pm 1^{\circ} \mathrm{C}$. From these results, it was concluded that the integration of FBG sensors on every single battery considerably improves safety as the BMS can be provided with far more accurate measurement information.

After using FBG sensors to measure diffusion processes [252] and intercalation stages [253] through strain, the team of Raghavan et al. [254] embedded FBG sensors for accurate internal monitoring battery states. The results have been published in a twofold paper [254,255]. Investigations published in the first version [254] revealed that the seal integrity, capacity retention and projected cycle life of batteries with embedded FBG sensors are highly comparable to batteries without FBG sensors. It was also shown that batteries with embedded sensors could be integrated into existing modules and that the corresponding system cost are in the range of a few hundreds of U.S. dollars, which is comparable with the conventional system cost. Therefore, this work established the possibility of embedding FBG sensors in large-format Li-ion batteries as a low cost, field-deployable option for internal state monitoring. Their second paper [255] focuses on using the measurements obtained from the embedded FBG sensors for SoC and SoH monitoring at different temperatures. It is shown that the SoC can be estimated with an error of less than $2.5 \%$ by using the strain measured by FBG sensors.

Similar work with embedding FBG sensors in coin-type batteries was performed by Fortier and colleagues [256]. During experiments, the authors found that the harsh FBG sensor cuts through the cathode and separator. This issue has been solved by using extra layers of separator material around the FBG sensors. However, Raghavan et al. [254] did not encounter this problem. A possible explanation can be that the used electrode stack was thicker and, therefore, more deformable. Thus, care should be taken with embedding FBG sensors in small electrode stacks.

Recently, an FBG sensor was used by Amietszajew et al. [257] to measure the internal temperature of a commercial 18650 high-energy battery. To protect the FBG sensor against electrical, 
chemical and mechanical stress, it was placed in an aluminium tube. The aluminium tube was then fully sealed with a fluorinated ethylene propylene heat-shrink. The sensor assembly was inserted in the centre of the battery. Thermocouples were used to measure the battery surface and ambient temperatures. In addition to the temperature sensors, a lithium metal reference electrode was used. Using the FBG sensor, thermocouple and reference electrode, it was possible to obtain the thermal and electrochemical responses of the battery. From the measurement results, it was found that the battery can be charged with a 6.7 times higher C-rate than specified by the manufacturer, without exceeding the electrochemical and thermal safety limits. Therefore, this study shows the high value of possible performance optimization by integrating internal temperature sensors and the application of reference electrodes.

It is remarkable to see that none of the authors showed calibrations and measurements with FBG temperature sensors for temperatures below $0^{\circ} \mathrm{C}$, which is a critical range in Li-ion battery operation. Obviously, the application of FBG sensors in the field of Li-ion batteries is quite recent and still requires thorough investigations, particularly for long-term (in situ) measurements and in the application. As FBG sensors offer great advantages, these can be seriously considered as temperature and strain sensors to measure states in battery-powered applications.

\subsection{Impedance-based temperature measurements}

Electrochemical Impedance Spectroscopy (EIS) is a non-destructive technique for characterizing the behaviour of electrochemical systems $[258,259]$. The impedance of a battery can be obtained by voltage or current excitations (typically sinusoidal) and, simultaneously, measuring the response. The ratio between input and output gives the (complex) impedance that can be defined as

$$
Z(j \omega)=\frac{V(j \omega)}{I(j \omega)},
$$


where $Z$ is the (complex) impedance, $V$ the voltage, $I$ the current, $\omega$ the angular frequency and $j$ the imaginary unit satisfying $j^{2}=-1$. When these measurements are performed at various frequencies, an impedance spectrum of the battery can be obtained. Note that the magnitude of the applied excitation signal should be sufficiently small to guarantee a linear response, yet not too small to prevent a poor Signal-to-Noise Ratio (SNR).

EIS is frequently used for extracting kinetic and transport properties of electrode materials, aging studies, modelling purposes, and determination of SoC and SoH [260-272]. However, EIS can also be used to measure the internal battery temperature by relating impedance parameters, such as the phase shift, real part, or imaginary part to the temperature. In that case, often it is referred to as impedance-based temperature indication or sensorless temperature indication. In the past five years, investigations on this subject gained substantial interest since impedance-based temperature indication offers quite some advantages with respect to conventional temperature measurements. For instance, no external or internal hardware temperature sensors are required, thermal measurement delay is short, it measures an average/integral temperature of the active material, and EIS measurements can also be used to determine additional states, such as SoC and SoH [273-276]. On the other hand, it also has some challenges, such as the SoC and aging dependence of the impedance and, moreover, the sensitivity for interference, such as (dis)charge currents and crosstalk signals $[277,278]$. These dependencies and the interference can considerably influence EIS-based temperature indications.

A number of impedance-based-related temperature indication methods have been presented. For example, Champlin [279] patented a method to determine internal battery temperature by performing EIS measurements and calculating time constants of RC-circuits, accordingly. These time constants can be readily used to determine the internal battery temperature. Details of the method, such as measurement accuracy and sensitivity to (dis)charge currents are, however, not revealed. 
Srinivasan et al. [273] reported that a correlation exists between phase shift of the impedance and internal temperature at any frequency between 40 and $100 \mathrm{~Hz}$. This correlation is demonstrated at a frequency of $40 \mathrm{~Hz}$ for three different batteries in a temperature range of -20 to $66^{\circ} \mathrm{C}$. For all batteries, a decreasing phase shift is found with increasing temperature and this behaviour is essentially SoC independent. In Fig. 19a, an example of the phase shift is shown as a function of temperature. The authors point out that this unique relationship does not hold for frequencies below $30 \mathrm{~Hz}$ since SoC independence is not guaranteed below these frequencies. In a successive publication of the same group [280], the phase-shift-method was used for real-time temperature monitoring of a 53 Ah Li-ion battery. The phase shift, that was related to the temperature of the negative electrode was measured at (dis)charge currents below $1 \mathrm{C}$-rate. For various conditions, it was demonstrated that the negative electrode temperature deviates from the measured surface temperature.

Schwarz and co-workers [281] also related the phase shift to the internal battery temperature. However, instead of using batteries with common graphite negative electrodes, they used batteries with titanate negative electrodes. In addition, a prototype Printed Circuit Board (PCB) was developed that can directly be connected to the used batteries, enabling online temperature estimation through the phase shift. The PCB was first used for phase-shift calibration measurements at a frequency of 1 $\mathrm{kHz}$ in a temperature range between 0 to $40^{\circ} \mathrm{C}$. These measurements showed a clear temperature dependence of phase shift and a small SoC dependence as well. After calibration, the authors measured the internal battery temperature using a PCB through two approaches. In the first approach, a SoC-specific calibration line, and in the second approach, an averaged calibration line was used to indicate temperature. An average deviation in temperature of 2.08 and $2.48^{\circ} \mathrm{C}$ was found with the first and second approach, respectively. Although these deviations are relatively large, a method for impedance-based temperature indication in battery-powered applications was realised with compact electronics. Furthermore, the authors did not (dis)charge the batteries during phase shift measurements. This implies that the batteries were measured under equilibrium conditions. 

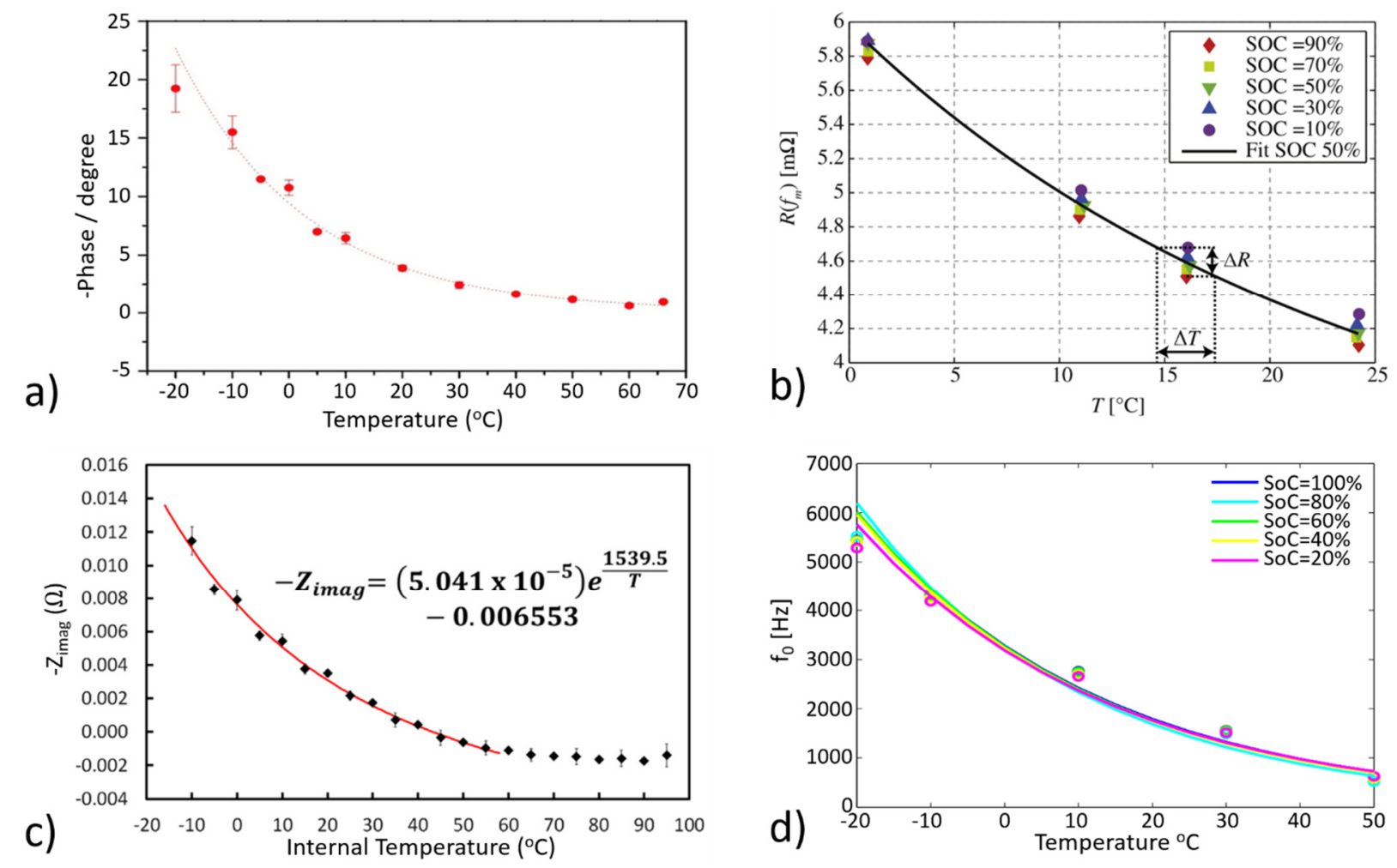

Fig. 19. (a) Phase shift (at $40 \mathrm{~Hz}$ ) as a function of temperature averaged over $20 \%, 50 \%$ and $80 \%$ SoC measured on a 4.4 Ah battery [273]; (b) Real part of the impedance (at $10.3 \mathrm{kHz}$ ) as a function of temperature, shown for various SoC of a 2 Ah pouch-type battery [274]; (c) Imaginary part of the impedance (at $300 \mathrm{~Hz}$ ) as a function of temperature, averaged over all measured SoC of a $2.6 \mathrm{Ah}$ cylindrical battery [282]; (d) Intercept frequency as a function of temperature shown for various SoC of a 2.3 Ah cylindrical battery [276].

Phase shifts under non-equilibrium conditions were measured by Zhu and colleagues [283].

The authors increased the EIS measurement complexity by measuring the impedance in the relaxation time after a sequence of current pulses. The phase shift at a frequency of $10 \mathrm{~Hz}$ was favourably selected as temperature indicator for a $30 \mathrm{Ah} \mathrm{LiFePO}_{4}$ battery, since it was found to be SoC independent. Remarkably, Srinivasan et al. [273] noted that SoC independence below $30 \mathrm{~Hz}$ cannot be guaranteed. This suggests that optimal frequency selection depends on the battery type. The measurement results of Zhu and colleagues [283] revealed that the phase decreases exponentially with increasing relaxation time. Appropriate equations were developed to correct the phase shift as a function of relaxation time. Using these equations impedance-based temperature measurement errors lower than $1^{\circ} \mathrm{C}$ can be obtained. 
Impedance-based temperature indication can also be performed by relating the real part of the impedance to the internal battery temperature. Schmidt et al. [274] were the first who demonstrated this concept and found an intrinsic relationship between real part and the temperature at a frequency of $10.3 \mathrm{kHz}$ for a 2 Ah pouch battery. In Fig. 19b an example of the real part as a function of temperature can be seen, measured at various $\mathrm{SoC}$ values. At isothermal conditions, this measurement concept can determine temperature within $\pm 0.17^{\circ} \mathrm{C}$ and $\pm 2.5^{\circ} \mathrm{C}$ for known and unknown SoC, respectively. In addition, it was shown that temperature gradients do not have a considerable influence on the measurement accuracy at the investigated frequency of $10.3 \mathrm{kHz}$. Therefore, the indicated temperature under gradients reflects the average temperature of the battery. However, it should be noted that the influence of thermal gradients on impedance spectra in the low-frequency range can be large $[143,284]$. Similar to Zhu and colleagues [283], Schmidt et al. [274] performed impedance-based temperature indication in the relaxation time after current pulses. However, no equations were used for corrections. The obtained impedance-based temperature was directly used as indicator for the internal battery temperature. Maximum deviations of $23 \%$ between internal and surface temperatures where found, indicating the complexities of measuring temperature gradients.

Richardson an co-workers $[275,285]$ advantageously used the real part of the impedance at a frequency of $215 \mathrm{~Hz}$ as an input parameter for thermal models. In a later contribution [286], the imaginary part, earlier related to internal temperature by Spinner et al. [282], was used since it was found to give superior results to the real part. An example of the imaginary part as a function of temperature is shown in Fig. 19c. The purpose of this unique combination of impedance-based temperature indication and thermal modelling was used for estimating non-uniform internal temperature distributions in cylindrical batteries. In these contributions, EIS measurements were also taken in the relaxation time to avoid measurements under DC-currents, providing results that are more accurate. 
A different approach of impedance-based temperature indication was developed by Raijmakers et al. [276] and, later, confirmed by Rainer and colleagues [287]. Instead of using a particular frequency to determine e.g. the real part, imaginary part or phase, the frequency at zero imaginary value is used for internal battery temperature indication. For several battery chemistries and capacities, it was found that this frequency decreases as a function of temperature and can therefore be used as a temperature indicator. An example of this behaviour is shown in Fig. $19 \mathrm{~d}$ at various SoC values. Interestingly, it was found that the intercept frequency is essentially SoC and aging independent, which favours on-board battery temperature indication. The method of the intercept frequency has been further developed to a so-called non-zero intercept frequency (NZIF) [277]. Using an NZIF, it is possible to avoid undesirable (current) interference from electric systems in batterypowered applications, such as EV. This offers great potential to increase the SNR and, consequently, to determine temperature more accurately. In addition to interference from electric systems, EIS measurements can be prone to crosstalk interference in battery packs [278]. This results in inaccurate EIS measurements and, consequently, inaccurate temperature indications. Therefore, careful design considerations should be taken to develop impedance-based temperature indication methods for battery packs.

Further complications can be met in selecting excitation frequencies, and/or e.g. real part, imaginary part, phase shift or intercept frequency to obtain optimal measurement accuracies. In order to investigate these issues, a comparison and accuracy analysis of impedance-based temperature estimation methods was performed by Beelen et al. [288,289]. It was shown that jointly selecting these parameters results in more accurate temperature indications in comparison to all previously discussed individual methods. A detailed study was performed to find a frequency that reveals maximum temperature sensitivity and minimum SoC dependence. In addition, both the real and imaginary part are used with a certain weight to obtain optimal accuracy. This new approach results in an absolute average bias of $0.4^{\circ} \mathrm{C}$ and average standard deviation of $0.7^{\circ} \mathrm{C}$ on a 90 Ah battery. However, these investigations were conducted for a battery that resides under equilibrium conditions in the 
laboratory. Therefore, it would be interesting to perform the same analysis on batteries under nonequilibrium conditions in real applications.

It can be concluded that the presented impedance-based temperature indication methods are valuable tools for temperature monitoring of Li-ion batteries. However, high DC (dis)charge currents, interference from electric components, crosstalk interference, $\mathrm{SoC}$ and aging dependencies make it challenging to implement. So far, most research on this subject was performed under equilibrium conditions, although impedance-based temperature indication also has been applied under current flow [277,290-292], and for thermal runaway monitoring [293]. However, more research efforts on the implementation of impedance-based temperature indication are necessary in order to obtain a clear understanding how accurately and fast it can be performed. $(\mathrm{H}) \mathrm{EV}$ would be perfect candidates for these investigations as these applications combine all disturbing ingredients, such as high load currents, electric and crosstalk interference, varying SoC and aging/cycling influences. In addition, the uncertainty of impedance-based temperature indication increases as the battery temperature increases $[282,286]$. This limits the measurement range and, therefore, puts challenges on monitoring high temperatures and to guarantee safe operation.

Obviously, the measurement uncertainty is also dependent on the used measurement equipment. Since common electrochemical measurement equipment is not suitable for on-board applications, several authors presented proof-of-concept PCB that can perform these on-board electrochemical measurements $[277,281,287,294-298]$. By integrating the PCB functionalities into a small chip [299], batteries inside a battery pack can be monitored for voltage, impedance and temperature by a single device, enabling accurate $\mathrm{SoC}$, SoH, and temperature measurements at individual battery level.

\subsection{Johnson Noise thermometry}

Johnson noise thermometry (JNT) is a method to measure temperature by making use of the random thermal fluctuations of free charge carriers in an electric conductor [300]. The method is 
named after Johnson, who first measured the effect of thermal agitation of electricity in conductors [301]. Later, Nyquist established the theoretical basis of the Johnson effect [302]. Generally, resistors are used as sensors for JNT. It is remarkable that the generated thermal noise voltage is independent of the resistor material [303]. The resistance, which should be known for JNT, changes as a function of temperature but can easily be measured with high accuracy. These properties allow great freedom in the resistor material selection and design for temperature determination through JNT. However, challenges used to be met in measuring the noise signal since it is extremely small and easily corrupted by other noise sources [304]. In addition, long integration times and high bandwidths are required to achieve small relative uncertainties and, with pure analogue electronics, it is impossible to define the system bandwidth [304,305]. At present, these challenges can be addressed by using fast and accurate analogue-to-digital converters [304] and quantum voltage noise sources [306,307].

In Fig. 20 the Johnson noise power, measured with a $50 \Omega$ resistor, using a autocorrelation and cross-correlation setup, is shown as a function of temperature [308]. When the noise power and resistance are measured, the temperature can be derived through the Johnson-Nyquist equation.

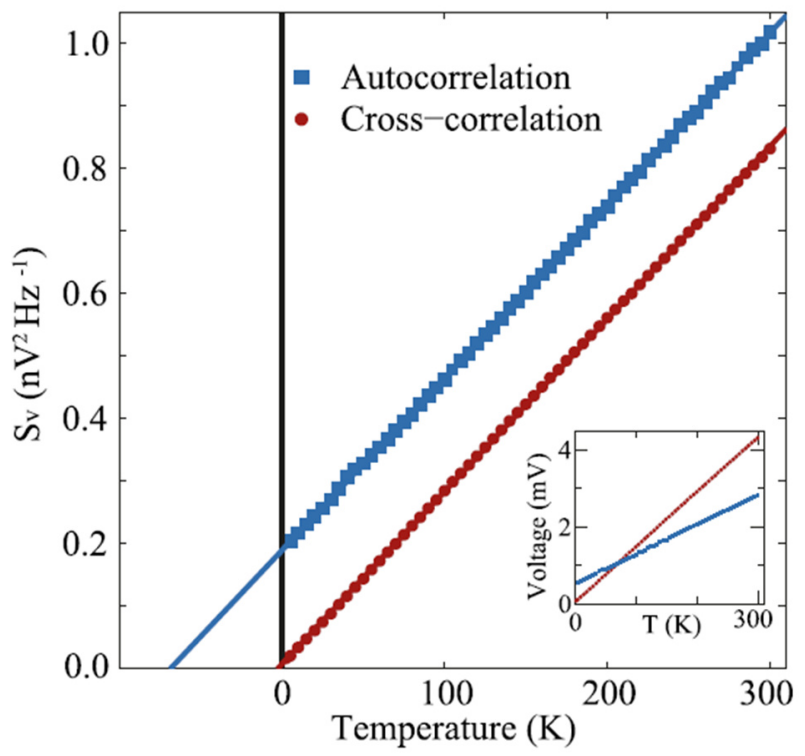

Fig. 20. Johnson noise as a function of temperature with a $50 \Omega$ resistor load as measured by auto- and cross- correlation setups. The inset shows the measured voltage as a function of temperature. This is converted to noise power by the Johnson-Nyquist equation. Adopted from Ref. [308]. 
Due to the good stability of the JNT method, it is favourable for measuring temperatures in metrological applications and harsh conditions, such as nuclear reactors [309,310]. However, recently JNT has also been used to measure the surface temperature of a lead acid battery pack applied in an EV testbed [311]. A JNT temperature measurement method was combined with a giant magnetoresistance (GMR) sensor. This combination results in a multifunctional sensor that can measure temperature, velocity, and current. The GMR-JNT sensor was, together with a K-type thermocouple, placed on the surface of the battery pack. In comparison to the thermocouple, measurement errors within the range from -2.67 to $3.08^{\circ} \mathrm{C}$ were obtained. These errors are relatively large. However, the GMR-JNT temperature measurements follow that of the thermocouple and are therefore feasible for dynamic temperature measurements on battery packs.

\subsection{Thermal imaging and liquid-crystal thermography}

Infrared (IR) thermal imaging and liquid-crystal thermography are used to measure and visualize the surface temperature of objects. IR thermal images can be produced with infrared cameras. Infrared cameras are non-contact devices that can detect thermal radiation with special infrared detectors and convert it into an electric signal [312]. The electric signal can then be processed to a thermal image or video, on which temperature profiles can be seen. Although surface temperatures advantageously can be obtained, IR thermal imaging is not straightforward in its use. A multitude of factors, such as radiation from objects under investigation, radiation from the atmosphere, and radiation from surrounding objects can influence IR images and, therefore, its interpretation [313]. For thermal imaging on Li-ion batteries, these issues can be solved to a large extend by, for example, coating the surface of the battery with a matte black paint and covering the battery surroundings with black material $[118,194,201,314-316]$. These measures increase the emissivity of the battery surface and surroundings, effectively eliminating reflections. In addition, the IR camera can be placed at a $45^{\circ}$ angle with respect to the battery in order to eliminate the radiation 
emitted or reflected by the camera and operator [317]. After accurate calibration within typically 0 to $120^{\circ} \mathrm{C}$, thermal sensitivities between 0.03 and $0.09^{\circ} \mathrm{C}$ can be obtained with $2 \%$ accuracy $[194,316]$. Depending on the measurement setup, spatial resolutions of 0.1 to $0.3 \mathrm{~mm}$ can be achieved $[315,318,319]$. A recent specific review on IR thermal imaging of electrochemical systems, including batteries and fuel cells, can be found in Ref. [320].

As with IR thermal imaging, so-called Thermochromic Liquid Crystals (TLC) also make it possible to measure surface temperatures. TLC are organic molecules that change colour as a function of temperature in a predictable and repeatable manner [321]. The method of using TLC to measure temperature is called liquid-crystal thermography. To measure temperature, surfaces can be coated with TLC material, which is commercially available in the form of adhesive sheets. The colour evolution can then be recorded by video cameras, and processed with image-processing software. However, before usage, careful calibration is necessary to determine the colour-temperature relationship [322].

TLC operate in a particular bandwidth that can be defined as the range at which light in the visible spectrum actively is reflected back. Beyond both sides of the bandwidth, TLC are transparent. When TLC pass through their bandwidth, they reflect visible light from long wavelengths (red) to short wavelengths (blue) with increasing temperature [323,324]. This behaviour is opposite in comparison to methods such as IR thermal imaging, which typically show high temperatures in red and cold temperatures in blue colours. Various TLC bandwidths are commercially available, ranging from narrowband (typically 0.5 to $4^{\circ} \mathrm{C}$ ) to wideband (typically 5 to $30^{\circ} \mathrm{C}$ ) bandwidths [323]. Measurement uncertainties vary with bandwidth and measurement setup properties, such as lighting and viewing angles, illumination sources, TLC coating thickness and hysteresis effect in $\operatorname{TLC}[325,326]$. For bandwidths of 5 and $10^{\circ} \mathrm{C}$ uncertainties of \pm 0.1 to $0.3^{\circ} \mathrm{C}$ and 0.2 to $0.4^{\circ} \mathrm{C}$ can be achieved, respectively [325]. 

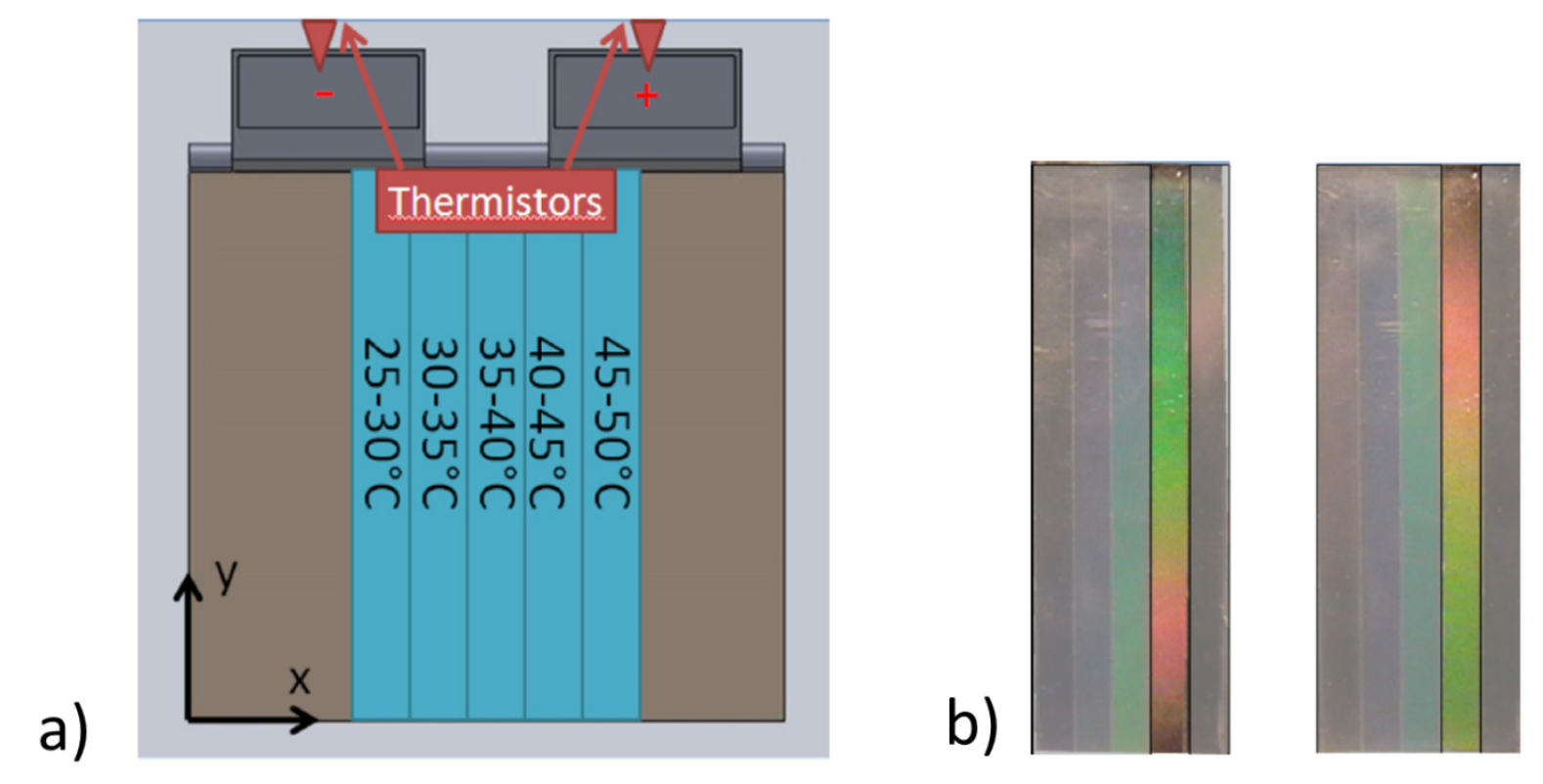

Fig. 21. Schematic view of a pouch-type battery surface, with five attached TLC sheets, all having a different range and a bandwidth of $5^{\circ} \mathrm{C}(\mathrm{a})$ and temperature profiles measured by TLC sheets without cooling (left) and with cooling (right) at a current of $300 \mathrm{~A}$ (b). Cooling causes the temperature profile to invert. Note that red colours are low temperatures and green/blue colours high temperatures. Adapted from Ref. [327].

Giuliano and co-workers [327] used liquid-crystal thermography to visualize temperature and temperature gradients on a pouch-type battery that was assembled in a stack. Five TLC sheets with an individual bandwidth of $5^{\circ} \mathrm{C}$ were attached to the surface of a single battery. All five TLC sheets had a different starting temperature, resulting in a total bandwidth of $25^{\circ} \mathrm{C}$. A schematic view of a battery with these five TLC sheets is shown in Fig. 21a. Using TLC with individual bandwidths of $5^{\circ} \mathrm{C}$ leads to higher temperature measurement accuracies. After calibrations, a measurement accuracy of $\pm 0.5^{\circ} \mathrm{C}$ was confirmed. The liquid-crystal-thermography results are shown in Fig. 21b. The left-hand side is without cooling and right-hand side with cooling conditions. It can be seen that the fourth TLC sheet from the left is the active sheet, indicating that the surface temperature is between 40 and $45^{\circ} \mathrm{C}$. The gradient from the top to the bottom of the battery is perfectly visualized by the TLC sheets. Note again that red colours indicate low temperatures and green/blue colours high temperatures. Using imageprocessing software the temperature can be quantitatively obtained. 
IR thermal imaging and liquid-crystal thermography provide very useful, accurate, and visual measurements on surface temperatures that cannot be obtained with the previously reviewed measurement techniques, such as thermistors, thermocouples and impedance-based methods. Advantageously, IR thermal imaging and liquid-crystal thermography can be used for qualitatively and quantitatively indicating temperature distributions on battery surfaces and for verifying thermal simulations, making them ideal for research purposes. However, at present these techniques are not suitable to indicate temperature in commercial battery-powered applications since IR thermal imaging and liquid-crystal thermography are delicate, non-practical and expensive in its use.

\section{Conclusions}

In Li-ion batteries, $\mathrm{Li}^{+}$ions shuttle between the positive and negative electrodes upon charging and discharging. This process occurs with certain inefficiencies, which result in heat generation. The heat flows from the electrode materials to the battery surface from where it is dissipated to the environment. Since heat is generated internally, thermal gradients develop, resulting in temperature measurement complications and position-dependent aging, which more rapidly reduces the SoH of battery packs. When the heat cannot be sufficiently dissipated, or when the battery is under abusive conditions, thermal runaway may occur, which leads to dangerous situations. In particular, if a battery inside a battery pack induces thermal runaway to adjacent batteries, it can propagate through the complete battery pack. Therefore, careful design considerations need to be taken on single-battery, module, and pack level in order to prevent dangerous situations and to maximize performance and lifetime.

Accurate temperature measurements must be performed to prevent these dangerous situations and to maximize performance and lifetime. However, due to above-mentioned issues this is rather challenging. Therefore, a proper temperature measurement method should be selected, particularly in terms of measurement range, accuracy, resolution, and cost. In this paper, various 
temperature measurement methods, suitable for Li-ion batteries, have been reviewed. A comparative overview of methods is given in Table 4 together with some of the main sensing properties. Since every sensor type, such as for example thermocouples, has many different versions, typical values are used to characterize their properties. Table 4 can therefore best be used as a guide to assist in the initial choice of a sensor selection, rather than for making a specific choice between versions of one method.

The traditional methods, such as thermistor, RTD, or thermocouple measurement methods, can be used for local surface or local internal temperature measurements. Although these traditional methods can be used for internal measurements as well, it is important that (i) the battery cycle life and performance should not be affected; (ii) the temperature measurement devices should be resistive to the chemical environment of the battery materials; and (iii) the temperature measurement devices should be compatible with the assembly process, especially in series-produced batteries. Based on the reviewed literature, it can be concluded that not all traditional methods meet these requirements. Recent improvements in the development and manufacturing process has noticeably decreased the size of sensors, which is highly promising for accurate (internal) temperature measurements. Nowadays, all traditional methods are mature, extensively used for Li-ion battery temperature sensing, and are favourable in terms of cost. Given the relatively narrow temperature range in which Li-ion batteries operate, thermistors would be a good choice among the traditional methods. Moreover, thermistors are relatively cheap and still reach acceptable measurement accuracies.

Fiber Bragg-grating temperature sensors also measure local temperatures but can be easily multiplexed in one single optical fiber, making temperature measurements possible at multiple locations. By multiplexing, a large number of cables and connections can be saved, especially with respect to traditional methods. In addition, fiber Bragg-grating sensors are immune to various kinds of interference, which is favourable for applying them in applications where interference is widely present. Another advantage is that the strong chemical resistivity makes them suitable for internal battery temperature measurements. However, the method of fiber Bragg-grating temperature sensing 
applied to Li-ion batteries is still in an early development stage, which also holds for the impedancebased temperature measurement methods.

The impedance-based methods, also referred to as sensorless methods, have the advantage of measuring the average internal battery temperature without using external or internal hardware temperature sensors and cables. In addition, as the temperature is measured through the impedance, thermal measurement delays are very short. Moreover, the impedance can be advantageously used for measuring other battery states, such as SoC and SoH. Various proof-of-concept impedance measurement PCBs have been developed, which eventually will lead to small chips that can be integrated into individual batteries. This enables $\mathrm{SoC}$, SoH and temperature monitoring on single battery level in battery-powered applications.

Imaging methods, such as IR thermal imaging and liquid-crystal thermography provide very useful and accurate measurements on surface temperatures that cannot be obtained with measurement techniques such as thermistors, thermocouples and impedance-based methods. IR thermal imaging and liquid crystal thermography are therefore ideal for research purposes, as thermal models can be easily verified. However, at present these techniques are not suitable for indicating temperature in commercial battery-powered applications, since IR thermal imaging and liquid crystal thermography are delicate, non-practical, and expensive.

In conclusion, it is emphasized that the selection of an appropriate temperature measurement method for Li-ion batteries largely depends on its application. For example, research applications often require surface temperature mapping or internal temperature measurements to validate models, while for most commercial applications only a local surface temperature measurement is already sufficient. This review facilitates in selecting the proper temperature measurement method for Li-ion batteries in the wide variety of applications. 


\section{Outlook}

Despite the remarkable advances that already have been made in the field of Li-ion battery temperature measurements, the current state of technology is still rather primitive for accurate temperature measurements in large-scale applications, particularly for applications in which numerous battery cells are used. One of the long-standing issues is the accurate and fast measurement of the internal temperature. Given the current status on deposition and fabrication techniques, small-size traditional temperature sensors, which have short response times, can be readily produced. However, attention still must be paid to a cost-effective, safe and practical implementation of these sensors into the battery core. Obviously, this holds for the implementation of any kind of temperature sensor into the battery core.

The advantage of the impedance-based temperature measurements methods is that these do not have to be inserted into a battery to measure the internal temperature. However, these methods are in a relatively early development stage and have been proven to be successful only under laboratory conditions. For this reason, there is still room for improvement on the performance outside the laboratory. Therefore, further development on long-term temperature measurements in batterypowered applications is necessary. Due to above-mentioned advantages it is, however, expected that these methods can compete with the traditional methods and will therefore emerge in the near future in large-scale battery-powered applications.

In addition, it is to be expected that future battery cells are multi-sensor batteries, which contain, for instance, reference electrodes, pressure-, deformation- and temperature sensors. The challenge herein is to reduce complexity and cabling. A solution would be to integrate all sensors into one component, e.g. a chip, and from there directly sent the relevant signals to a central control unit. 
Table 2. List of abbreviations.

\begin{tabular}{ll}
\hline Abbreviation & Description \\
\hline ARC & Accelerating rate calorimetry \\
BMS & Battery Management System \\
EIS & Electrochemical Impedance Spectroscopy \\
EMF & Electromotive force \\
EQC & Equivalent circuit \\
ERT & Electrical resistance tomography \\
ETIS & Electrothermal impedance spectroscopy \\
EV & Electric vehicle \\
FBG & Fiber Bragg-grating \\
HEV & Hybrid electric vehicle \\
IR & Infrared \\
Li-ion & Lithium ion \\
NMC & LiNiMnCo-Oxide \\
NTC & Negative temperature coefficient \\
NZIF & Non-zero-intercept frequency \\
OCP & Open circuit potential \\
OCV & Open circuit voltage \\
PCB & Printed circuit board \\
PTC & Positive temperature coefficient \\
RC-circuit & Electric circuit containing resistors and capacitors \\
RTD & Resistance temperature detector \\
SEI & Solid-electrolyte-interface \\
SNR & Signal-to-noise ratio \\
SoC & State-of-charge \\
SoH & State-of-health \\
TCR & Temperature coefficient of resistance \\
TLC & Thermochromic liquid crystals \\
TMS & Thermal management system \\
UV-light & Ultraviolet light \\
\hline
\end{tabular}


Table 3. List of symbols.

\begin{tabular}{|c|c|c|}
\hline Symbol & Description & Unit \\
\hline$A$ & Battery surface area & $\mathrm{m}^{2}$ \\
\hline$C_{p}$ & Specific heat capacity & $\mathrm{J} /(\mathrm{kg} \cdot \mathrm{K})$ \\
\hline$E$ & Voltage & V \\
\hline$E_{\text {bat }}$ & Battery voltage at terminals & V \\
\hline$E_{\text {bat }}^{e q}$ & Battery EMF & V \\
\hline$F$ & Faraday constant (96485) & $\mathrm{A} \cdot \mathrm{s} / \mathrm{mol}$ \\
\hline$\Delta G$ & Gibbs free energy change & $\mathrm{J} / \mathrm{mol}$ \\
\hline$h$ & Heat transfer coefficient & $\mathrm{W} /\left(\mathrm{m}^{2} \cdot \mathrm{K}\right)$ \\
\hline$\Delta H$ & Enthalpy change & $\mathrm{J} / \mathrm{mol}$ \\
\hline$I$ & Current & A \\
\hline$j$ & Imaginary unit satisfying $j^{2}=-1$ & - \\
\hline$k$ & Thermal conductivity & $\mathrm{W} /(\mathrm{m} \cdot \mathrm{K})$ \\
\hline$m$ & Mass & $\mathrm{kg}$ \\
\hline$n$ & Charge number of mobile ionic species & - \\
\hline$\vec{n}$ & Unit (outer) normal vector at boundary & - \\
\hline$n_{e f f}$ & Effective core index of refraction & - \\
\hline$p$ & Pressure & $\mathrm{Pa}$ \\
\hline$Q_{\eta}$ & Irreversible heat power calculated by overpotential $\eta$ & W \\
\hline$Q_{\text {conv }}$ & Convective heat power & W \\
\hline$\vec{q}_{\text {cond }}$ & Heat flux & $\mathrm{W} / \mathrm{m}^{2}$ \\
\hline$Q_{\text {in }}$ & Total heat generation power & W \\
\hline$q_{\text {in }}$ & Volumetric heat power & $\mathrm{W} / \mathrm{m}^{3}$ \\
\hline$Q_{\text {out }}$ & Total heat dissipation power & W \\
\hline$Q_{R}$ & Irreversible heat power calculated by resistance $R$ & W \\
\hline$Q_{\text {rad }}$ & Radiative heat power & W \\
\hline$Q_{S}$ & Reversible heat power & W \\
\hline$R$ & Resistance & $\Omega$ \\
\hline$\Delta S$ & Entropy change & $\mathrm{J} /(\mathrm{mol} \cdot \mathrm{K})$ \\
\hline$T$ & Battery temperature & K \\
\hline$T_{a}$ & Ambient temperature & K \\
\hline$\nabla T$ & Temperature gradient & $\mathrm{K} / \mathrm{m}$ \\
\hline$x$ & Stoichiometric coefficient of the positive electrode & - \\
\hline
\end{tabular}


$y \quad$ Stoichiometric coefficient of the negative electrode

$\begin{array}{lll}Z & \text { Impedance } & \Omega\end{array}$

$\varepsilon \quad$ Emissivity of surface material -

$\Lambda \quad$ Grating spacing m

$\begin{array}{lll}\lambda_{B} & \text { Bragg wavelength } & \mathrm{m}\end{array}$

$\eta_{\text {bat }} \quad$ Battery overpotential $\quad \mathrm{V}$

$\eta_{c t} \quad$ Charge-transfer overpotential V

$\eta_{d} \quad$ Diffusion overpotential $\quad \mathrm{V}$

$\eta_{e l} \quad$ Electrolyte overpotential $\quad \mathrm{V}$

$\eta_{\text {neg }} \quad$ Overpotential negative electrode V

$\eta_{\Omega} \quad$ Overpotential from Ohmic losses $\quad \mathrm{V}$

$\eta_{\text {pos }} \quad$ Overpotential positive electrode $\mathrm{V}$

$\rho \quad$ Density $\mathrm{kg} / \mathrm{m}^{3}$

$\sigma \quad$ Stefan-Boltzmann constant $\left(5.67 \cdot 10^{-8}\right) \quad W /\left(\mathrm{m}^{2} \cdot \mathrm{K}^{4}\right)$

$\xi \quad$ Reaction progress or $\mathrm{SoC}$ 
Table 4. Comparative table with temperature measurement methods for Li-ion batteries.

\begin{tabular}{|c|c|c|c|c|c|c|c|c|}
\hline Sensor type* & $\begin{array}{l}\text { Temperature } \\
\text { range }\end{array}$ & Accuracy & Sensitivity & $\begin{array}{l}\text { Response } \\
\text { time } * *\end{array}$ & Resolution & $\begin{array}{l}\text { Relative } \\
\text { Cost }\end{array}$ & $\begin{array}{l}\text { Multiple } \\
\text { parameter }\end{array}$ & Comments \\
\hline $\begin{array}{l}\text { Thermistors } \\
{[181,182]}\end{array}$ & $-55 \sim 300$ & $\pm 1^{\circ} \mathrm{C}$ & $\sim-4.3 \% /{ }^{\circ} \mathrm{C}$ & $\begin{array}{l}0.10 \text { to } 10 \\
\mathrm{~s}\end{array}$ & Local & Very low & No & $\begin{array}{l}\text { For temperatures higher than } 300^{\circ} \mathrm{C} \text {, other } \\
\text { materials must be used. Virtually unaffected by } \\
\text { cable resistance. Sensitivity is dependent on } \\
\text { temperature due to nonlinear nature of resistance } \\
\text { curve. }\end{array}$ \\
\hline $\begin{array}{l}\text { Resistance } \\
\text { Temperature } \\
\text { Detectors } \\
{[44,182]}\end{array}$ & $-260 \sim 960$ & $\begin{array}{l} \pm 0.01^{\circ} \mathrm{C} \\
\text { to } \pm 0.2^{\circ} \mathrm{C}\end{array}$ & $0.38 \% /{ }^{\circ} \mathrm{C}$. & 1 to $50 \mathrm{~s}$ & Local & Medium & No & $\begin{array}{l}\text { The linear resistance behaviour as a function of } \\
\text { temperature makes it convenient for use in an } \\
\text { application. Very stable over long time. }\end{array}$ \\
\hline $\begin{array}{l}\text { Thermo- } \\
\text { junctive } \\
\text { devices } \\
{[44,198,217]}\end{array}$ & -270 to 1820 & $\begin{array}{l} \pm 1^{\circ} \mathrm{C} \text { to } \\
\pm 2^{\circ} \mathrm{C}\end{array}$ & 1 to $70 \mu \mathrm{V} /{ }^{\circ} \mathrm{C}$ & $\begin{array}{l}0.10 \text { to } 10 \\
\mathrm{~s}\end{array}$ & Local & Low & No & $\begin{array}{l}\text { Needs reference-junction compensation; is } \\
\text { sensitive to corrosion; cables cannot simply be } \\
\text { extended; EMF is a nonlinear function of } \\
\text { temperature. Robust and high temperature range. }\end{array}$ \\
\hline $\begin{array}{l}\text { Fiber Bragg- } \\
\text { grating } \\
{[236,237,239} \\
\text {,242] }\end{array}$ & -190 to 385 & $\begin{array}{l} \pm 0.2^{\circ} \mathrm{C} \text { to } \\
\pm 0.4^{\circ} \mathrm{C}\end{array}$ & $\sim 10 \mathrm{pm} /{ }^{\circ} \mathrm{C}$ & $0.25 \mathrm{~s}$ & Local & High & $\begin{array}{l}\text { Temperature, } \\
\text { strain, } \\
\text { pressure, } \\
\text { magnetic field }\end{array}$ & $\begin{array}{l}\text { Temperature range depends on fiber coating; } \\
\text { passive nature; immune to interference; long- } \\
\text { term reliability; multiplexing; linear wavelength } \\
\text { shift; strong chemical resistivity. }\end{array}$ \\
\hline $\begin{array}{l}\text { Impedance- } \\
\text { based } \\
{[273,274,289} \\
]\end{array}$ & -20 to 70 & $\begin{array}{l} \pm 0.17^{\circ} \mathrm{C} \\
\text { to } \pm 2.5^{\circ} \mathrm{C}\end{array}$ & $\begin{array}{l}\text { Dependent } \\
\text { on battery } \\
\text { type and } \\
\text { measurement } \\
\text { settings }\end{array}$ & Very fast & Integral & $\begin{array}{l}\text { Implement } \\
\text { ation } \\
\text { dependent }\end{array}$ & $\begin{array}{l}\text { Temperature, } \\
\text { SoC, SoH }\end{array}$ & $\begin{array}{l}\text { Measures the internal average battery } \\
\text { temperature without insertion of a hardware } \\
\text { temperature sensor. Additional states (SoC and } \\
\text { SoH) can be measured as well. High DC currents, } \\
\text { interference, SoC and aging dependencies make } \\
\text { this measurement challenging. At present IC's for }\end{array}$ \\
\hline
\end{tabular}




$\begin{aligned} & \text { Johnson } \\ & \text { noise } \\ & {[300,303,304}\end{aligned}$
311]

*A sensor type can have many versions. Parameters such as temperature range, accuracy, sensitivity, and response time can vary among the different versions.

Therefore, typical values are used and for this reason this table can be considered as a guide to assist in the initial choice of a temperature measurement method for Li-ion batteries.

${ }^{* *}$ The response time is strongly dependent on the size/mass of the device, the insulating material, and the heat transfer capability. Therefore, an approximate/typical value or verbal description is used. 


\section{Acknowledgements}

This work was supported by ADEM, A green Deal in Energy Materials, of the Ministry of Economic Affairs of The Netherlands. The authors appreciate financial support from the Horizon 2020 program of the European Union under the grant of the AutoDrive (Grant No. 737469) and DEMOBASE project (Grant No. 769900). 


\section{References}

[1] U.S. Energy Information Administration (EIA), International Energy Outlook 2017 Overview, 2017. https://www.eia.gov/outlooks/ieo/.

[2] M. Höök, X. Tang, Depletion of fossil fuels and anthropogenic climate change - A review, Energy Policy. 52 (2013) 797-809. doi:10.1016/j.enpol.2012.10.046.

[3] N. Abas, A. Kalair, N. Khan, Review of fossil fuels and future energy technologies, Futures. 69 (2015) 31-49. doi:10.1016/j.futures.2015.03.003.

[4] M. Lenzen, Life cycle energy and greenhouse gas emissions of nuclear energy: A review, Energy Convers. Manag. 49 (2008) 2178-2199. doi:10.1016/j.enconman.2008.01.033.

[5] B.K. Sovacool, Valuing the greenhouse gas emissions from nuclear power: A critical survey, Energy Policy. 36 (2008) 2940-2953. doi:10.1016/j.enpol.2008.04.017.

[6] N.L. Panwar, S.C. Kaushik, S. Kothari, Role of renewable energy sources in environmental protection: A review, Renew. Sustain. Energy Rev. 15 (2011) 1513-1524. doi:10.1016/j.rser.2010.11.037.

[7] A. Adamantiades, I. Kessides, Nuclear power for sustainable development: Current status and future prospects, Energy Policy. 37 (2009) 5149-5166. doi:10.1016/j.enpol.2009.07.052.

[8] O. Ellabban, H. Abu-Rub, F. Blaabjerg, Renewable energy resources: Current status, future prospects and their enabling technology, Renew. Sustain. Energy Rev. 39 (2014) 748-764. doi:10.1016/j.rser.2014.07.113.

[9] X. Luo, J. Wang, M. Dooner, J. Clarke, Overview of current development in electrical energy storage technologies and the application potential in power system operation, Appl. Energy. 137 (2015) 511-536. doi:10.1016/j.apenergy.2014.09.081. 
[10] M. Aneke, M. Wang, Energy storage technologies and real life applications - A state of the art review, Appl. Energy. 179 (2016) 350-377. doi:10.1016/j.apenergy.2016.06.097.

[11] T.M.I. Mahlia, T.J. Saktisahdan, A. Jannifar, M.H. Hasan, H.S.C. Matseelar, A review of available methods and development on energy storage; Technology update, Renew. Sustain. Energy Rev. 33 (2014) 532-545. doi:10.1016/j.rser.2014.01.068.

[12] P. Poizot, F. Dolhem, Clean energy new deal for a sustainable world: from non-CO2 generating energy sources to greener electrochemical storage devices, Energy Environ. Sci. 4 (2011) 2003. doi:10.1039/c0ee00731e.

[13] P. Alotto, M. Guarnieri, F. Moro, Redox flow batteries for the storage of renewable energy: A review, Renew. Sustain. Energy Rev. 29 (2014) 325-335. doi:10.1016/j.rser.2013.08.001.

[14] A. Jaiswal, Lithium-ion battery based renewable energy solution for off-grid electricity: A techno-economic analysis, Renew. Sustain. Energy Rev. 72 (2017) 922-934. doi:10.1016/j.rser.2017.01.049.

[15] Z. Rezvani, J. Jansson, J. Bodin, Advances in consumer electric vehicle adoption research: A review and research agenda, Transp. Res. Part D. 34 (2015) 122-136. doi:10.1016/j.trd.2014.10.010.

[16] S. Steinhilber, P. Wells, S. Thankappan, Socio-technical inertia: Understanding the barriers to electric vehicles, Energy Policy. 60 (2013) 531-539. doi:10.1016/j.enpol.2013.04.076.

[17] O. Egbue, S. Long, Barriers to widespread adoption of electric vehicles: An analysis of consumer attitudes and perceptions, Energy Policy. 48 (2012) 717-729. doi:10.1016/j.enpol.2012.06.009.

[18] B. Diouf, R. Pode, Potential of lithium-ion batteries in renewable energy, Renew. Energy. 76 (2015) 375-380. doi:10.1016/j.renene.2014.11.058. 
[19] A. Opitz, P. Badami, L. Shen, K. Vignarooban, A. Kannan, Can Li-Ion batteries be the panacea for automotive applications?, Renew. Sustain. Energy Rev. 68 (2017) 685-692. doi:10.1016/j.rser.2016.10.019.

[20] L. Lu, X. Han, J. Li, J. Hua, M. Ouyang, A review on the key issues for lithium-ion battery management in electric vehicles, J. Power Sources. 226 (2013) 272-288. doi:10.1016/j.jpowsour.2012.10.060.

[21] W. Waag, C. Fleischer, D.U. Sauer, Critical review of the methods for monitoring of lithium-ion batteries in electric and hybrid vehicles, J. Power Sources. 258 (2014) 321-339. doi:10.1016/j.jpowsour.2014.02.064.

[22] M.U. Cuma, T. Koroglu, A comprehensive review on estimation strategies used in hybrid and battery electric vehicles, Renew. Sustain. Energy Rev. 42 (2015) 517-531. doi:10.1016/j.rser.2014.10.047.

[23] V. Pop, H.J. Bergveld, P.H.L. Notten, P.P.L. Regtien, State-of-the-art of battery state-of-charge, Meas. Sci. Technol. 16 (2005) R93-R110. doi:10.1088/0957-0233/16/12/R01.

[24] Y. Xing, E.W.M. Ma, K.L. Tsui, M. Pecht, Battery Management Systems in Electric and Hybrid Vehicles, Energies. 4 (2011) 1840-1857. doi:10.3390/en4111840.

[25] H. Rahimi-eichi, U. Ojha, F. Baronti, M.-Y. Chow, Battery Management System, IEEE Ind. Electron. Mag. 7 (2013) 4-16. doi:10.1109/MIE.2013.2250351.

[26] M.A. Hannan, M.S.H. Lipu, A. Hussain, A. Mohamed, A review of lithium-ion battery state of charge estimation and management system in electric vehicle applications: Challenges and recommendations, Renew. Sustain. Energy Rev. 78 (2017) 834-854. doi:10.1016/j.rser.2017.05.001.

[27] F.V. Conte, Battery and battery management for hybrid electric vehicles: a review, 
Elektrotechnik Und Informationstechnik. 123 (2006) 424-431. doi:10.1007/s00502-006-0383-

6.

[28] K. Liu, K. Li, Q. Peng, C. Zhang, A brief review on key technologies in the battery management system of electric vehicles, Front. Mech. Eng. (2018) 1-18. doi:10.1007/s11465-018-0516-8.

[29] M. Lelie, T. Braun, M. Knips, H. Nordmann, F. Ringbeck, H. Zappen, D.U. Sauer, Battery Management System Hardware Concepts: An Overview, Appl. Sci. 8 (2018) 1-27. doi:10.3390/app8040534.

[30] M.R. Khan, M.J. Swierczynski, S.K. Kær, Towards an Ultimate Battery Thermal Management System: A Review, Batteries. 3 (2017) 1-18. doi:10.3390/batteries3010009.

[31] Z. Rao, S. Wang, A review of power battery thermal energy management, Renew. Sustain. Energy Rev. 15 (2011) 4554-4571. doi:10.1016/j.rser.2011.07.096.

[32] T.M. Bandhauer, S. Garimella, T.F. Fuller, A Critical Review of Thermal Issues in Lithium-Ion Batteries, J. Electrochem. Soc. 158 (2011) R1-R25. doi:10.1149/1.3515880.

[33] H. Liu, Z. Wei, W. He, J. Zhao, Thermal issues about Li-ion batteries and recent progress in battery thermal management systems: A review, Energy Convers. Manag. 150 (2017) 304330. doi:10.1016/j.enconman.2017.08.016.

[34] J. Jaguemont, L. Boulon, Y. Dubé, A comprehensive review of lithium-ion batteries used in hybrid and electric vehicles at cold temperatures, Appl. Energy. 164 (2016) 99-114. doi:10.1016/j.apenergy.2015.11.034.

[35] A. Sharma, V. V Tyagi, C.R. Chen, D. Buddhi, Review on thermal energy storage with phase change materials and applications, Renew. Sustain. Energy Rev. 13 (2009) 318-345. doi:10.1016/j.rser.2007.10.005.

[36] R. Zhao, S. Zhang, J. Liu, J. Gu, A review of thermal performance improving methods of lithium 
ion battery: Electrode modification and thermal management system, J. Power Sources. 299 (2015) 557-577. doi:10.1016/j.jpowsour.2015.09.001.

[37] S.S. Madani, M. Swierczynski, S.K. Kaer, A Review of Thermal Management and Safety for Lithium Ion Batteries, in: Twelfth Int. Conf. Ecol. Veh. Renew. Energies, IEEE, Monte Carlo, Monaco, 2017. doi:10.1109/EVER.2017.7935914.

[38] G. Xia, L. Cao, G. Bi, A review on battery thermal management in electric vehicle application, J. Power Sources. 367 (2017) 90-105. doi:10.1016/j.jpowsour.2017.09.046.

[39] A.N. Zhoujian, J.I.A. Li, D. Yong, D. Chao, L.I. Xuejiao, A Review on Lithium-ion Power Battery Thermal Management Technologies and Thermal Safety, J. Therm. Sci. 26 (2017) 391-412. doi:10.1007/s11630-017-0955-2.

[40] T.D. McGee, Principles and methods of temperature measurement, John Wiley \& Sons, 1988.

[41] R.E. Bentley, Handbook of Temperature Measurement Vol. 3: The Theory and Practice of Thermoelectric Thermometry, Springer, 1998.

[42] J. Michalski, Ludwig Eckersdorf, Krystyna Kucharski, J. McGhee, Temperature measurement, 2nd ed., John Wiley \& Sons, 2001.

[43] J. Fischer, B. Fellmuth, Temperature metrology, Reports Prog. Phys. 68 (2005) 1043-1094. doi:10.1088/0034-4885/68/5/R02.

[44] P.R.N. Childs, J.R. Greenwood, C.A. Long, Review of temperature measurement, Rev. Sci. Instrum. 71 (2000) 2959-2978. doi:10.1063/1.1305516.

[45] S. Myung, Y. Hitoshi, Y. Sun, Electrochemical behavior and passivation of current collectors in lithium-ion batteries, J. Mater. Chem. 21 (2011) 9891-9911. doi:10.1039/c0jm04353b.

[46] R. Hausbrand, G. Cherkashinin, H. Ehrenberg, M. Gröting, K. Albe, C. Hess, W. Jaegermann, 
Fundamental degradation mechanisms of layered oxide Li-ion battery cathode materials: Methodology, insights and novel approaches, Mater. Sci. Eng. B. 192 (2015) 3-25. doi:10.1016/j.mseb.2014.11.014.

[47] A. Manthiram, B. Song, W. Li, A perspective on nickel-rich layered oxide cathodes for lithiumion batteries, Energy Storage Mater. 6 (2017) 125-139. doi:10.1016/j.ensm.2016.10.007.

[48] Y. Ding, D. Mu, B. Wu, R. Wang, Z. Zhao, F. Wu, Recent progresses on nickel-rich layered oxide positive electrode materials used in lithium-ion batteries for electric vehicles, Appl. Energy. 195 (2017) 586-599. doi:10.1016/j.apenergy.2017.03.074.

[49] M.N. Obrovac, V.L. Chevrier, Alloy Negative Electrodes for Li-lon Batteries, Chem. Rev. 114 (2014) 11444-11502. doi:10.1021/cr500207g.

[50] K. Kinoshita, K. Zaghib, Negative electrodes for Li-ion batteries, J. Power Sources. 110 (2002) 416-423. doi:10.1016/\$0378-7753(02)00206-9.

[51] P. Verma, P. Maire, P. Novák, A review of the features and analyses of the solid electrolyte interphase in Li-ion batteries, Electrochim. Acta. 55 (2010) 6332-6341. doi:10.1016/j.electacta.2010.05.072.

[52] R. Huggins, Advanced batteries, 1st ed., Springer US, 2009. doi:10.1007/978-0-387-76424-5.

[53] H. Gerischer, F. Decker, B. Scrosati, The Electronic and the Ionic Contribution to the Free Energy of Alkali Metals in Intercalation Compounds, J. Electrochem. Soc. 141 (1994) 22972300. doi:10.1149/1.2055115.

[54] C. Liu, Z.G. Neale, G. Cao, Understanding electrochemical potentials of cathode materials in rechargeable batteries, Mater. Today. 19 (2016) 109-123. doi:10.1016/j.mattod.2015.10.009.

[55] K.M. Abraham, Prospects and Limits of Energy Storage in Batteries, J. Phys. Chem. Lett. 6 (2015) 830-844. doi:10.1021/jz5026273. 
[56] K. Kam, M. Doeff, Electrode Materials for Lithium Ion Batteries, Mater. Matters. 7 (2012) 5662. http://www.sigmaaldrich.com/content/dam/sigmaaldrich/docs/Aldrich/Brochure/1/material-matters-v7n4.pdf.

[57] N. Nitta, F. Wu, J.T. Lee, G. Yushin, Li-ion battery materials: present and future, Mater. Today. 18 (2015) 252-264. doi:10.1016/j.mattod.2014.10.040.

[58] B. Scrosati, J. Garche, Lithium batteries: Status, prospects and future, J. Power Sources. 195 (2010) 2419-2430. doi:10.1016/j.jpowsour.2009.11.048.

[59] J.B. Goodenough, K.-S. Park, The Li-lon Rechargeable Battery: A Perspective, J. Am. Chem. Soc. 135 (2013) 1167-1176. doi:10.1021/ja3091438.

[60] J. Kasnatscheew, U. Rodehorst, B. Streipert, S. Wiemers-meyer, R. Jakelski, R. Wagner, C. Laskovic, M. Winter, Learning from Overpotentials in Lithium Ion Batteries: A Case Study on the $\mathrm{LiNi}_{1 / 3} \mathrm{Co}_{1 / 3} \mathrm{Mn}_{1 / 3} \mathrm{O}_{2}$ (NCM) Cathode, J. Electrochem. Soc. 163 (2016) 2943-2950. doi:10.1149/2.0461614jes.

[61] H. Bergveld, W. Kruijt, P. Notten, Battery management systems: design by modelling, Kluwer Academic Publishers, Dordrecht, 2002.

[62] V. Pop, H. Bergveld, J. Op het Veld, P. Regtien, D. Danilov, P. Notten, Modeling Battery Behavior for Accurate State-of-Charge Indication, J. Electrochem. Soc. 153 (2006) A2013A2022. doi:10.1149/1.2335951.

[63] D.L. Danilov, R.A.H. Niessen, P.H.L. Notten, Modeling All-Solid-State Li-Ion Batteries, J. Electrochem. Soc. 158 (2011) A215-A222. doi:10.1149/1.3521414.

[64] C. Heubner, M. Schneider, C. Lämmel, A. Michaelis, Local Heat Generation in a Single Stack Lithium Ion Battery Cell, Electrochim. Acta. 186 (2015) 404-412. doi:10.1016/j.electacta.2015.10.182. 
[65] D. Danilov, P.H.L. Notten, Mathematical modelling of ionic transport in the electrolyte of Liion batteries, Electrochim. Acta. 53 (2008) 5569-5578. doi:10.1016/j.electacta.2008.02.086.

[66] D. Grazioli, M. Magri, A. Salvadori, Computational modeling of Li-ion batteries, Comput. Mech. 58 (2016) 889-909. doi:10.1007/s00466-016-1325-8.

[67] D. Andre, M. Meiler, K. Steiner, C. Wimmer, T. Soczka-Guth, D.U. Sauer, Characterization of high-power lithium-ion batteries by electrochemical impedance spectroscopy. I. Experimental investigation, J. Power Sources. 196 (2011) 5334-5341. doi:10.1016/j.jpowsour.2010.12.102.

[68] E. Schuster, C. Ziebert, A. Melcher, M. Rohde, H.J. Seifert, Thermal behavior and electrochemical heat generation in a commercial 40 Ah lithium ion pouch cell, J. Power Sources. 286 (2015) 580-589. doi:10.1016/j.jpowsour.2015.03.170.

[69] A. De Vita, A. Maheshwari, M. Destro, M. Santarelli, Transient thermal analysis of a lithium-ion battery pack comparing different cooling solutions for automotive applications, Appl. Energy. 206 (2017) 101-112. doi:10.1016/j.apenergy.2017.08.184.

[70] R.E. Williford, V. V Viswanathan, J. Zhang, Effects of entropy changes in anodes and cathodes on the thermal behavior of lithium ion batteries, J. Power Sources. 189 (2009) 101-107. doi:10.1016/j.jpowsour.2008.10.078.

[71] X. Yang, G. Zhang, C. Wang, Computational design and refinement of self-heating lithium ion batteries, J. Power Sources. 328 (2016) 203-211. doi:10.1016/j.jpowsour.2016.08.028.

[72] M. Ecker, J.B. Gerschler, J. Vogel, S. Käbitz, F. Hust, P. Dechent, D.U. Sauer, Development of a lifetime prediction model for lithium-ion batteries based on extended accelerated aging test data, J. Power Sources. 215 (2012) 248-257. doi:10.1016/j.jpowsour.2012.05.012.

[73] A. Eddahech, O. Briat, J. Vinassa, Performance comparison of four lithium-ion battery technologies under calendar aging, Energy. 84 (2015) 542-550. 
doi:10.1016/j.energy.2015.03.019.

[74] J. Schmitt, A. Maheshwari, M. Heck, S. Lux, M. Vetter, Impedance change and capacity fade of lithium nickel manganese cobalt oxide-based batteries during calendar aging, J. Power Sources. 353 (2017) 183-194. doi:10.1016/j.jpowsour.2017.03.090.

[75] L. Rao, J. Newman, Heat-Generation Rate and General Energy Balance for Insertion Battery Systems, J. Electrochem. Soc. 144 (1997) 2697-2704. doi:10.1149/1.1837884.

[76] M. Guo, G. Sikha, R.E. White, Single-Particle Model for a Lithium-Ion Cell: Thermal Behavior, J. Electrochem. Soc. 158 (2011) 122-132. doi:10.1149/1.3521314.

[77] D. Bernardi, E. Pawlikowski, J. Newman, A General Energy Balance for Battery Systems, J. Electrochem. Soc. 132 (1970) 5-12. doi:10.1149/1.2113792.

[78] H.F. Gibbard, Thermal Properties of Battery Systems, J. Electrochem. Soc. 125 (1978) 353-358. doi:10.1149/1.2131448.

[79] M. Shadman Rad, D.L. Danilov, M. Baghalha, M. Kazemeini, P.H.L. Notten, Adaptive thermal modeling of Li-ion batteries, Electrochim. Acta. 102 (2013) 183-195. doi:10.1016/j.electacta.2013.03.167.

[80] X. Zhang, Y. Zhao, Y. Patel, T. Zhang, W. Liu, M. Chen, J. Offer, Y. Yan, Potentiometric measurement of entropy change for lithium batteries, Phys. Chem. Chem. Phys. 19 (2017) 9833-9842. doi:10.1039/С6CP08505A.

[81] J.P. Schmidt, A. Weber, E. Ivers-tiffée, A novel and precise measuring method for the entropy of lithium-ion cells: $\Delta$ S via electrothermal impedance spectroscopy, Electrochim. Acta. 137 (2014) 311-319. doi:10.1016/j.electacta.2014.05.153.

[82] P.J. Osswald, M. del Rosario, J. Garche, A. Jossen, H.E. Hoster, Fast and Accurate Measurement of Entropy Profiles of Commercial Lithium-Ion Cells, Electrochim. Acta. 177 
(2015) 270-276. doi:10.1016/j.electacta.2015.01.191.

[83] Z.H.C. Daud, D. Chrenko, F. Dos Santos, E. Aglzim, A. Keromnes, L. Le Moyne, 3D electrothermal modelling and experimental validation of lithium polymer-based batteries for automotive applications, Int. J. Energy Res. 40 (2016) 1144-1154. doi:10.1002/er.3524.

[84] M. Guo, R.E. White, A distributed thermal model for a Li-ion electrode plate pair, J. Power Sources. 221 (2013) 334-344. doi:10.1016/j.jpowsour.2012.08.012.

[85] M. Debert, G. Colin, G. Bloch, Y. Chamaillard, An observer looks at the cell temperature in automotive battery packs, Control Eng. Pract. 21 (2013) 1035-1042. doi:10.1016/j.conengprac.2013.03.001.

[86] Z. Liu, H. Li, A Spatiotemporal Estimation Method for Temperature Distribution in Lithium-lon Batteries, IEEE Trans. Ind. INFORMATICS. 10 (2014) 2300-2307. doi:10.1109/TII.2014.2341955.

[87] L. Song, J.W. Evans, Electrochemical-Thermal Model of Lithium Polymer Batteries, J. Electrochem. Soc. 147 (2000) 2086-2095. doi:10.1149/1.1393490.

[88] F. Richter, S. Kjelstrup, P.J.S. Vie, O.S. Burheim, Thermal conductivity and internal temperature profiles of Li-ion secondary batteries, J. Power Sources. 359 (2017) 592-600. doi:10.1016/j.jpowsour.2017.05.045.

[89] K.E. Thomas, J. Newman, Thermal Modeling of Porous Insertion Electrodes, J. Electrochem. Soc. 150 (2003) 176-192. doi:10.1149/1.1531194.

[90] V. V Viswanathan, D. Choi, D. Wang, W. Xu, S. Towne, R.E. Williford, J. Zhang, J. Liu, Z. Yang, Effect of entropy change of lithium intercalation in cathodes and anodes on Li-ion battery thermal management, J. Power Sources. 195 (2010) 3720-3729. doi:10.1016/j.jpowsour.2009.11.103. 
[91] W.B. Gu, C.Y. Wang, Thermal-Electrochemical Modeling of Battery Systems, J. Electrochem. Soc. 147 (2000) 2910-2922. doi:10.1149/1.1393625.

[92] C. Forgez, D. Vinh Do, G. Friedrich, M. Morcrette, C. Delacourt, Thermal modeling of a cylindrical LiFePO$/$ /graphite lithium-ion battery, J. Power Sources. 195 (2010) 2961-2968. doi:10.1016/j.jpowsour.2009.10.105.

[93] J.H. Lienhard, A Heat Transfer Textbook, 4th ed., Phlogiston Press, Cambridge, 2017. https://books.google.nl/books?id=P8iV6ljNtl8C.

[94] F.P. Incropera, Fundamentals of heat and mass transfer, 6th ed., John Wiley and Sons, Michigan, 2007. https://books.google.nl/books/about/Fundamentals_of_heat_and_mass_transfer.html?id=_P 9QAAAAMAAJ\&redir_esc=y.

[95] A. Bejan, A.D. Kraus, Heat Transfer Handbook, John Wiley and Sons, New Jersey, 2003. https://books.google.nl/books?id=d4cgNG_IUq8C\&dq=Heat+Transfer+Handbook,+JohnWiley +\%26+Sons\&|r=\&hl=nl\&source=gbs_navlinks_s.

[96] O.S. Burheim, M.A. Onsrud, J.G. Pharoah, F. Vullum-bruer, P.J.S. Vie, Thermal Conductivity, Heat Sources and Temperature Profiles of Li-ion Batteries, J. Electrochem. Soc. 58 (2014) 145171. doi:10.1149/05848.0145ecst.

[97] T. Wang, K.J. Tseng, J. Zhao, Z. Wei, Thermal investigation of lithium-ion battery module with different cell arrangement structures and forced air-cooling strategies, Appl. Energy. 134 (2014) 229-238. doi:10.1016/j.apenergy.2014.08.013.

[98] H. Park, A design of air flow configuration for cooling lithium ion battery in hybrid electric vehicles, J. Power Sources. 239 (2013) 30-36. doi:10.1016/j.jpowsour.2013.03.102.

[99] L. Fan, J.M. Khodadadi, A.A. Pesaran, A parametric study on thermal management of an air- 
cooled lithium-ion battery module for plug-in hybrid electric vehicles, J. Power Sources. 238 (2013) 301-312. doi:10.1016/j.jpowsour.2013.03.050.

[100] W. Tong, K. Somasundaram, E. Birgersson, A.S. Mujumdar, C. Yap, Numerical investigation of water cooling for a lithium-ion bipolar battery pack, Int. J. Therm. Sci. 94 (2015) 259-269. doi:10.1016/j.ijthermalsci.2015.03.005.

[101] L.H. Saw, A.A.O. Tay, L.W. Zhang, Thermal Management of Lithium-ion Battery Pack with Liquid Cooling, in: Therm. Meas. Model. Manag. Symp. (SEMI-THERM), 2015 31st, IEEE, San Jose, CA, USA, 2015: pp. 298-302. doi:10.1109/SEMI-THERM.2015.7100176.

[102] G. Kim, J. Gonder, J. Lustbader, A. Pesaran, Thermal Management of Batteries in Advanced Vehicles Using Phase-Change Materials, World Electr. Veh. J. 2 (2008) 0134-0147. https://www.researchgate.net/profile/Ahmad_Pesaran/publication/237695508_Thermal_Ma nagement_of_Batteries_in_Advanced_Vehicles_Using_PhaseChange_Materials/links/54b450 650cf2318f0f96d586.pdf.

[103] Y. Azizi, S.M. Sadrameli, Thermal management of a $\mathrm{LiFePO}_{4}$ battery pack at high temperature environment using a composite of phase change materials and aluminum wire mesh plates, Energy Convers. Manag. 128 (2016) 294-302. doi:10.1016/j.enconman.2016.09.081.

[104] S. Wilke, B. Schweitzer, S. Khateeb, S. Al-hallaj, Preventing thermal runaway propagation in lithium ion battery packs using a phase change composite material: An experimental study, J. Power Sources. 340 (2017) 51-59. doi:10.1016/j.jpowsour.2016.11.018.

[105] Z. Rao, S. Wang, G. Zhang, Simulation and experiment of thermal energy management with phase change material for ageing $\mathrm{LiFePO}_{4}$ power battery, Energy Convers. Manag. 52 (2011) 3408-3414. doi:10.1016/j.enconman.2011.07.009.

[106] A. Greco, D. Cao, X. Jiang, H. Yang, A theoretical and computational study of lithium-ion 
battery thermal management for electric vehicles using heat pipes, J. Power Sources. 257 (2014) 344-355. doi:10.1016/j.jpowsour.2014.02.004.

[107] T. Tran, S. Harmand, B. Desmet, S. Filangi, Experimental investigation on the feasibility of heat pipe cooling for HEV/EV lithium-ion battery, Appl. Therm. Eng. 63 (2014) 551-558. doi:10.1016/j.applthermaleng.2013.11.048.

[108] R. Zhao, J. Gu, J. Liu, An experimental study of heat pipe thermal management system with wet cooling method for lithium ion batteries, J. Power Sources. 273 (2015) 1089-1097. doi:10.1016/j.jpowsour.2014.10.007.

[109] S.K. Mohammadian, Y. Zhang, Thermal management optimization of an air-cooled Li-ion battery module using pin-fin heat sinks for hybrid electric vehicles, J. Power Sources. 273 (2015) 431-439. doi:10.1016/j.jpowsour.2014.09.110.

[110] J. Smith, M. Hinterberger, C. Schneider, J. Koehler, Energy savings and increased electric vehicle range through improved battery thermal management, Appl. Therm. Eng. 101 (2016) 647-656. doi:10.1016/j.applthermaleng.2015.12.034.

[111] L.H. Saw, Y. Ye, M.C. Yew, W.T. Chong, M.K. Yew, T.C. Ng, Computational fluid dynamics simulation on open cell aluminium foams for Li-ion battery cooling system, Appl. Energy. (2017). doi:10.1016/j.apenergy.2017.04.022.

[112] R.W. Van Gils, D. Danilov, P.H.L. Notten, M.F.M. Speetjens, H. Nijmeijer, Battery thermal management by boiling heat-transfer, Energy Convers. Manag. 79 (2014) 9-17. doi:10.1016/j.enconman.2013.12.006.

[113] S.K. Mohammadian, Y. He, Y. Zhang, Internal cooling of a lithium-ion battery using electrolyte as coolant through microchannels embedded inside the electrodes, J. Power Sources. 293 (2015) 458-466. doi:10.1016/j.jpowsour.2015.05.055. 
[114] T.M. Bandhauer, S. Garimella, Passive, internal thermal management system for batteries using microscale liquid-vapor phase change, Appl. Therm. Eng. 61 (2013) 756-769. doi:10.1016/j.applthermaleng.2013.08.004.

[115] D. Anthony, D. Wong, D. Wetz, A. Jain, Improved Thermal Performance of a Li-lon Cell through Heat Pipe Insertion, J. Electrochem. Soc. 164 (2017) A961-A967. doi:10.1149/2.0191706jes.

[116] K. Shah, C. Mckee, D. Chalise, A. Jain, Experimental and numerical investigation of core cooling of Li-ion cells using heat pipes, Energy. 113 (2016) 852-860. doi:10.1016/j.energy.2016.07.076.

[117] H. Dai, L. Zhu, J. Zhu, X. Wei, Z. Sun, Adaptive Kalman filtering based internal temperature estimation with an equivalent electrical network thermal model for hard-cased batteries, J. Power Sources. 293 (2015) 351-365. doi:10.1016/j.jpowsour.2015.05.087.

[118] F. Bahiraei, M. Ghalkhani, A. Fartaj, G.-A. Nazri, A pseudo 3D electrochemical-thermal modeling and analysis of a lithium-ion battery for electric vehicle thermal management applications, Appl. Therm. Eng. 125 (2017) 904-918. doi:10.1016/j.applthermaleng.2017.07.060.

[119] Q. Wang, Y. He, J. Shen, Z. Ma, G. Zhong, A unified modeling framework for lithium-ion batteries: An artificial neural network based thermal coupled equivalent circuit model approach, Energy. 138 (2017) 118-132. doi:10.1016/j.energy.2017.07.035.

[120] L. Cai, R.E. White, An Efficient Electrochemical-Thermal Model for a Lithium-lon Cell by Using the Proper Orthogonal Decomposition Method, J. Electrochem. Soc. 157 (2010) 1188-1195. doi:10.1149/1.3486082.

[121] W. Fang, O.J. Kwon, C. Wang, Electrochemical-thermal modeling of automotive Li-ion batteries and experimental validation using a three-electrode cell, Int. J. Energy Res. 34 (2010) 
107-115. doi:10.1002/er.

[122] S. Panchal, I. Dincer, M. Agelin-chaab, R. Fraser, M. Fowler, Experimental and theoretical investigations of heat generation rates for a water cooled $\mathrm{LiFePO}_{4}$ battery, Int. J. Heat Mass Transf. 101 (2016) 1093-1102. doi:10.1016/j.ijheatmasstransfer.2016.05.126.

[123] B. Schweitzer, S. Wilke, S. Khateeb, S. Al-hallaj, Experimental validation of a 0-D numerical model for phase change thermal management systems in lithium-ion batteries, J. Power Sources. 287 (2015) 211-219. doi:10.1016/j.jpowsour.2015.04.016.

[124] D.W. Hahn, M.N. Özisik, Heat Conduction, 3rd ed., John Wiley and Sons, New Jersey, 2012. http://eu.wiley.com/WileyCDA/WileyTitle/productCd-0470902930.html.

[125] U.S. Kim, J. Yi, C.B. Shin, T. Han, S. Park, Modeling the Thermal Behaviors of a Lithium-Ion Battery during Constant-Power Discharge and Charge Operations, J. Electrochem. Soc. 160 (2013) A990-A995. doi:10.1149/2.146306jes.

[126] B. Rieger, S. V. Erhard, S. Kosch, M. Venator, A. Rheinfeld, A. Jossen, Multi-Dimensional Modeling of the Influence of Cell Design on Temperature, Displacement and Stress Inhomogeneity in Large-Format Lithium-Ion Cells, J. Electrochem. Soc. 163 (2016) A3099A3110. doi:10.1149/2.1051614jes.

[127] J. Yi, U. Seong, C. Burm, T. Han, S. Park, Modeling the temperature dependence of the discharge behavior of a lithium-ion battery in low environmental temperature, J. Power Sources. 244 (2013) 143-148. doi:10.1016/j.jpowsour.2013.02.085.

[128] K. Lee, K. Smith, A. Pesaran, G. Kim, Three dimensional thermal-, electrical-, and electrochemical-coupled model for cylindrical wound large format lithium-ion batteries, J. Power Sources. 241 (2013) 20-32. doi:10.1016/j.jpowsour.2013.03.007.

[129] X. Lin, H.E. Perez, J.B. Siegel, A.G. Stefanopoulou, Y. Li, R.D. Anderson, Y. Ding, M.P. Castanier, 
Online parameterization of lumped thermal dynamics in cylindrical lithium ion batteries for core temperature estimation and health monitoring, IEEE Trans. Control Syst. Technol. 21 (2013) 1745-1755. doi:10.1109/TCST.2012.2217143.

[130] V. Lystianingrum, B. Hredzak, V.G. Agelidis, Multiple model estimator based detection of abnormal cell overheating in a Li-ion battery string with minimum number of temperature sensors, J. Power Sources. 273 (2015) 1171-1181. doi:10.1016/j.jpowsour.2014.09.166.

[131] I. Arasaratnam, J. Tjong, R. Ahmed, M. El-Sayed, S. Habibi, Adaptive temperature monitoring for battery thermal management, in: IEEE Transp. Electrif. Conf. Expo, IEEE, Detroit, MI, USA, 2013. doi:10.1109/ITEC.2013.6574504.

[132] K.S. Hariharan, A coupled nonlinear equivalent circuit - Thermal model for lithium ion cells, J. Power Sources. 227 (2013) 171-176. doi:10.1016/j.jpowsour.2012.11.044.

[133] A.A. Franco, Multiscale modelling and numerical simulation of rechargeable lithium ion batteries: concepts, methods and challenges, RSC Adv. 3 (2013) 13027-13058. doi:10.1039/c3ra23502e.

[134] S. Goutam, A. Nikolian, J. Jaguemont, J. Smekens, N. Omar, P. Van Dan Bossche, J. Van Mierlo, Three-dimensional electro-thermal model of li-ion pouch cell: Analysis and comparison of cell design factors and model assumptions, Appl. Therm. Eng. 126 (2017) 796-808. doi:10.1016/j.applthermaleng.2017.07.206.

[135] K. Gopalakrishnan, T. Zhang, G.J. Offer, A Fast, Memory-Efficient Discrete-Time Realization Algorithm for Reduced-Order Li-Ion Battery Models, J. Electrochem. Energy Convers. Storage. 14 (2017). doi:10.1115/1.4035526.

[136] J. Zhang, B. Wu, Z. Li, J. Huang, Simultaneous estimation of thermal parameters for largeformat laminated lithium-ion batteries, J. Power Sources. 259 (2014) 106-116. 
doi:10.1016/j.jpowsour.2014.02.079.

[137] K.A. Murashko, A. V. Mityakov, J. Pyrhönen, V.Y. Mityakov, S.S. Sapozhnikov, Thermal parameters determination of battery cells by local heat flux measurements, J. Power Sources. 271 (2014) 48-54. doi:10.1016/j.jpowsour.2014.07.117.

[138] Q. Wang, B. Jiang, B. Li, Y. Yan, A critical review of thermal management models and solutions of lithium-ion batteries for the development of pure electric vehicles, Renew. Sustain. Energy Rev. 64 (2016) 106-128. doi:10.1016/j.rser.2016.05.033.

[139] S. Abada, G. Marlair, A. Lecocq, M. Petit, V. Sauvant-Moynot, F. Huet, Safety focused modeling of lithium-ion batteries: A review, J. Power Sources. 306 (2016) 178-192. doi:10.1016/j.jpowsour.2015.11.100.

[140] M.B. Effat, C. Wu, F. Ciucci, Modeling efforts in the key areas of thermal management and safety of lithium ion battery cells: a mini review, ASIA-PACIFIC J. Chem. Eng. 11 (2016) 399406. doi:10.1002/apj.

[141] M. Fleckenstein, O. Bohlen, M.A. Roscher, B. Bäker, Current density and state of charge inhomogeneities in Li-ion battery cells with $\mathrm{LiFePO}_{4}$ as cathode material due to temperature gradients, J. Power Sources. 196 (2011) 4769-4778. doi:10.1016/j.jpowsour.2011.01.043.

[142] T. Waldmann, G. Bisle, S. Stumpp, M.A. Danzer, M. Kasper, P. Axmann, M. Wohlfahrtmehrens, Influence of Cell Design on Temperatures and Temperature Gradients in Lithium-Ion Cells: An In Operando Study, J. Electrochem. Soc. 162 (2015) A921-A927. doi:10.1149/2.0561506jes.

[143] Y. Troxler, B. Wu, M. Marinescu, V. Yufit, Y. Patel, A.J. Marquis, N.P. Brandon, G.J. Offer, The effect of thermal gradients on the performance of lithium-ion batteries, J. Power Sources. 247 (2014) 1018-1025. doi:10.1016/j.jpowsour.2013.06.084. 
[144] O. Veneri, ed., Technologies and Applications for Smart Charging of Electric and Plug-in Hybrid Vehicles, Springer International Publishing, Naples, 2017. doi:10.1007/978-3-319-43651-7.

[145] N. Yang, X. Zhang, B. Shang, G. Li, Unbalanced discharging and aging due to temperature differences among the cells in a lithium-ion battery pack with parallel combination, J. Power Sources. 306 (2016) 733-741. doi:10.1016/j.jpowsour.2015.12.079.

[146] W. Shi, X. Hu, C. Jin, J. Jiang, Y. Zhang, T. Yip, Effects of imbalanced currents on large-format $\mathrm{LiFePO}_{4} /$ graphite batteries systems connected in parallel, J. Power Sources. 313 (2016) 198204. doi:10.1016/j.jpowsour.2016.02.087.

[147] K. Yu, X. Yang, Y. Cheng, C. Li, Thermal analysis and two-directional air flow thermal management for lithium-ion battery pack, J. Power Sources. 270 (2014) 193-200. doi:10.1016/j.jpowsour.2014.07.086.

[148] X. Zhang, Thermal analysis of a cylindrical lithium-ion battery, Electrochim. Acta. 56 (2011) 1246-1255. doi:10.1016/j.electacta.2010.10.054.

[149] G. Zhang, L. Cao, S. Ge, C. Wang, C.E. Shaffer, C.D. Rahn, In Situ Measurement of Radial Temperature Distributions in Cylindrical Li-Ion Cells, J. Electrochem. Soc. 161 (2014) 14991507. doi:10.1149/2.0051410jes.

[150] R. Kizilel, R. Sabbah, J.R. Selman, S. Al-Hallaj, An alternative cooling system to enhance the safety of Li-ion battery packs, J. Power Sources. 194 (2009) 1105-1112. doi:10.1016/j.jpowsour.2009.06.074.

[151] I.A. Hunt, Y. Zhao, Y. Patel, G.J. Offer, Surface Cooling Causes Accelerated Degradation Compared to Tab Cooling for Lithium-Ion Pouch Cells, J. Electrochem. Soc. 163 (2016) 18461852. doi:10.1149/2.0361609jes.

[152] D. Worwood, Q. Kellner, M. Wojtala, W.D. Widanage, M. Ryan, D. Greenwood, J. Marco, A 
new approach to the internal thermal management of cylindrical battery cells for automotive applications, J. Power Sources. 346 (2017) 151-166. doi:10.1016/j.jpowsour.2017.02.023.

[153] A.A. Pesaran, Battery thermal models for hybrid vehicle simulations, J. Power Sources. 110 (2002) 377-382. doi:10.1016/S0378-7753(02)00200-8.

[154] G. Karimi, X. Li, Thermal management of lithium-ion batteries for electric vehicles, Int. J. Energy Res. 37 (2013) 13-24. doi:10.1002/er.

[155] L. Florence, Safety Issues for Lithium-Ion Batteries, 2012. http://www.ul.com/global/documents/newscience/whitepapers/firesafety/FS_Safety Issues for Lithium-Ion Batteries_10-12.pdf.

[156] D. Lisbona, T. Snee, A review of hazards associated with primary lithium and lithium-ion batteries, Process Saf. Environ. Prot. 89 (2011) 434-442. doi:10.1016/j.psep.2011.06.022.

[157] X. Feng, M. Fang, X. He, M. Ouyang, L. Lu, H. Wang, M. Zhang, Thermal runaway features of large format prismatic lithium ion battery using extended volume accelerating rate calorimetry, J. Power Sources. 255 (2014) 294-301. doi:10.1016/j.jpowsour.2014.01.005.

[158] D. Doughty, E.P. Roth, A General Discussion of Li lon Battery Safety, Electrochem. Soc. Interface. 21 (2012) 37-44. doi:10.1149/2.F03122if.

[159] J. Wen, Y. Yu, C. Chen, A Review of Lithium-Ionn Batteries Safety Issues: Existing Problems and Possible Solutions, Mater. Express. 2 (2012) 197-212. doi:10.1166/mex.2012.1075.

[160] D.P. Abraham, E.P. Roth, R. Kostecki, K. Mccarthy, S. Maclaren, D.H. Doughty, Diagnostic examination of thermally abused high-power lithium-ion cells, J. Power Sources. 161 (2006) 648-657. doi:10.1016/j.jpowsour.2006.04.088.

[161] E.P. Roth, Abuse Response of 18650 Li-Ion Cells with Different Cathodes Using EC:EMC/LiPF 6 and EC:PC:DMC/LiPF6 Electrolytes, ECS Trans. 11 (2008) 19-41. doi:10.1149/1.2897969. 
[162] R. Spotnitz, J. Franklin, Abuse behavior of high-power, lithium-ion cells, J. Power Sources. 113 (2003) 81-100. doi:10.1016/S0378-7753(02)00488-3.

[163] J.R. Dahn, E.W. Fuller, Thermal stability of $\mathrm{Li}_{x} \mathrm{CoO}_{2}, \mathrm{Li}_{x} \mathrm{NiO}_{2}$ and $\lambda-\mathrm{MnO}_{2}$ and consequences for the safety of Li-ion cells, Solid State Ionics. 69 (1994) 265-270. doi:10.1016/01672738(94)90415-4.

[164] H. Arai, M. Tsuda, K. Saito, M. Hayashi, Y. Sakurai, Thermal Reactions Between Delithiated Lithium Nickelate and Electrolyte Solutions, J. Electrochem. Soc. 149 (2002) A401-A406. doi:10.1149/1.1452114.

[165] E.P. Roth, D.H. Doughty, Thermal abuse performance of high-power 18650 Li-ion cells, J. Power Sources. 128 (2004) 308-318. doi:10.1016/j.jpowsour.2003.09.068.

[166] Q. Wang, P. Ping, X. Zhao, G. Chu, J. Sun, C. Chen, Thermal runaway caused fire and explosion of lithium ion battery, J. Power Sources. 208 (2012) 210-224. doi:10.1016/j.jpowsour.2012.02.038.

[167] M. Brand, S. Gläser, J. Geder, S. Menacher, S. Obpacher, A. Jossen, D. Quinger, Electrical safety of commercial Li-ion cells based on NMC and NCA technology compared to LFP technology, in: EVS27 Int. Batter. Hybrid Fuel Cell Electr. Veh. Symp., IEEE, Barcelona, Spain, 2013: pp. 1-9. doi:10.1109/EVS.2013.6914893.

[168] J. Jiang, J.R. Dahn, ARC studies of the thermal stability of three different cathode materials:

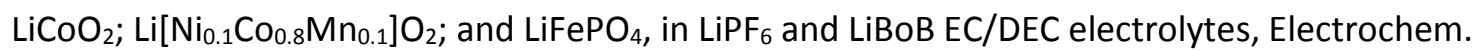
Commun. 6 (2004) 39-43. doi:10.1016/j.elecom.2003.10.011.

[169] D.D. Macneil, Z. Lu, Z. Chen, J.R. Dahn, A comparison of the electrode/electrolyte reaction at elevated temperatures for various Li-ion battery cathodes, J. Power Sources. 108 (2002) 8-14. doi:10.1016/S0378-7753(01)01013-8. 
[170] S. Al Hallaj, H. Maleki, J.S. Hong, J.R. Selman, Thermal modeling and design considerations of lithium-ion batteries, J. Power Sources. 83 (1999) 1-8. doi:10.1016/S0378-7753(99)00178-0.

[171] O.S. Mendoza-hernandez, H. Ishikawa, Y. Nishikawa, Y. Maruyama, M. Umeda, Cathode material comparison of thermal runaway behavior of Li-ion cells at different state of charges including over charge, J. Power Sources. 280 (2015) 499-504. doi:10.1016/j.jpowsour.2015.01.143.

[172] S.E.L. Khakani, D. Rochefort, D.D. Macneil, ARC Study of LiFePO 4 with Different Morphologies Prepared via Three Synthetic Routes, J. Electrochem. Soc. 163 (2016) A1311-A1316. doi:10.1149/2.0801607jes.

[173] J. Jiang, J.R. Dahn, Effects of particle size and electrolyte salt on the thermal stability of $\mathrm{Li}_{0.5} \mathrm{CoO}_{2}$, Electrochim. Acta. 49 (2004) 2661-2666. doi:10.1016/j.electacta.2004.02.017.

[174] P.G. Balakrishnan, R. Ramesh, T.P. Kumar, Safety mechanisms in lithium-ion batteries, J. Power Sources. 155 (2006) 401-414. doi:10.1016/j.jpowsour.2005.12.002.

[175] R.M. Spotnitz, J. Weaver, G. Yeduvaka, D.H. Doughty, E.P. Roth, Simulation of abuse tolerance of lithium-ion battery packs, J. Power Sources. 163 (2007) 1080-1086. doi:10.1016/j.jpowsour.2006.10.013.

[176] J. Lamb, C.J. Orendorff, L.A.M. Steele, S.W. Spangler, Failure propagation in multi-cell lithium ion batteries, J. Power Sources. 283 (2015) 517-523. doi:10.1016/j.jpowsour.2014.10.081.

[177] X. Feng, L. Lu, M. Ouyang, J. Li, X. He, A 3D thermal runaway propagation model for a large format lithium ion battery module, Energy. 115 (2016) 194-208. doi:10.1016/j.energy.2016.08.094.

[178] X. Feng, X. He, M. Ouyang, L. Lu, P. Wu, C. Kulp, S. Prasser, Thermal runaway propagation model for designing a safer battery pack with $25 \mathrm{Ah} \mathrm{LiNix}_{x} \mathrm{Co}_{y} \mathrm{Mn}_{z} \mathrm{O}_{2}$ large format lithium ion 
battery, Appl. Energy. 154 (2015) 74-91. doi:10.1016/j.apenergy.2015.04.118.

[179] F. Larsson, J. Anderson, P. Andersson, B. Mellander, Thermal Modelling of Cell-to-Cell Fire Propagation and Cascading Thermal Runaway Failure Effects for Lithium-Ion Battery Cells and Modules Using Fire Walls, J. Electrochem. Soc. 163 (2016) A2854-A2865. doi:10.1149/2.0131614jes.

[180] P.T. Coman, E.C. Darcy, C.T. Veje, R.E. White, Numerical analysis of heat propagation in a battery pack using a novel technology for triggering thermal runaway, Appl. Energy. 203 (2017) 189-200. doi:10.1016/j.apenergy.2017.06.033.

[181] J.A. Becker, C.B. Green, G.L. Pearson, Properties and Uses of Thermistors - Thermally Sensitive Resistors, Trans. Am. Inst. Electr. Eng. 65 (1946) 711-725. doi:10.1109/T-AIEE.1946.5059235.

[182] P.L. Melo de, Thermistors, in: J.G. Webster (Ed.), Encycl. Med. Devices Instrum., 2nd ed., John Wiley and Sons, 2006: pp. 320-340. doi:10.1002/0471732877.emd245.

[183] E.A. Boucher, Theory and Applications of Thermistors, J. Chem. Educ. 44 (1967) A935-A966. http://pubs.acs.org/doi/pdf/10.1021/ed044pA935.

[184] S.D. Wood, B.W. Mangum, J.J. Filliben, S.B. Tillett, An investigation of the stability of thermistors, J. Res. Natl. Bur. Stand. (1934). 83 (1978) 247-263. http://nvlpubs.nist.gov/nistpubs/jres/83/jresv83n3p247_A1b.pdf.

[185] T.J. Edwards, Observations on the stability of thermistors, Rev. Sci. Instrum. 54 (1983) 613617. doi:10.1063/1.1137423.

[186] K.M. Lawton, S.R. Patterson, Long-term relative stability of thermistors, Precis. Eng. 25 (2001) 24-28. doi:10.1016/\$0141-6359(00)00051-9.

[187] K.M. Lawton, S.R. Patterson, Long-term relative stability of thermistors: Part 2, Precis. Eng. 26 (2002) 340-345. doi:10.1016/S0141-6359(02)00110-1. 
[188] S. Rudtsch, C. Von Rohden, Calibration and self-validation of thermistors for high-precision temperature measurements, Measurement. 76 (2015) 1-6. doi:10.1016/j.measurement.2015.07.028.

[189] R.K. Kamat, G.M. Naik, Thermistors - in search of new applications, manufacturers cultivate advanced NTC techniques, Sens. Rev. 22 (2002) 334-340. doi:10.1108/02602280210444654.

[190] J. Cao, A. Emadi, Batteries Need Electronics, IEEE Ind. Electron. Mag. 5 (2011) 27-35. doi:10.1109/MIE.2011.940251.

[191] S. Dearborn, Charging Li-ion Batteries for Maximum Run Times, Power Electroncis Today. 31 (2005) 40-49.

https://pdfs.semanticscholar.org/e46c/5f4c635e1ae98dacc76bfca3e8aa71a2800d.pdf.

[192] B. Fleming, Sensors-A Forecast, IEEE Veh. Technol. Mag. 8 (2013) 4-12. doi:10.1109/MVT.2013.2268420.

[193] A.M. Aucamp, A. Janse van Rensburg, Real-Time Monitoring of Temperature Distribution in a Lithium-lon Battery Pack, in: P.S. Heyns, P.A. van Vuuren, G. van Schoor, R.B.K.N. Rao (Eds.), 31st Conf. Cond. Monit. Diagnostic Eng. Manag., North-West University, South Africa, Sun City, Rustenburg, South Africa, 2018: pp. 140-147.

[194] S. Goutam, J. Timmermans, N. Omar, P. Van Den Bossche, J. Van Mierlo, Comparative Study of Surface Temperature Behavior of Commercial Li-Ion Pouch Cells of Different Chemistries and Capacities by Infrared Thermography, Energies. 8 (2015) 8175-8192. doi:10.3390/en8088175.

[195] J. Christensen, D. Cook, P. Albertus, An Efficient Parallelizable 3D Thermoelectrochemical Model of a Li-Ion Cell, J. Electrochem. Soc. 160 (2013) A2258-A2267. doi:10.1149/2.086311jes.

[196] J. Grosch, E. Teuber, M. Jank, V. Lorentz, M. März, L. Frey, Device Optimization and 
Application Study of low cost Printed Temperature Sensor for mobile and stationary battery based Energy Storage Systems, in: IEEE Int. Conf. Smart Energy Grid Eng., IEEE, Oshawa, 2015: pp. 1-7. doi:10.1109/SEGE.2015.7324599.

[197] Q. Cai, Y.-C. Chen, C. Tsai, J.F. DeNatale, Development of a platinum resistance thermometer on the silicon substrate for phase change studies, J. Micromechanics Microengineering. 22 (2012) 1-7. doi:10.1088/0960-1317/22/8/085012.

[198] A. Tong, Improving the accuracy of temperature measurements, Sens. Rev. 21 (2001) 193198. doi:10.1108/02602280110398044.

[199] S. Tippmann, D. Walper, L. Balboa, B. Spier, W.G. Bessler, Low-temperature charging of lithium-ion cells part I: Electrochemical modeling and experimental investigation of degradation behavior, J. Power Sources. 252 (2014) 305-316. doi:10.1016/j.jpowsour.2013.12.022.

[200] D. Chalise, K. Shah, T. Halama, L. Komsiyska, A. Jain, An experimentally validated method for temperature prediction during cyclic operation of a Li-ion cell, Int. J. Heat Mass Transf. 112 (2017) 89-96. doi:10.1016/j.ijheatmasstransfer.2017.04.115.

[201] K. Murashko, J. Pyrhonen, L. Laurila, Three-dimensional thermal model of a lithium ion battery for hybrid mobile working machines: Determination of the model parameters in a pouch cell, IEEE Trans. Energy Convers. 28 (2013) 335-343. doi:10.1109/TEC.2013.2255291.

[202] M.S. Rad, D.L. Danilov, M. Baghalha, M. Kazemeini, P.H.L. Notten, Thermal Modeling of Cylindrical LiFePO 4 Batteries, J. Mod. Phys. 04 (2013) 1-7. doi:10.4236/jmp.2013.47A2001.

[203] R.P. Day, J. Xia, R. Petibon, J. Rucska, H. Wang, A.T.B. Wright, J.R. Dahn, Differential Thermal Analysis of Li-Ion Cells as an Effective Probe of Liquid Electrolyte Evolution during Aging, J. Electrochem. Soc. 162 (2015) 14-18. doi:10.1149/2.0181514jes. 
[204] P. Wang, X. Zhang, L. Yang, X. Zhang, M. Yang, Real-time monitoring of internal temperature evolution of the lithium-ion coin cell battery during the charge and discharge process, Extrem. Mech. Lett. (2016) 1-8. doi:10.1016/j.eml.2016.03.013.

[205] C.-Y. Wang, G. Zhang, S. Ge, T. Xu, Y. Ji, X.-G. Yang, Y. Leng, Lithium-ion battery structure that self-heats at low temperatures, Nature. 529 (2016) 515-518. doi:10.1038/nature16502.

[206] G. Zhang, S. Ge, T. Xu, X.-G. Yang, H. Tian, C.-Y. Wang, Rapid self-heating and internal temperature sensing of lithium-ion batteries at low temperatures, Electrochim. Acta. 218 (2016) 149-155. doi:10.1016/j.electacta.2016.09.117.

[207] X.-G. Yang, T. Liu, C.-Y. Wang, Innovative heating of large-size automotive Li-ion cells, J. Power Sources. 342 (2017) 598-604. doi:10.1016/j.jpowsour.2016.12.102.

[208] C.Y. Lee, S.J. Lee, M.S. Tang, P.C. Chen, In situ monitoring of temperature inside lithium-ion batteries by flexible micro temperature sensors, Sensors. 11 (2011) 9942-9950. doi:10.3390/s111009942.

[209] C.-Y. Lee, S.-J. Lee, Y.-H. Chen, M.-Y. Chung, K.-C. Han, In-situ Monitoring of Temperature and Voltage in Lithium-Ion Battery by Embedded Flexible Micro Temperature and Voltage Sensor, Int. J. Electrochem. Sci. 8 (2013) 2968-2976. http://electrochemsci.org/papers/vol8/80202968.pdf.

[210] C.-Y. Lee, H.-C. Peng, S.-J. Lee, I.-M. Hung, C.-T. Hsieh, C.-S. Chiou, Y.-M. Chang, Y.-P. Huang, A Flexible Three-in-One Microsensor for Real-Time Monitoring of Internal Temperature, Voltage and Current of Lithium Batteries, Sensors. 15 (2015) 11485-11498. doi:10.3390/s150511485.

[211] C.-Y. Lee, S.-J. Lee, Y.-M. Hung, C.-T. Hsieh, Y.-M. Chang, Y.-T. Huang, J.-T. Lin, Integrated microsensor for real-time microscopic monitoring of local temperature, voltage and current inside lithium ion battery, Sensors Actuators A Phys. 253 (2017) 59-68. 
doi:10.1016/j.sna.2016.10.011.

[212] M. Sharifi, B. Young, Chemical Engineering Research and Design Electrical Resistance Tomography ( ERT ) applications to Chemical Engineering, Chem. Eng. Res. Des. 91 (2013) 1625-1645. doi:10.1016/j.cherd.2013.05.026.

[213] S.R. Aw, R.A. Rahim, M.H.F. Rahiman, F.R.M. Yunus, L.C. Goh, Electrical resistance tomography: A review of the application of conducting vessel walls, Powder Technol. 254 (2014) 256-264. doi:10.1016/j.powtec.2014.01.050.

[214] X. Hong, N. Li, J. Feng, Q. Kong, G. Liu, Multi-Electrode Resistivity Probe for Investigation of Local Temperature Inside Metal Shell Battery Cells via Resistivity: Experiments and Evaluation of Electrical Resistance Tomography, Energies. 8 (2015) 742-764. doi:10.3390/en8020742.

[215] X. Hong, N. Li, Q. Kong, G. Liu, M. Ho, Local cell temperature monitoring for aluminum shell lithium-ion battery based on electrical resistance tomography, Measurement. 86 (2016) 227238. doi:10.1016/j.measurement.2016.02.039.

[216] A.W. van Herwaarden, P.M. Sarro, Thermal sensors based on the Seebeck effect, Sensors and Actuators. 10 (1986) 321-346. doi:10.1016/0250-6874(86)80053-1.

[217] B.M. Duff, J. Towey, Two Ways to Measure Temperature Using Thermocouples Feature Simplicity, Accuracy, and Flexibility, Analog Dialogue. 44 (2010) 1-6. http://www.mouser.be/pdfdocs/src-tutorials/Measure-Temperature-withThermocouples.pdf.

[218] D.C. Ripple, NIST ITS-90 Thermocouple Database, NIST Stand. Ref. Database 60. (2000). https://srdata.nist.gov/its90/main/ (accessed April 11, 2018).

[219] G. Vertiz, M. Oyarbide, H. Macicior, O. Miguel, I. Cantero, P.F. De Arroiabe, I. Ulacia, Thermal characterization of large size lithium-ion pouch cell based on 1d electro-thermal model, J. 
Power Sources. 272 (2014) 476-484. doi:10.1016/j.jpowsour.2014.08.092.

[220] A. Hofmann, N. UhImann, C. Ziebert, O. Wiegand, A. Schmidt, T. Hanemann, Preventing Li-ion cell explosion during thermal runaway with reduced pressure, Appl. Therm. Eng. 124 (2017) 539-544. doi:10.1016/j.applthermaleng.2017.06.056.

[221] Y. Xiao, Model-Based Virtual Thermal Sensors for Lithium-Ion Battery in EV Applications, IEEE Trans. Ind. Electron. 62 (2015) 3112-3122. doi:10.1109/TIE.2014.2386793.

[222] J. Sun, G. Wei, L. Pei, R. Lu, K. Song, C. Wu, C. Zhu, Online Internal Temperature Estimation for Lithium-Ion Batteries Based on Kalman Filter, Energies. 8 (2015) 4400-4415. doi:10.3390/en8054400.

[223] M. Parhizi, M.B. Ahmed, A. Jain, Determination of the core temperature of a Li-ion cell during thermal runaway, J. Power Sources. 370 (2017) 27-35. doi:10.1016/j.jpowsour.2017.09.086.

[224] D. Anthony, D. Wong, D. Wetz, A. Jain, Non-invasive measurement of internal temperature of a cylindrical Li-ion cell during high-rate discharge, Int. J. Heat Mass Transf. 111 (2017) 223231. doi:10.1016/j.ijheatmasstransfer.2017.03.095.

[225] S. Dey, Z.A. Biron, S. Tatipamula, N. Das, S. Mohon, B. Ayalew, P. Pisu, Model-based real-time thermal fault diagnosis of Lithium-ion batteries, Control Eng. Pract. 56 (2016) 37-48. doi:10.1016/j.conengprac.2016.08.002.

[226] T. Waldmann, M. Wohlfahrt-mehrens, In-Operando Measurement of Temperature Gradients in Cylindrical Lithium-Ion Cells during High-Current Discharge, ECS Electrochem. Lett. 4 (2015) A1-A3. doi:10.1149/2.0031501eel.

[227] C. Heubner, M. Schneider, C. Lämmel, U. Langklotz, A. Michaelis, In-operando temperature measurement across the interfaces of a lithium-ion battery cell, Electrochim. Acta. 113 (2013) 730-734. doi:10.1016/j.electacta.2013.08.091. 
[228] S.J. Drake, M. Martin, D.A. Wetz, J.K. Ostanek, S.P. Miller, J.M. Heinzel, A. Jain, Heat generation rate measurement in a Li-ion cell at large C-rates through temperature and heat flux measurements, J. Power Sources. 285 (2015) 266-273. doi:10.1016/j.jpowsour.2015.03.008.

[229] J.G. Zhu, Z.C. Sun, X.Z. Wei, H.F. Dai, A new lithium-ion battery internal temperature on-line estimate method based on electrochemical impedance spectroscopy measurement, J. Power Sources. 274 (2015) 990-1004. doi:10.1016/j.jpowsour.2014.10.182.

[230] Z. Li, J. Zhang, B. Wu, J. Huang, Z. Nie, Y. Sun, F. An, N. Wu, Examining temporal and spatial variations of internal temperature in large-format laminated battery with embedded thermocouples, J. Power Sources. 241 (2013) 536-553. doi:10.1016/j.jpowsour.2013.04.117.

[231] X. Li, F. He, L. Ma, Thermal management of cylindrical batteries investigated using wind tunnel testing and computational fluid dynamics simulation, J. Power Sources. 238 (2013) 395-402. doi:10.1016/j.jpowsour.2013.04.073.

[232] G. Zhang, L. Cao, S. Ge, C.-Y. Wang, C.E. Shaffer, C.D. Rahn, Reaction temperature sensing (RTS)-based control for Li-ion battery safety, Sci. Rep. 5 (2015) 1-6. doi:10.1038/srep18237.

[233] M.S.K. Mutyala, J. Zhao, J. Li, H. Pan, C. Yuan, X. Li, In-situ temperature measurement in lithium ion battery by transferable flexible thin film thermocouples, J. Power Sources. 260 (2014) 43-49. doi:10.1016/j.jpowsour.2014.03.004.

[234] N. Martiny, A. Rheinfled, J. Geder, Y. Wang, W. Kraus, A. Jossen, Development of an all Kapton-based thin-film thermocouple matrix for in-situ temperature measurement in a lithium ion pouch cell, IEEE Sens. J. 14 (2014) 3377-3384. doi:10.1109/ICSENS.2013.6688485.

[235] N. Martiny, J. Geder, Y. Wang, W. Kraus, A. Jossen, Development of a thin-film thermocouple matrix for in-situ temperature measurement in a lithium ion pouch cell, in: IEEE Sensors, IEEE, 
Baltimore, MD, USA, 2013. doi:10.1109/ICSENS.2013.6688485.

[236] K.O. Hill, G. Meltz, Fiber Bragg Grating Technology Fundamentals and Overview, J. Light. Technol. 15 (1997) 1263-1276. doi:10.1109/50.618320.

[237] Y.-J. Rao, In-fibre Bragg grating sensors, Meas. Sci. Technol. 8 (1997) 355-375. doi:10.1088/0957-0233/8/4/002.

[238] F. Jülich, J. Roths, Determination of the Effective Refractive Index of Various Single Mode Fibres for Fibre Bragg Grating Sensor Applications, in: SENSOR+TEST Conf., AMA Conferences, Nürnberg, 2009: pp. 119-124. doi:10.5162/opto09/op2.

[239] A. Othonos, Fiber Bragg gratings, Rev. Sci. Instrum. 68 (1997) 4309-4341. doi:10.1063/1.1148392.

[240] S.J. Mihailov, Fiber Bragg Grating Sensors for Harsh Environments, Sensors. 12 (2012) 18981918. doi:10.3390/s120201898.

[241] W.-C. Du, X.-M. Tao, H.-Y. Tam, Fiber Bragg Grating Cavity Sensor for Simultaneous Measurement of Strain and Temperature, IEEE Photonics Technol. Lett. 11 (1999) 105-107. doi:10.1109/68.736409.

[242] R.J. Black, B. Moslehi, Advanced end-to-end fiber optic sensing system for demanding environments, Proc. SPIE, Nanophotonics Macrophotonics Sp. Environ. IV. 7817 (2010) 78170L1-78170L9. doi:10.1117/12.862227.

[243] Y.-J. Rao, D.J. Webb, D.A. Jackson, L. Zhang, I. Bennion, In-Fiber Bragg-Grating Temperature Sensor System for Medical Applications, J. Light. Technol. 15 (1997) 779-785. doi:10.1109/50.580812.

[244] N.A. David, P.M. Wild, J. Hu, N. Djilali, In-fibre Bragg grating sensors for distributed temperature measurement in a polymer electrolyte membrane fuel cell, J. Power Sources. 
192 (2009) 376-380. doi:10.1016/j.jpowsour.2009.03.021.

[245] N.A. David, P.M. Wild, J. Jensen, T. Navessin, N. Djilali, Simultaneous In Situ Measurement of Temperature and Relative Humidity in a PEMFC Using Optical Fiber Sensors, J. Electrochem. Soc. 157 (2010) B1173-B1179. doi:10.1149/1.3436652.

[246] G. Yang, C. Leitao, Y. Li, J. Pinto, X. Jiang, Real-time temperature measurement with fiber Bragg sensors in lithium batteries for safety usage, Measurement. 46 (2013) 3166-3172. doi:10.1016/j.measurement.2013.05.027.

[247] L.W. Sommer, A. Raghavan, P. Kiesel, B. Saha, T. Staudt, A. Lochbaum, A. Gunguli, C.-J. Bae, M. Alamgir, Embedded fiber optic sensing for accurate state estimation in advanced battery management systems, in: MRS Spring Meet. Symp. Q, Cambridge University Press, 2014. doi:10.1557/opl.2014.560.

[248] J. Meyer, A. Nedjalkov, A. Doering, M. Angelmahr, W. Schade, Fiber optical sensors for enhanced battery safety, in: SPIE Sens. Technol. Appl., Baltimore, Maryland, United States, 2015: p. 94800Z-1. doi:10.1117/12.2183325.

[249] M. Nascimento, S. Novais, C. Leitao, F. Domingues, N. Alberto, Lithium batteries temperature and strain fiber temperature monitoring, in: 24th Int. Conf. Opt. Fibre Sensors, Proc. of SPIE, Curitiba, Brazil, 2015: p. 96347V-1. doi:10.1117/12.2195218.

[250] S. Novais, M. Nascimento, L. Grande, M.F. Domingues, P. Antunes, N. Alberto, C. Leitao, R. Oliveira, S. Koch, G.T. Kim, S. Passerini, J. Pinto, Internal and External Temperature Monitoring of a Li-Ion Battery with Fiber Bragg Grating Sensors, Sensors. 16 (2016) 1394. doi:10.3390/s16091394.

[251] M. Nascimento, M.S. Ferreira, J.L. Pinto, Real time thermal monitoring of lithium batteries with fiber sensors and thermocouples: A comparative study, Measurement. 111 (2017) 260- 
263. doi:10.1016/j.measurement.2017.07.049.

[252] L.W. Sommer, P. Kiesel, A. Ganguli, A. Lochbaum, B. Saha, J. Schwartz, C.-J. Bae, M. Alamgir, A. Raghavan, Fast and slow ion diffusion processes in lithium ion pouch cells during cycling observed with fi ber optic strain sensors, J. Power Sources. 296 (2015) 46-52. doi:10.1016/j.jpowsour.2015.07.025.

[253] L.W. Sommer, A. Raghavan, P. Kiesel, B. Saha, J. Schwartz, A. Lochbaum, A. Ganguli, C.-J. Bae, M. Alamgir, Monitoring of Intercalation Stages in Lithium-Ion Cells over Charge-Discharge Cycles with Fiber Optic Sensors, J. Electrochem. Soc. 162 (2015) A2664-A2669. doi:10.1149/2.0361514jes.

[254] A. Raghavan, P. Kiesel, L.W. Sommer, J. Schwartz, A. Lochbaum, A. Hegyi, A. Schuh, K. Arakaki, B. Saha, A. Ganguli, K.H. Kim, C. Kim, H.J. Hah, S. Kim, G.-O. Hwang, G.-C. Chung, B. Choi, M. Alamgir, Embedded fiber-optic sensing for accurate internal monitoring of cell state in advanced battery management systems part 1: Cell embedding method and performance, J. Power Sources. 341 (2017) 466-473. doi:10.1016/j.jpowsour.2016.11.104.

[255] A. Ganguli, B. Saha, A. Raghavan, P. Kiesel, K. Arakaki, A. Schuh, J. Schwartz, A. Hegyi, L.W. Sommer, A. Lochbaum, S. Sahu, M. Alamgir, Embedded fiber-optic sensing for accurate internal monitoring of cell state in advanced battery management systems part 2: Internal cell signals and utility for state estimation, J. Power Sources. 341 (2017) 474-482. doi:10.1016/j.jpowsour.2016.11.103.

[256] A. Fortier, M. Tsao, N.D. Williard, Y. Xing, M.G. Pecht, Preliminary Study on Integration of Fiber Optic Bragg Grating Sensors in Li-Ion Batteries and In Situ Strain and Temperature Monitoring of Battery Cells, Energies. 10 (2017) 838. doi:10.3390/en10070838.

[257] T. Amietszajew, E. McTurk, J. Fleming, R. Bhagat, Understanding the limits of rapid charging using instrumented commercial 18650 high-energy Li-ion cells, Electrochim. Acta. 263 (2018) 
346-352. doi:10.1016/j.electacta.2018.01.076.

[258] M.E. Orazem, B. Tribollet, Electrochmical Impedance Spectroscopy, John Wiley and Sons, 2011. doi:10.1002/9780470381588.

[259] E. Barsoukov, J.R. Macdonald, Impedance Spectroscopy Theory, Experiment, and Applications, Second, John Wiley and Sons, 2005. http://eu.wiley.com/WileyCDA/WileyTitle/productCd0471647497.html.

[260] W. Waag, S. Käbitz, D.U. Sauer, Experimental investigation of the lithium-ion battery impedance characteristic at various conditions and aging states and its influence on the application, Appl. Energy. 102 (2013) 885-897. doi:10.1016/j.apenergy.2012.09.030.

[261] K.M. Shaju, G. V. Subba Rao, B.V.R. Chowdari, Electrochemical Kinetic Studies of Li-lon in O2Structured $\mathrm{Li}_{2 / 3}\left(\mathrm{Ni}_{1 / 3} \mathrm{Mn}_{2 / 3}\right) \mathrm{O}_{2}$ and $\mathrm{Li}_{(2 / 3)+\times}\left(\mathrm{Ni}_{1 / 3} \mathrm{Mn}_{2 / 3}\right) \mathrm{O}_{2}$ by EIS and GITT, J. Electrochem. Soc. 150 (2003) A1. doi:10.1149/1.1521754.

[262] Y. Xie, J. Li, C. Yuan, Mathematical modeling of the electrochemical impedance spectroscopy in lithium ion battery cycling, Electrochim. Acta. 127 (2014) 266-275. doi:10.1016/j.electacta.2014.02.035.

[263] L. Gagneur, A.L. Driemeyer-Franco, C. Forgez, G. Friedrich, Modeling of the diffusion phenomenon in a lithium-ion cell using frequency or time domain identification, Microelectron. Reliab. 53 (2013) 784-796. doi:10.1016/j.microrel.2013.03.009.

[264] U. Westerhoff, T. Kroker, K. Kurbach, M. Kurrat, Electrochemical impedance spectroscopy based estimation of the state of charge of lithium-ion batteries, J. Energy Storage. 8 (2016) 244-256. doi:10.1016/j.est.2016.09.001.

[265] J.-H. Lee, W.-J. Choi, Novel State-of-Charge Estimation Method for Lithium Polymer Batteries Using Electrochemical Impedance Spectroscopy, J. Power Electron. 11 (2011) 237-243. 
doi:10.6113/JPE.2011.11.2.237.

[266] M.-H. Hung, C.-H. Lin, L.-C. Lee, C.-M. Wang, State-of-charge and state-of-health estimation for lithium-ion batteries based on dynamic impedance technique, J. Power Sources. 268 (2014) 861-873. doi:10.1016/j.jpowsour.2014.06.083.

[267] C.T. Love, M.B. V Virji, R.E. Rocheleau, K.E. Swider-Lyons, State-of-health monitoring of 18650 4S packs with a single-point impedance diagnostic, J. Power Sources. 266 (2014) 512-519. doi:10.1016/j.jpowsour.2014.05.033.

[268] Y. Zhang, C.-Y. Wang, Cycle-Life Characterization of Automotive Lithium-Ion Batteries with $\mathrm{LiNiO}_{2}$ Cathode, J. Electrochem. Soc. 156 (2009) A527. doi:10.1149/1.3126385.

[269] X.-Y. Qiu, Q.-C. Zhuang, Q.-Q. Zhang, R. Cao, P.-Z. Ying, Y.-H. Qiang, S.-G. Sun, Electrochemical and electronic properties of $\mathrm{LiCoO}_{2}$ cathode investigated by galvanostatic cycling and EIS, Phys. Chem. Chem. Phys. 14 (2012) 2617. doi:10.1039/c2cp23626e.

[270] E. Samadani, S. Farhad, W. Scott, M. Mastali, L.E. Gimenez, M. Fowler, R.A. Fraser, Empirical modeling of lithium-ion batteries based on electrochemical impedance spectroscopy tests, Electrochim. Acta. 160 (2015) 169-177. doi:10.1016/j.electacta.2015.02.021.

[271] P. Gao, C. Zhang, G. Wen, Equivalent circuit model analysis on electrochemical impedance spectroscopy of lithium metal batteries, J. Power Sources. 294 (2015) 67-74. doi:10.1016/j.jpowsour.2015.06.032.

[272] N. Mellgren, S. Brown, M. Vynnycky, G. Lindbergh, Impedance as a Tool for Investigating Aging in Lithium-Ion Porous Electrodes, J. Electrochem. Soc. 155 (2008) A304. doi:10.1149/1.2840015.

[273] R. Srinivasan, B.G. Carkhuff, M.H. Butler, A.C. Baisden, Instantaneous measurement of the internal temperature in lithium-ion rechargeable cells, Electrochim. Acta. 56 (2011) 6198- 
6204. doi:10.1016/j.electacta.2011.03.136.

[274] J.P. Schmidt, S. Arnold, A. Loges, D. Werner, T. Wetzel, E. Ivers-Tiffée, Measurement of the internal cell temperature via impedance: Evaluation and application of a new method, J. Power Sources. 243 (2013) 110-117. doi:10.1016/j.jpowsour.2013.06.013.

[275] R.R. Richardson, P.T. Ireland, D. a. Howey, Battery internal temperature estimation by combined impedance and surface temperature measurement, J. Power Sources. 265 (2014) 254-261. doi:10.1016/j.jpowsour.2014.04.129.

[276] L.H.J. Raijmakers, D.L. Danilov, J.P.M. Van Lammeren, M.J.G. Lammers, P.H.L. Notten, Sensorless battery temperature measurements based on electrochemical impedance spectroscopy, J. Power Sources. 247 (2014) 539-544. doi:10.1016/j.jpowsour.2013.09.005.

[277] L.H.J. Raijmakers, D.L. Danilov, J.P.M. Van Lammeren, M.J.G. Lammers, H.J. Bergveld, P.H.L. Notten, Non-Zero Intercept Frequency : An Accurate Method to Determine the Integral Temperature of Li-ion Batteries, IEEE Trans. Ind. Electron. 63 (2016) 3168-3178. doi:10.1109/TIE.2016.2516961.

[278] L.H.J. Raijmakers, K.M. Shivakumar, M.C.F. Donkers, M.J.G. Lammers, H.J. Bergveld, Crosstalk Interferences on Impedance Measurements in Battery Packs, IFAC-PapersOnLine. 49 (2016) 42-47. doi:10.1016/j.ifacol.2016.08.007.

[279] K.S. Champlin, Method and apparatus for electronically evaluating the internal temperature of an electrochemical cell or battery, US 6,294,897 B1, 2001. https://www.google.com/patents/US6294897.

[280] R. Srinivasan, Monitoring dynamic thermal behavior of the carbon anode in a lithium-ion cell using a four-probe technique, J. Power Sources. 198 (2012) 351-358. doi:10.1016/j.jpowsour.2011.09.077. 
[281] R. Schwarz, K. Semmler, M. Wenger, V.R.H. Lorentz, M. März, Sensorless Battery Cell Temperature Estimation Circuit for Enhanced Safety in Battery Systems, in: 41st Annu. Conf. IEEE Ind. Electron. Soc., IEEE, Yokohama, Japan, 2015. doi:10.1109/IECON.2015.7392319.

[282] N.S. Spinner, C.T. Love, S.L. Rose-Pehrsson, S.G. Tuttle, Expanding the Operational Limits of the Single-Point Impedance Diagnostic for Internal Temperature Monitoring of Lithium-ion Batteries, Electrochim. Acta. 174 (2015) 488-493. doi:10.1016/j.electacta.2015.06.003.

[283] J. Zhu, Z. Sun, X. Wei, H. Dai, Battery Internal Temperature Estimation for $\mathrm{LiFePO}_{4}$ Battery Based on Impedance Phase Shift under Operating Conditions, Energies. 10 (2017) 1-17. doi:10.3390/en10010060.

[284] H. Dai, B. Jiang, X. Wei, Impedance Characterization and Modeling of Lithium-Ion Batteries Considering the Internal Temperature Gradient, Energies. 11 (2018) 220. doi:10.3390/en11010220.

[285] R.R. Richardson, D.A. Howey, Sensorless Battery Internal Temperature Estimation using a Kalman Filter with Impedance Measurement, IEEE Trans. Sustain. Energy. 6 (2015) 1190-1199. doi:10.1109/TSTE.2015.2420375.

[286] R.R. Richardson, S. Zhao, D.A. Howey, On-board monitoring of 2-D spatially-resolved temperatures in cylindrical lithium-ion batteries: Part II. State estimation via impedancebased temperature sensing, J. Power Sources. 327 (2016) 726-735. doi:10.1016/j.jpowsour.2016.06.103.

[287] M. Ranieri, D. Alberto, H. Piret, V. Cattin, Electronic Module for the Thermal Monitoring of a Li-ion Battery Cell through the Electrochemical Impedance Estimation, in: Therminic 2016 22nd Int. Work. Therm. Investig. ICs Syst., IEEE, Budapest, Hungary, 2016: pp. 294-297. doi:10.1109/THERMINIC.2016.7749069. 
[288] H.P.G.J. Beelen, L.H.J. Raijmakers, M.C.F. Donkers, P.H.L. Notten, H.J. Bergveld, An Improved Impedance-Based Temperature Estimation Method for Li-ion Batteries, IFAC-PapersOnLine. 48 (2015) 383-388. doi:10.1016/j.ifacol.2015.10.055.

[289] H.P.G.J. Beelen, L.H.J. Raijmakers, M.C.F. Donkers, P.H.L. Notten, H.J. Bergveld, A comparison and accuracy analysis of impedance-based temperature estimation methods for Li-ion batteries, Appl. Energy. 175 (2016) 128-140. doi:10.1016/j.apenergy.2016.04.103.

[290] P. Haussmann, J. Melbert, Internal Cell Temperature Measurement and Thermal Modeling of Lithium Ion Cells for Automotive Applications by Means of Electrochemical Impedance Spectroscopy, SAE Int. J. Altern. Powertrains. 6 (2017) 261-270. doi:10.4271/2017-01-1215.

[291] S. Socher, C. Jehle, U. Potthoff, Improving the functional safety of automotive batteries using in-situ impedance spectroscopy, Transp. Res. Procedia. 14 (2016) 3661-3666. doi:10.1016/j.trpro.2016.05.437.

[292] R. Koch, A. Jossen, Temperature Measurement of Large Format Pouch Cells with Impedance Spectroscopy, in: EVS 28 Int. Electr. Veh. Symp. Exhib., Goyang, Korea, 2015: pp. 1-9. http://www.evs28.org/event_file/event_file/1/pfile/Temperature Measurement of Large Format Pouch Cells with Impedance Spectroscopy_rev3.pdf.

[293] R. Srinivasan, P.A. Demirev, B.G. Carkhuff, Rapid monitoring of impedance phase shifts in lithium-ion batteries for hazard prevention, J. Power Sources. 405 (2018) 30-36. doi:10.1016/j.jpowsour.2018.10.014.

[294] V. Roscher, M. Schneider, P. Durdaut, N. Sassano, S. Pereguda, E. Mense, K.R. Riemschneider, Synchronisation using wireless trigger-broadcast for impedance spectroscopy of battery cells, in: SAS 2015 - 2015 IEEE Sensors Appl. Symp. Proc., IEEE, Zadar, Croatia, 2015. doi:10.1109/SAS.2015.7133608. 
[295] B.G. Carkhuff, P.A. Demirev, R. Srinivasan, Impedance-Based Battery Management System for Safety Monitoring of Lithium-Ion Batteries, IEEE Trans. Ind. Electron. PP (2018). doi:10.1109/TIE.2017.2786199.

[296] X. Wei, X. Wang, H. Dai, Practical on-board measurement of lithium ion battery impedance based on distributed voltage and current sampling, Energies. 11 (2018) 64. doi:10.3390/en11010064.

[297] Z. Gong, Z. Liu, Y. Wang, K. Gupta, C. Da Silva, T. Liu, Z.H. Zheng, W.P. Zhang, J.P.M. Van Lammeren, H.J. Bergveld, C.H. Amon, O. Trescases, IC for online EIS in automotive batteries and hybrid architecture for high-current perturbation in low-impedance cells, in: IEEE Appl. Power Electron. Conf. Expo. - APEC, IEEE, San Antonio, TX, USA, 2018: pp. 1922-1929. doi:10.1109/APEC.2018.8341280.

[298] R. Morello, R. Di Rienzo, R. Roncella, R. Saletti, R. Schwarz, V.R.. Lorentz, H. E.R.G., B. Rosca, F. Baronti, Advances in Li-Ion Battery Management for Electric Vehicles, in: IECON 2018 - 44th Annu. Conf. IEEE Ind. Electron. Soc., IEEE, DC, USA, 2018: pp. 4949-4955. doi:10.1109/IECON.2018.8591185.

[299] Datang-NXP-Semiconductors, Battery Management IC （DNB1168）, (n.d.). http://www.datangnxp.com/cpjs/info_59.aspx?itemid=162\&/cid=32\&pid=41.

[300] F. Edler, P. Seefeld, Self-validating contact thermometry sensors for higher temperatures, Meas. Sci. Technol. 26 (2015). doi:10.1088/0957-0233/26/1/015102.

[301] J.B. Johnson, Thermal Agitation of Electricity in Conductors, Nature. 119 (1927) 50-51. doi:doi:10.1038/119050c0.

[302] H. Nyquist, Thermal agitation of electric charge in conductors, Phys. Rev. 32 (1928) 110-113. doi:10.1103/PhysRev.32.110. 
[303] C.J. Borkowski, T. V. Blalock, A new method of Johnson noise thermometry, Rev. Sci. Instrum. 45 (1974) 151-162. doi:10.1063/1.1686578.

[304] D.R. White, R. Galleano, A. Actis, H. Brixy, M. De Groot, J. Dubbeldam, A.L. Reesink, F. Edler, H. Sakurai, R.L. Shepard, J.C. Gallop, The status of Johnson noise thermometry, Metrologia. 33 (1996) 325-335. doi:10.1088/0026-1394/33/4/6.

[305] J. Qu, S.P. Benz, A. Pollarolo, H. Rogalla, W.L. Tew, R. White, K. Zhou, Improved electronic measurement of the Boltzmann constant by Johnson noise thermometry, Metrologia. 52 (2017) S242-256. doi:doi:10.1088/0026-1394/52/5/S242.

[306] S. Nam, S. Benz, P. Dresselhaus, C.J. Burroughs, W.L. Tew, D.R. White, J.M. Martinis, Progress on Johnson noise thermometry using a quantum voltage noise source for calibration, CPEM Dig. (Conference Precis. Electromagn. Meas. 54 (2005) 653-657. doi:10.1109/TIM.2005.843574.

[307] T. Yamada, C. Urano, M. Maezawa, Demonstration of Johnson noise thermometry with allsuperconducting quantum voltage noise source, Appl. Phys. Lett. 108 (2016). doi:10.1063/1.4940926.

[308] J. Crossno, X. Liu, T.A. Ohki, P. Kim, K.C. Fong, Development of high frequency and wide bandwidth Johnson noise thermometry, Appl. Phys. Lett. 106 (2015). doi:10.1063/1.4905926.

[309] H.G. Brixy, Temperature measurement in nuclear reactors by noise thermometry, Nucl. Instruments Methods. 97 (1971) 75-80. doi:10.1016/0029-554X(71)90514-3.

[310] D.C. Agouridis, Noise thermometers For Hostile Environments: A Theoretical Evaluation, IEEE Trans. Instrum. Meas. 39 (1990) 780-784. doi:10.1109/19.58625.

[311] X. Liu, C. Zheng, C. Liu, P.W.T. Pong, Experimental Investigation of a Johnson Noise Thermometry using GMR Sensor for Electric Vehicle Applications, IEEE Sens. J. 18 (2018) 
3098-3107. doi:10.1109/JSEN.2018.2805309.

[312] K.-P. Möllmann, M. Vollmer, Infrared thermal imaging as a tool in university physics education, Eur. J. Phys. 28 (2007) S37-S50. doi:10.1088/0143-0807/28/3/S04.

[313] M. Vollmer, K.-P. Möllmann, Infrared Thermal Imaging: Fundamentals, Research and Applications, 2nd ed., John Wiley and Sons, Weinheim, Germany, 2017. https://books.google.nl/books?hl=nl\&lr=\&id=0Q3DwAAQBAJ\&oi=fnd\&pg=PP2\&dq=Infrared+Thermal+Imaging\&ots=HzxuipZ3iO\&sig=8RVfbr 0qXAh5MTzxfnTI1iffJ5k\#v=onepage\&q=Infrared Thermal Imaging\&f=false.

[314] J.B. Robinson, E. Engebretsen, D.P. Finegan, J. Darr, G. Hinds, P.R. Shearing, D.J.L. Brett, Detection of Internal Defects in Lithium-Ion Batteries Using Lock-in Thermography, ECS Electrochem. Lett. 4 (2015) A106-A109. doi:10.1149/2.0071509eel.

[315] J.B. Robinson, J. a. Darr, D.S. Eastwood, G. Hinds, P.D. Lee, P.R. Shearing, O.O. Taiwo, D.J.L. Brett, Non-uniform temperature distribution in Li-ion batteries during discharge - A combined thermal imaging, X-ray micro-tomography and electrochemical impedance approach, J. Power Sources. 252 (2014) 51-57. doi:10.1016/j.jpowsour.2013.11.059.

[316] S. Kosch, A. Rheinfeld, S. V Erhard, A. Jossen, An extended polarization model to study the in fl uence of current collector geometry of large-format lithium-ion pouch cells, J. Power Sources. 342 (2017) 666-676. doi:10.1016/j.jpowsour.2016.12.110.

[317] S. Panchal, I. Dincer, M. Agelin-chaab, R. Fraser, M. Fowler, Experimental and simulated temperature variations in a $\mathrm{LiFePO}_{4}-20$ Ah battery during discharge process, Appl. Energy. 180 (2016) 504-515. doi:10.1016/j.apenergy.2016.08.008.

[318] D.J. Cumming, R.H. Elder, Thermal imaging of solid oxide cells operating under electrolysis conditions, J. Power Sources. 280 (2015) 387-392. doi:10.1016/j.jpowsour.2015.01.109. 
[319] M.B. Pomfret, D.A. Steinhurst, D.A. Kidwell, J.C. Owrutsky, Thermal imaging of solid oxide fuel cell anode processes, J. Power Sources. 195 (2010) 257-262. doi:10.1016/j.jpowsour.2009.06.072.

[320] J.B. Robinson, P.R. Shearing, D.J.L. Brett, Thermal Imaging of Electrochemical Power Systems: A Review, J. Imaging. 2 (2016) 1-20. doi:10.3390/jimaging2010002.

[321] K. Toriyama, S. Tada, K. Ichimiya, S. Funatani, Y. Tomita, A new method of temperature measurement using thermochromic liquid crystals (extension of measurable range based on spectral intensity in the narrow-band wavelength), Int. J. Heat Mass Transf. 92 (2016) 483489. doi:10.1016/j.ijheatmasstransfer.2015.09.002.

[322] V.U. Kakade, G.D. Lock, M. Wilson, J.M. Owen, J.E. Mayhew, Accurate heat transfer measurements using thermochromic liquid crystal. Part 1: Calibration and characteristics of crystals, Int. J. Heat Fluid Flow. 30 (2009) 939-949. doi:10.1016/j.ijheatfluidflow.2009.04.007.

[323] N. Abdullah, A.R. Abu Talib, A.A. Jaafar, M.A. Mohd Salleh, W.T. Chong, The basics and issues of Thermochromic Liquid Crystal Calibrations, Exp. Therm. Fluid Sci. 34 (2010) 1089-1121. doi:10.1016/j.expthermflusci.2010.03.011.

[324] C.R. Smith, D.R. Sabatino, T.J. Praisner, Temperature sensing with thermochromic liquid crystals, Exp. Fluids. 30 (2001) 190-201. doi:10.1007/s003480000154.

[325] Y. Rao, S. Zang, Calibrations and the measurement uncertainty of wide-band liquid crystal thermography, Meas. Sci. Technol. 21 (2010). doi:10.1088/0957-0233/21/1/015105.

[326] D.R. Sabatino, T.J. Praisner, C.R. Smith, A high-accuracy calibration technique for thermochromic liquid crystal temperature measurements, Exp. Fluids. 28 (2000) 497-505. doi:10.1007/s003480050411.

[327] M.R. Giuliano, S.G. Advani, A.K. Prasad, Thermal analysis and management of lithium - 
titanate batteries, J. Power Sources. 196 (2011) 6517-6524.

doi:10.1016/j.jpowsour.2011.03.099. 